\title{
Thin Films on Cantilevers
}

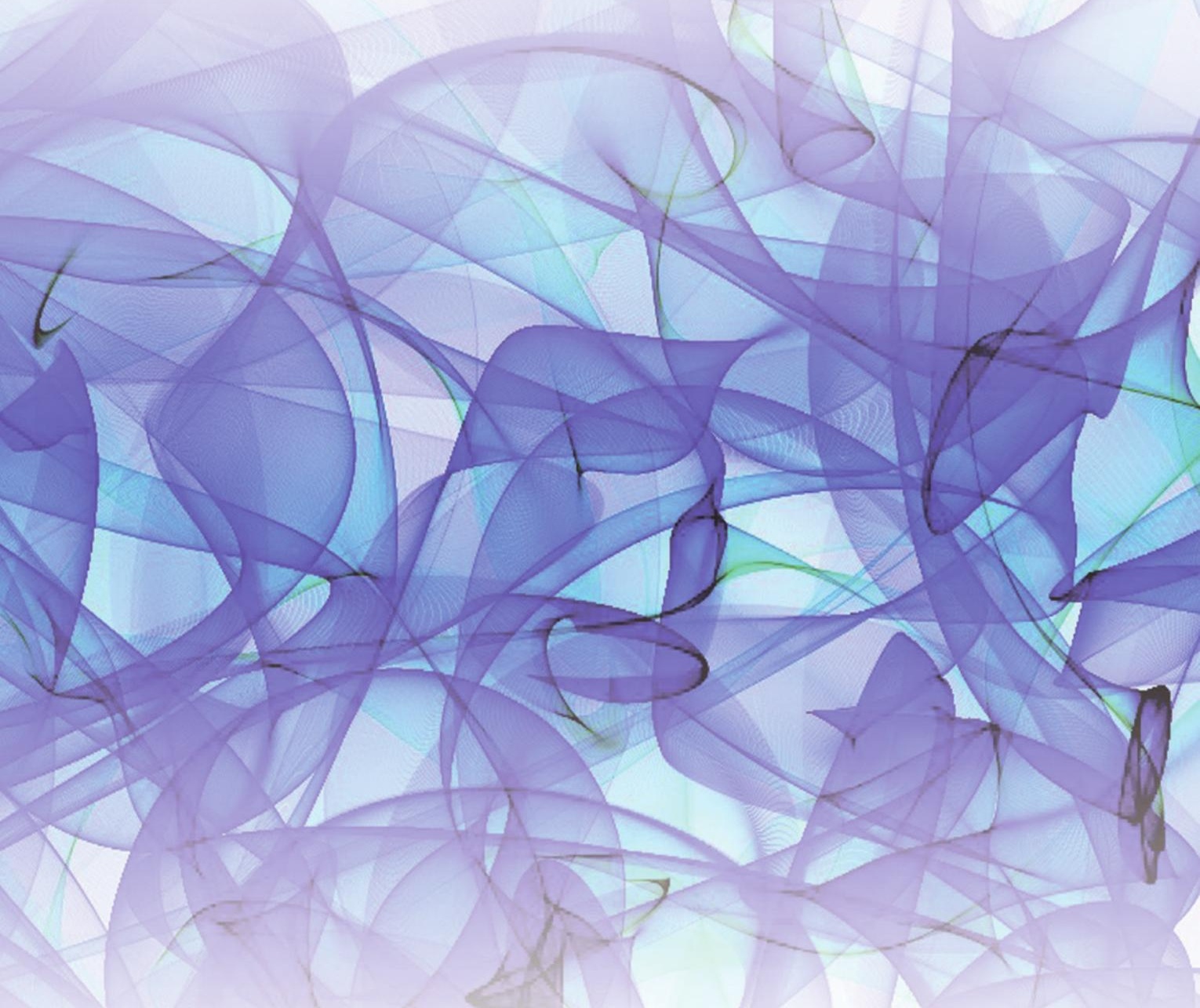

Hammad Nazeer 


\section{Graduation committee}

Prof. dr. ir. Ton J. Mouthaan

Prof. dr. Miko C. Elwenspoek

Prof. dr. ir. Gijs J. M. Krijnen

Dr. ir. Leon Abelmann

Prof. dr. Ian M. Reaney

Prof. dr. ing. Guus Rijnders

Prof. dr. ir. Rob A. M. Wolters

Dr. Harish Bhaskaran

Dr. ir. W. Merlijn van Spengen
University of Twente (chairman and secretary)

University of Twente (promotor)

University of Twente (promotor)

University of Twente (assistant promotor)

University of Sheffield, United Kingdom

University of Twente

University of Twente

University of Exeter, United Kingdom

Delft University of Technology

\section{Paranymphs}

Usma Azam, MSc

Rolf Vermeer, MSc

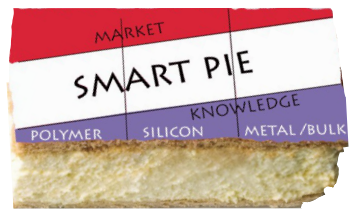

\section{UNIVERSITY OF TWENTE.}

The research described in this dissertation was carried out at the Transducers Science and Technology group, part of the $\mathrm{MESA}^{+}$Institute for Nanotechnology at the University of Twente, Enschede, the Netherlands. The work is supported by the SmartMix Program 'SmartPie' of the Netherlands Ministry of Economic Affairs and the Netherlands Ministry of Education, Culture and Science.

Cover design by $\mathcal{M}$. Akmal Ataullah

Printed by Ipskamp Drukkers, Enschede, the Netherlands.

(c) H. Nazeer, Enschede, the Netherlands, 2012.

Electronic mail address: h. nazeer@alumnus.utwente.nl

ISBN 978-90-365-3345-4

DOI 10.3990/1.9789036533454 


\section{THIN FILMS ON CANTILEVERS}

\section{DISSERTATION}

to obtain

the degree of doctor at the University of Twente, on the authority of the rector magnificus,

prof. dr. H. Brinksma,

on account of the decision of the graduation committee,

to be publicly defended

on Friday, 20 April 2012 at 14:45

by

\section{Hammad Nazeer}

born on 30 September 1975,

in Karachi, Pakistan 
This dissertation is approved by Prof. dr. Miko C. Elwenspoek Prof. dr. ir. Gijs J. M. Krijnen

University of Twente (promotor)

Dr. ir. Leon Abelmann University of Twente (promotor) University of Twente (assistant promotor) 
....to my Parents,

Sister, Wife and uncle Zaheer for their Love, Endless Support and Encouragement. 



\section{Contents}

$\begin{array}{ll}\text { Contents } & \text { iii }\end{array}$

1 Introduction 1

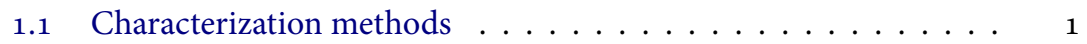

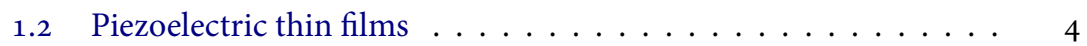

1.3 Phase-change thin films ................. 4

1.4 Thesis outline.................. 4

2 Silicon cantilevers: What do we know? 7

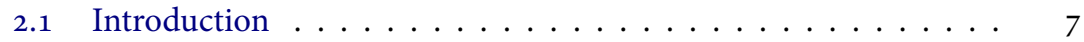

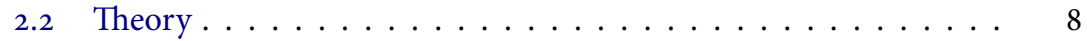

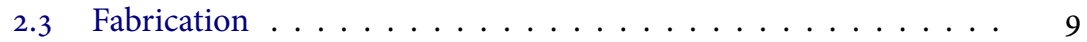

2.4 Measurements . . . . . . . . . . . . . . . . 11

2.5 Results and discussion $\ldots \ldots \ldots \ldots \ldots \ldots$

2.6 Conclusion . . . . . . . . . . . . . . . . . . 14

3 Measurement of Young's modulus $\quad 15$

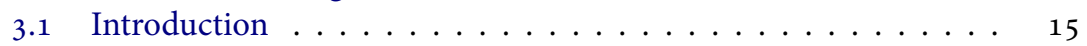

3.2 Theory......................... 16

3.2.1 Analytical relation for the resonance frequency of cantilevers 16

3.2.2 Analytical model for the Young's modulus of PZT . . . . 16

3.2.3 Analysis of uncertainties . . . . . . . . . . . . . 17

3.3 Fabrication . . . . . . . . . . . . . . . . . 17

3.3.1 Fabrication of silicon cantilevers . . . . . . . . . 17

3.3.2 Deposition of PZT by PLD . . . . . . . . . 18

3.4 Experimental details . . . . . . . . . . . . . . . . 18

3.4.1 Resonance frequency measurements . . . . . . . . 18

3.4 .2 Thickness of cantilevers . . . . . . . . . . . 18

$3.4 .3 \quad$ XRD measurements . . . . . . . . . . . . . . 19

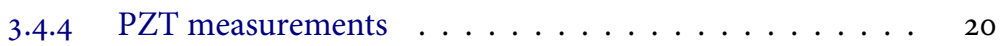

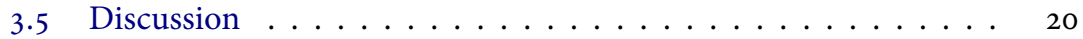

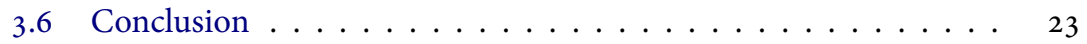

4 PZT films with (110) orientation $\quad 25$ 


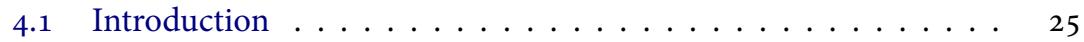

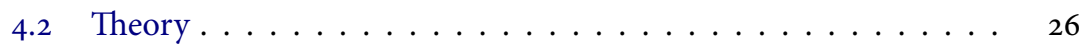

4.2.1 Longitudinal piezoelectric coefficient $d_{33, \mathrm{f}} \ldots \ldots \ldots$

4.2.2 Analytical model for the Young's modulus of PZT thin films 27

4.3 Experimental details . . . . . . . . . . . . . . . 27

4.3.1 Fabrication of PZT capacitors ........... 27

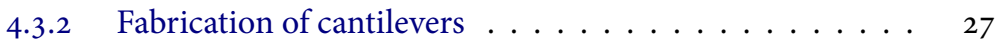

4.3 .3 XRD measurements .................. 29

4.3.4 Measurements of the longitudinal piezoelectric coefficient $d_{33, \mathrm{f}} \ldots \ldots \ldots \ldots \ldots \ldots \ldots$

4.3.5 Measurements of the Young's modulus . . . . . . . . . 29

4.3.6 Measurements of the dielectric constant $\varepsilon \ldots . . \ldots 30$

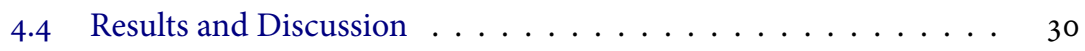

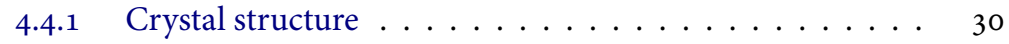

4.4 .2 Piezoelectric coefficient . . . . . . . . . . . 31

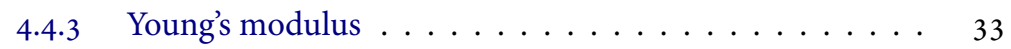

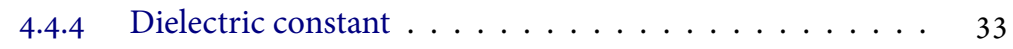

4.5 Conclusion ........................ 34

5 Comparison of $(110)$ and (oo1) oriented PZT 37

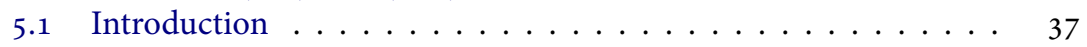

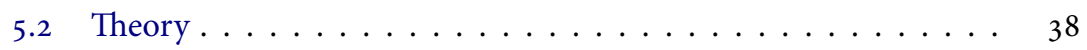

5.2 .1 Analytical model . . . . . . . . . . . . . 38

5.3 Experimental details . . . . . . . . . . . . . . . . . . 38

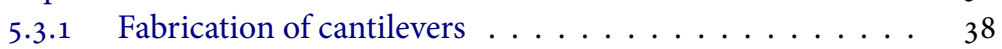

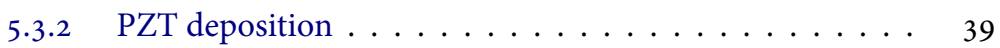

5.3 .3 XRD measurements ..................... 40

5.3.4 Resonance frequency measurements . . . . . . . . 40

5.3.5 Measurements of piezoelectric coefficient . . . . . . . . 42

5.4 Measurement Results . . . . . . . . . . . . . . . . 42

5.4 .1 Crystal structure . . . . . . . . . . . . . 42

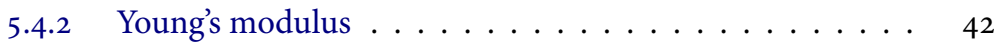

5.5 Discussion ........................ 43

5.5.1 Young's modulus compared to bulk PZT ceramic . . . . 43

5.5 .2 Young's modulus compared to (110) PZT . . . . . . . . 45

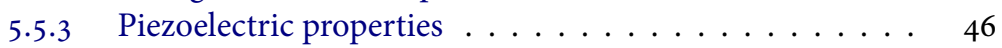

5.6 Conclusion .................... 47

6 Measurement of residual stress 49

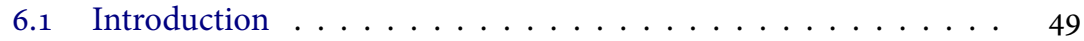

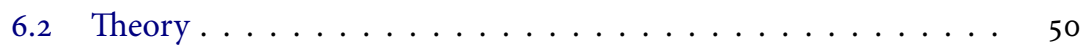

6.2.1 Stress determined from cantilever bending . . . . . . . 50

6.2.2 Stress originating from thermal expansion differences .. 51

6.2.3 Stress determined from lattice strain . . . . . . . . . 51

6.3 Experimental details . . . . . . . . . . . . . 52 
6.3.1 Fabrication of cantilevers ..................... 52

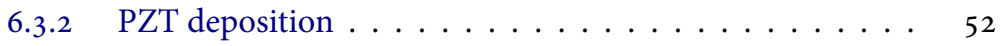

6.3 .3 XRD measurements ........................ 52

6.3.4 Resonance frequency measurements ......... 52

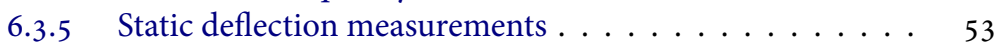

6.4 Measurement Results . . . . . . . . . . . . . . . . 53

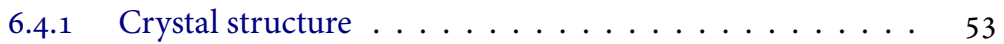

6.4 .2 Young's modulus . . . . . . . . . . . . . . . . 55

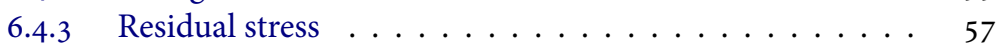

6.5 Discussion ....................... 58

6.5.1 Residual stress estimated from difference in thermal expansion ....................... 58

6.5.2 Residual stress estimated from lattice parameters . . . . 60

6.6 Conclusion ..................... 60

7 Mechanical properties of GeSbTe phase-change thin films 63

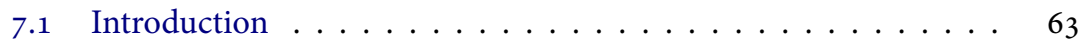

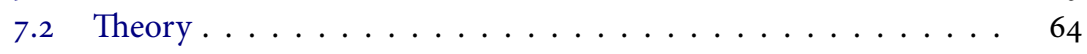

7.2.1 Analytical model for the Young's modulus of GST thin films in amorphous and crystalline states . . . . . . . . 64

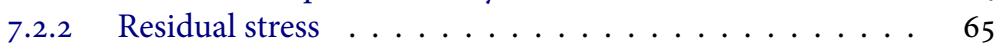

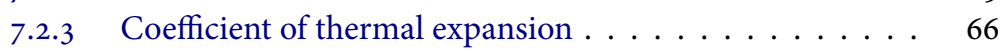

$7 \cdot 3$ Experimental details . . . . . . . . . . . . . . . 66

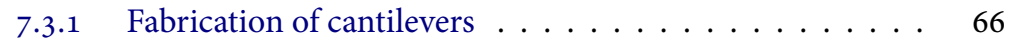

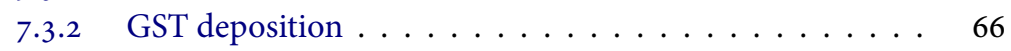

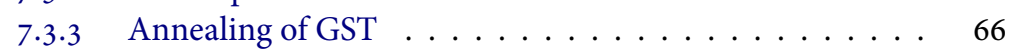

7.3.4 Resonance frequency measurements . . . . . . . . . . . 67

7.3 .5 Static deflection measurements . . . . . . . . . . . . 67

7.3 .6 Sheet resistance measurements . . . . . . . . . . . . . 67

7.4 Measurement Results . . . . . . . . . . . . . . . . . . . . . 69

7.4 .1 Young's modulus . . . . . . . . . . . . . . . . . 69

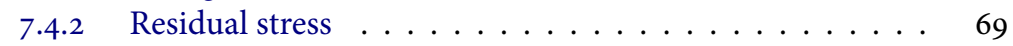

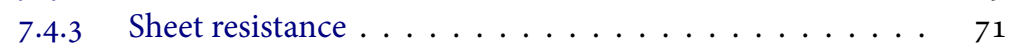

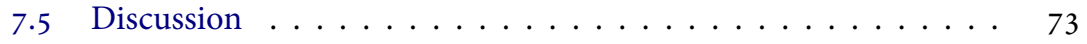

7.6 Conclusion ...................... 73

8 Summary and conclusions $\quad 77$

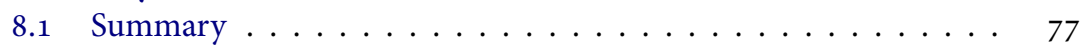

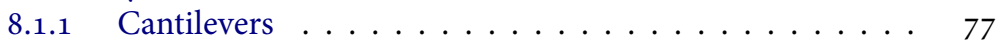

8.1.2 Anisotropic Young's modulus . . . . . . . . . . . 78

8.1.3 Compositional dependence ............... 78

8.1.4 Residual stress in PZT thin films . . . . . . . . . . . . 79

8.1.5 Investigation of phase-change thin films . . . . . . . 79

8.2 Conclusions . . . . . . . . . . . . . . . 79

8.2.1 Determination of Young's modulus . . . . . . . . . 79 
8.2.2 PZT piezoelectric thin films . . . . . . . . . . . . 80

8.2.3 GeTeSb phase change thin films ........... 80

$\begin{array}{lr}\text { Appendices } & \mathbf{8 1}\end{array}$

$\begin{array}{lr}\text { A Cantilever process flow } & \mathbf{8 3}\end{array}$

B Modified fabrication process document $\quad 91$

$\begin{array}{lr}\text { Bibliography } & 98\end{array}$

$\begin{array}{lr}\text { Samenvatting } & 110\end{array}$

$\begin{array}{lr}\text { Acknowledgements } & 114\end{array}$

$\begin{array}{lr}\text { Publications } & 118\end{array}$

$\begin{array}{lr}\text { About the author } & 120\end{array}$ 


\section{Chapter 1}

\section{Introduction}

We are living in a society where active materials are hidden in complex devices and instruments, but serve as the main core of the purpose. Recent technological advancement is based on the explored materials and is well expressed as:

"Materials have always had a large influence on society. This was obvious in the Stone Age, Bronze Age or Iron Age. We have named these eras by the most advanced material in that period, since these materials determine and limit the state of technology at that time."

Brinkman, 2011

Therefore we might call our time the era of smart materials, because their influence is omnipresent. Smart materials find their applications in a wide range of fields. In order to utilize newly developed materials efficiently in devices, we need to understand and characterize them. The need for highly sensitive sensors and powerful actuators led the micro electromechanical systems (MEMS) industry to explore different materials in the micro- and nano domain (Poelma et al., 2011). To support the use of these materials in MEMS applications, information is needed on the properties in the thin film domain, certainly since these properties can differ from those of bulk materials (Agrawal and Espinosa, 2009; Delobelle et al., 2004). These properties are also very much needed as key input for numerical simulations, so that we can predict device performance and reliability (Liang et al., 2007). The properties of thin film materials cannot be simply downscaled from the bulk ceramic counterparts because testing of bulk materials is based on the dimensions much larger than the micro-structures (Kraft and Volkert, 2001). Also, properties of thin films may vary on the fabrication processes (Walmsley et al., 2005).

\subsection{Characterization methods}

Several techniques have been established to characterize mechanical properties of thin films, like nano-indentation (Oliver and Pharr, 1992; Poon et al., 2008), bulge 


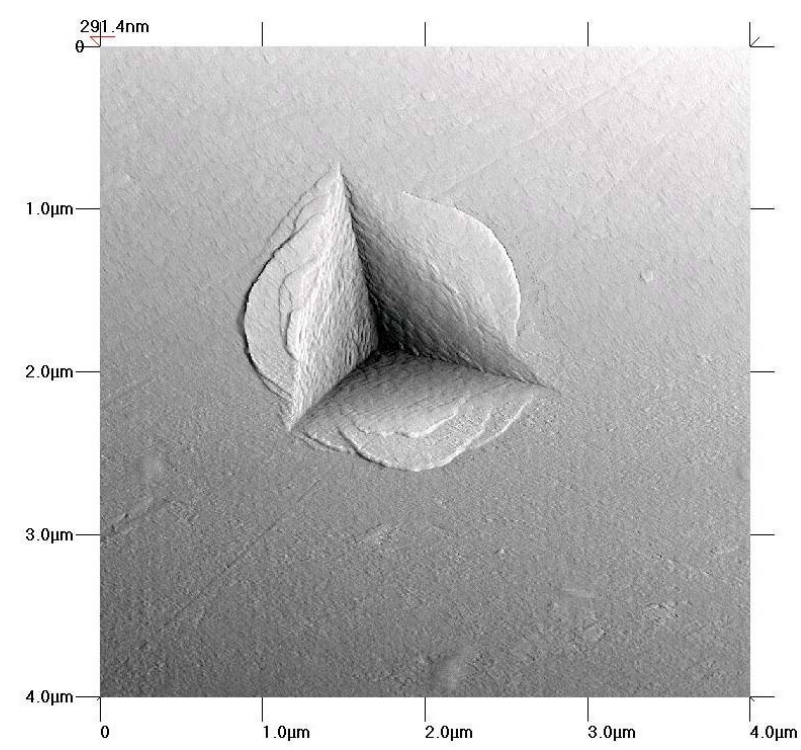

FIGURE 1.1 - The pressure used to indent the thin films during nano-indentation process may result in local alteration of the thin film structure, as is illustrated by this image taken from (Wikipedia).

test (Hall et al., 2002), tensile test (Tsuchiya et al., 2002; Yagnamurthy et al., 2008), acoustic wave-based test (Schneider and Tucker, 1996) and stress measurements based on XRD (Nix, 1989). Every characterization method has its advantages and disadvantages. For instance, nano-indentation suffers from uncertainties caused by the pressure of the indenter, which may alter the structure of the film (see Figure 1.1), influence of the substrate, tip effect, indentation depth and film thickness (Oliver and Pharr, 2004). In addition, the conventional nano-indentation technique does not provide in-plane properties of the elastically anisotropic thin films (Delobelle et al., 2004), and information about the Poisson's ratio is essential to calculate the Young's modulus from the biaxial modulus of the thin films. On their turn bulge and tensile tests require complex free standing structures and experimental setups, and for certain thin films the required removal of the film from the substrate is rather difficult (Weihs et al., 1988). Similarly, problems exists for load-deflection tests of free standing cantilevers using a nano-indenter or manipulator. The slip and friction between the indenter/manipulator and the film is a cause of errors. Finally, the use of acoustic testing for the determination of the Young's modulus is limited by level of sophistication required for instrumentation and data reduction (Liang et al., 2007).

The resonance frequency measurement technique for characterizing thin films has an advantage over conventional tension tests (see Figure 1.2 (Tsuchiya et al., 2005)) because of the ease of fabrication, absence of force loading requirements 

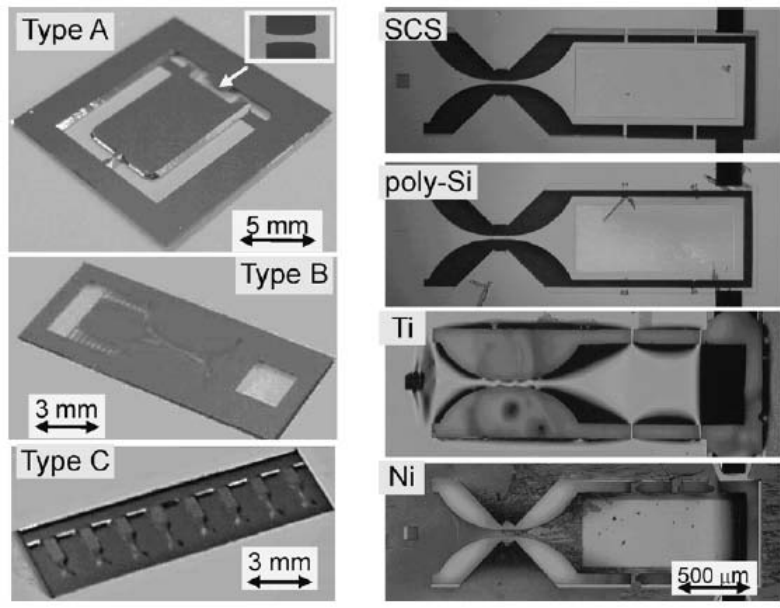

FIGURE 1.2 - Complex tensile test structures fabricated by Tsuchiya et al. (2005) to investigate the material properties. Fabrication, handling and measurements of the thin film properties using these types of structures are rather difficult as compared to the resonance frequency measurements of cantilevers.

and simple detection without the need of a complex measurement setup. Different types of micrometer sized structures were employed to characterize the thin films in the micro- and nano-domain using resonance frequencies, such as cantilevers, membranes and bridges (Isarakorn et al., 2010; Ræder et al., 2007; Schweitz, 1991). In particular cantilevers are among the most widely used test structures for this purpose (Finot et al., 2008; Nguyen et al., 2010) because of ease of fabrication, simple modelling and more accurate analysis (Nazeer et al., 2011a). Moreover, bi-layer cantilevers have a direct application in the field of highly selective and sensitive (bio)chemical sensors. By using micro-cantilevers we obtain information on the material properties on a local scale, rather than averaged over the complete wafer. This is especially useful for thin films that can only be deposited uniformly on a small area, which is for instance the case in pulsed laser deposition (PLD). There is no need to drive the resonance of micro-cantilevers by external excitation force, because they are already thermally excited at an amplitude in the picometer range. Of course this requires sufficiently sensitive detection, such as provided by interferometry.

In this thesis we apply the cantilever analysis method to two very different materials: a high quality piezoelectric film deposited by pulsed laser depostion and a phase-change material. 


\subsection{Piezoelectric thin films}

For the development of various types of micro-electromechanical systems (MEMS), such as sensors and actuators, there are strict requirements on the piezoelectric material properties. Since the properties of $\mathrm{Pb}\left(\mathrm{Zr}_{x} \mathrm{Ti}_{1-x}\right) \mathrm{O}_{3}$ (PZT) thin films are tuneable by varying the $\mathrm{Zr} / \mathrm{Ti}$ ratio, this material is very suitable for a broad range of applications in micro- and nano-systems (Piekarski et al., 2002). This was realized and stated by Trolier-Mckinstry and Muralt:

"Given the plethora of mechanisms by which the environment can be detected and/or useful responses made, it is worth considering the impetus for integrating piezoelectric thin films into $\mathcal{M E \mathcal { M S }}$ devices (i.e. what advantages offset the need to introduce new materials into the cleanroom environment?)."

Trolier-Mckinstry and Muralt, 2004

However, a better understanding of the piezoelectric and ferroelectric properties, as well as the mechanical behaviour of PZT thin films of various compositions is necessary to use PZT thin films efficiently in MEMS. For instance, the compositional dependence of these properties of the epitaxial PLD-PZT thin films investigated in this thesis shows quite a distinct behaviour compared to the bulk ceramic counterparts, due to the reasons like epitaxial growth on substrate and clamping of the films.

\subsection{Phase-change thin films}

The phase transition between the amorphous and crystalline phase in phase-change films is exploited in for non-volatile storage, either by detecting a change in optical reflectivity (rewriteable DVDs) or electrical conductivity (solid state memories or probe storage (Wright et al., 2006)). Also the mechanical properties, such as Young's modulus or residual stress, of the films are very different for the two phases. This opens a route towards exciting new possibilities of the use of phase change materials in nanomechanical devices, similar to what has been demonstrated with ferromagnetic films by Bhaskaran et al. (2011). In this thesis we investigate $\mathrm{Ge}-\mathrm{Sb}$ Te alloys (GST) thin films. For the cantilever resonance technique, these GST thin films have the advantage that their Young's modulus increases upon crystallization without a change in mass. In this way we can beautifully illustrate the opposite effect of additional mass and increase in Young's modulus on the resonance frequency of the cantilever.

\subsection{Thesis outline}

This thesis continues with the understanding of the cantilever itself, necessary to eliminate errors in the determination of the thin films properties. The argument 
between the use of the plate modulus or the Young's modulus for particular cantilever dimensions is presented in Chapter 2. Kaldor and Noyan stated this challenge as;

"In general usage, beam and plate components are distinguished by dimensions alone. In mechanics, however, beams and plates are differentiated based on their flexural rigidity and stress state. Since current textbooks do not provide a quantitative technique for selecting the proper constitutive equations for these two types of structures, we suggest the extension of an analysis for isotropic materials originated by Searle [G. F. C. Searle, Experimental Elasticity (Cambridge University Press, Cambridge, 1908), pp. 40-58] and expanded on by Ashwell [D. G. Ashwell, J. R. Aeronaut. Soc. 54, 708 (1950)]."

Kaldor and Noyan, 2002

In the same chapter the complete fabrication process of the cantilevers is presented. We discuss the effect of cantilever undercut that is caused by the fabrication process and introduce an effective undercut length to combat this problem.

A new analytical relation to determine the Young's modulus of PZT thin films using the resonance frequency of cantilevers before and after the deposition of the thin films is introduced in Chapter 3. The effect of thickness variation over the wafer is also part of the Chapter 3. The in-plane Young's modulus of the epitaxial PZT thin films grown by pulsed laser deposition (PLD) can be anisotropic, which we discuss in the second part of the same chapter by using rigorous error analysis.

The properties of the PZT thin films depend on the composition of $\mathrm{Zr}$ and $\mathrm{Ti}$ in the $\mathrm{Pb}\left(\mathrm{Zr}_{x} \mathrm{Ti}_{1-x}\right) \mathrm{O}_{3}$, therefore the compositional dependence of the (110) oriented PZT thin films properties is shown in Chapter 4, along with the properties of the bulk ceramic counterparts.

In Chapter 5, we compare (110) and (oo1) oriented PZT thin films and on the basis of the coupling coefficient, recommend the particular composition and orientation best suited for applications.

Residual stress in the thin films is crucial for the design of MEMS devices. In Chapter 6, the residual stress in PZT thin films of varying composition is determined by different techniques. The average coefficient of thermal expansion (CTE) in PLD-PZT thin films is analyzed with respect to results obtained for the PZT thin films fabricated by other processes and bulk PZT ceramics.

Material properties of phase change thin films ( $\mathrm{Ge}-\mathrm{Sb}-\mathrm{Te})$ depend on the phase of the thin film (amorphous or crystalline). The variation in the Young's modulus, residual stress and sheet resistance with annealing temperature of the two different compositions of the GST thin films is shown in Chapter 7. The variation in these properties with temperature while the thin film is already on the cantilever isolates the effect of any change in mass.

The final chapter is devoted to the summary and conclusions. 



\section{Chapter 2}

\section{Silicon cantilevers: What do we know?}

\subsection{Introduction}

Design of micro electromechanical systems (MEMS) requires detailed information about material parameters such as the Young's modulus. As industry is increasingly focusing on micro devices, we need information on the mechanical properties of materials in the thin film domain. These properties can differ from those of bulk materials (Delobelle et al., 2004). Many micro-sized structures such as cantilevers, membranes and bridges have been employed as test structures for determining the mechanical properties of thin films. Cantilevers are among the most widely used test structures for this purpose (Finot et al., 2008; Nguyen et al., 2010).

Calculation of the resonance frequency of cantilevers fabricated from silicon, which is an elastically anisotropic material, requires the use of an appropriate effective Young's modulus (Kaldor and Noyan, 2002). A technique is introduced to determine the appropriate effective Young's modulus that needs to be used in the resonance frequency calculation of our cantilevers. We took extra care to eliminate the errors in the determination of the effective Young's modulus of the thin films deposited on the cantilevers. At this precision, conventional analytical expressions (Volterra and Zachmanoglou, 1965) to calculate resonance frequencies of silicon cantilevers need to be verified. We used ${ }_{3} \mathrm{D}$ finite-element (FE) simulations to estimate the deviations between these simulations that use anisotropic elastic properties of silicon and the values calculated analytically for our $<110\rangle$ and $<100\rangle$ aligned cantilevers.

Any uncertainty about the length of cantilevers introduces an error in the resonance frequency calculations of silicon cantilevers, as well as in the determined value of the effective Young's modulus of the thin films. In order to be precise, we determined the effective undercut length using least square fitting of the measured resonance frequencies data for cantilevers with a wide range of lengths. The obtained effective length of the cantilevers is then used in the calculations of the 
TABLE 2.1 - Elastic anisotropic properties of single crystal silicon. Values of $E$ and $v$ are taken from Brantley (1973).

\begin{tabular}{|c|c|c|c|}
\hline \multicolumn{4}{|c|}{ Crystal plane $\{100\}$} \\
\hline Direction & $\begin{array}{c}E \\
{[\mathrm{GPa}]}\end{array}$ & $v$ & $\begin{array}{c}E /\left(1-v^{2}\right) \\
{[\mathrm{GPa}]}\end{array}$ \\
\hline$\langle 110\rangle$ & 168.9 & 0.064 & 169.8 \\
\hline$<100\rangle$ & 130.2 & 0.279 & 141.0 \\
\hline
\end{tabular}

effective Young's modulus of the thin film.

\subsection{Theory}

The resonance frequency of a cantilever is calculated by using the analytical relation defined in Equation (2.1) (Volterra and Zachmanoglou, 1965):

$$
f_{n}=\frac{C_{n}^{2} t_{\mathrm{s}}}{2 \pi L^{2}} \sqrt{\frac{E_{\mathrm{s}}^{*}}{12 \rho}},
$$

where $f_{n}$ is the resonance frequency, $C_{n}$ is a constant which depends on the vibration mode $n, C_{\mathrm{o}}=1.875$ for the fundamental resonance frequency $\left(f_{0}\right), E_{\mathrm{s}}^{*}$ is the effective Young's modulus, $\rho$ is the density of silicon (Deslattes et al., 1974), $t_{\mathrm{s}}$ is the thickness and $L$ is the length of the cantilevers. The best approximation for the effective Young's modulus is required to calculate the resonance frequency of cantilevers. However, single crystal silicon is elastically anisotropic. Therefore the effective Young's modulus of silicon is different for different crystal orientations. Consequently, the resonance frequencies of the cantilevers depend on their orientation with regard to the crystal lattice.

Equation (2.1) is a two dimensional approximation. The third dimension is taken into account in the effective Young's modulus, which depends on the width of the cantilever. If the width is much larger than the length, the strain along that direction is zero. In this case, for very thin cantilevers and isotropic materials we can use the plate modulus $E /\left(1-v^{2}\right)$ as an approximation for the effective Young's modulus $E^{*}$ (Rasmussen, 2003), where $E$ and $v$ are the Young's modulus and Poisson's ratio, see Table 2.1. With reducing width, the stress in that direction is relaxed and the effective Young's modulus decreases to $E$ for a width much smaller than the cantilever length. In our situation, the cantilever width is smaller than the length. Moreover, single crystal silicon is anisotropic (Brantley, 1973), so the two-dimensional situation was checked by finite element calculations for silicon cantilevers aligned parallel to the $\langle 110\rangle$ and $\langle 100\rangle$ crystal directions of the silicon crystal lattice.

Full $3 \mathrm{D}$ finite-element simulations were carried out using the COMSOL software package and compared with the analytical results that were obtained using Equation (2.1). To define cantilevers parallel to the $<110>$ orientation in COMSOL, 
TABLE 2.2 - Calculated and simulated fundamental resonance frequency of silicon cantilevers with length $L=300 \mu \mathrm{m}$, thickness $t_{s}=3 \mu \mathrm{m}$ and width $w=30 \mu \mathrm{m}$.

\begin{tabular}{|c|c|c|c|}
\hline Direction & $\begin{array}{c}\text { Calculated } \\
f_{0}(\mathrm{~Hz}) \\
\text { using } \\
E\end{array}$ & $\begin{array}{c}\text { Calculated } \\
f_{0}(\mathrm{~Hz}) \\
\text { using } \\
E /\left(1-v^{2}\right)\end{array}$ & $\begin{array}{c}\text { FE- } \\
\text { Simulations } \\
(\mathrm{Hz})\end{array}$ \\
\hline$\langle 110\rangle$ & 45834 & 45956 & 45978 \\
\hline$<100\rangle$ & 40242 & 41878 & 40541 \\
\hline
\end{tabular}

the cantilever geometry was drawn in the xy-plane with the length axis parallel to the $\mathrm{x}$-axis and then rotated $45^{\circ}$ around the $\mathrm{z}$-axis. For the $\left.<100\right\rangle$ cantilevers, no rotation was given to the cantilever. Standard anisotropic elastic properties of single crystal silicon, as defined in the material section of the COMSOL, were used for the simulations. The elastic stiffness coefficients are identical to values quoted in literature (Brantley, 1973).

Table 2.2 lists the analytical calculations of resonance frequencies using Equation (2.1) and the results of the FE simulations of a silicon cantilever with a length of $300 \mu \mathrm{m}$, thickness of $3 \mu \mathrm{m}$ and width of $30 \mu \mathrm{m}$. The analytical values of the resonance frequencies calculated using Young's modulus $E$ agree with the FE simulations to within $0.3 \%$ for the $<110\rangle$ direction and $0.7 \%$ for $<100\rangle$ direction. The FEM results differ by $3 \%$ when using the plate modulus $E /\left(1-v^{2}\right)$ for $<100>$ aligned cantilevers. The results verify that, for the cantilever geometry which we have used in this work, the factor of $\left(1-v^{2}\right)$ can not be used in the denominator of $E$.

\subsection{Fabrication}

To ensure precise control of the dimensions of the cantilevers, we fabricated our $3 \mu \mathrm{m}$ thick silicon cantilevers in a dedicated SOI/MEMS fabrication process. Refer to Appendix A for a detailed list of the complete process flow. The cantilevers are designed such that their length varies from $250 \mu \mathrm{m}$ to $350 \mu \mathrm{m}$ in steps of $10 \mu \mathrm{m}$, with a fixed width of $30 \mu \mathrm{m}$. Cantilevers were fabricated on the front side of (oo1) single crystal silicon on insulator (SOI) wafers with the sequence as detailed in Figure 2.1. A double side polished SOI wafer with a $3 \mu \mathrm{m}$ thick device layer and a $500 \mathrm{~nm}$ thick $\mathrm{SiO}_{2}$ buried oxide (BOX) layer was selected $(a)$, the buried oxide serves as an etch stop during the etching of the cantilevers and releasing these from the handle wafer. Fabrication of the cantilevers was started by the application and patterning of the photoresist mask for defining the cantilevers ( $b$ and $c$ ). Subsequently, cantilevers were anisotropically etched by deep reactive ion etching (DRIE) (Jansen et al., 2009) using $\mathrm{SF}_{6}, \mathrm{O}_{2}$ and $\mathrm{C}_{4} \mathrm{~F}_{8}$ gases $(d)$. After etching of the cantilevers, any remaining photoresist mask material was removed from the front side of the wafers by oxygen plasma $(e)$. In the last step of the front side processing of the SOI wafers, polyimide pyralin was spin coated to protect the front side $(f)$. In particular, this layer protects 
(a)

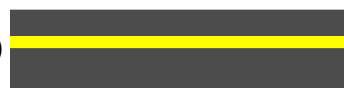

(b)

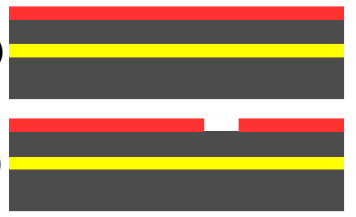

(d)

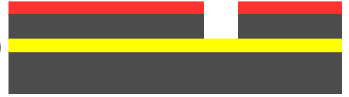

(e)

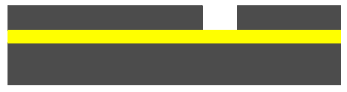

(f)

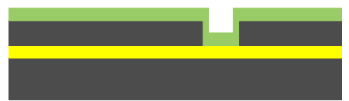

Silicon

$\mathrm{SiO}_{2}$

Photoresist

Pyralin

FIGURE 2.1 - Outline of the fabrication process to obtain cantilevers on the front side of the wafers. (a) SOI wafer, (b) application of photoresist on the front side, (c) patterning of photoresist, (d) DRIE of the silicon device layer, (e) photoresist removal, $(f)$ application of polyimide pyralin as protective layer.

(a)

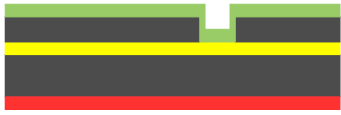

(b)

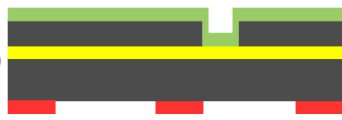

(c)

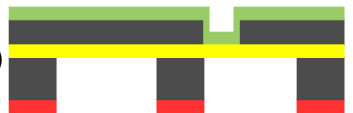

(d)

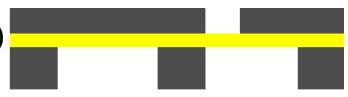

(e)

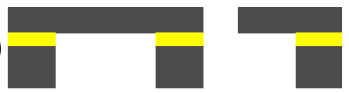

FIGURE 2.2 - Outline of the fabrication steps on the back side of the wafers for releasing the cantilevers. (a) application of photoresist on the back side, (b) patterning of photoresist, (c) wafer through DRIE, (d) pyralin and photoresist removal from front and back sides, (e) etching of buried oxide layer using VHF.

the cantilevers from damage during the back side processing of the wafers (Loh et al., 2002).

Subsequently, cantilevers were released from the handle wafer by making waferthrough holes from the back side of the wafers according to the steps shown in Figure 2.2. Starting with the application and patterning of the photoresist on the back side of wafers for defining the holes ( $a$ and $b$ ), etching the back side of wafers was performed by DRIE (Jansen et al., 2009) using $\mathrm{SF}_{6}, \mathrm{O}_{2}$ and $\mathrm{CHF}_{3}$ gases (c). Subsequently polyimide pyralin from the front side and photoresist material from the back side of wafers were removed by oxygen plasma $(d)$. Finally, the cantilevers were released by etching of the buried oxide layer using vapours of hydrofluoric acid 


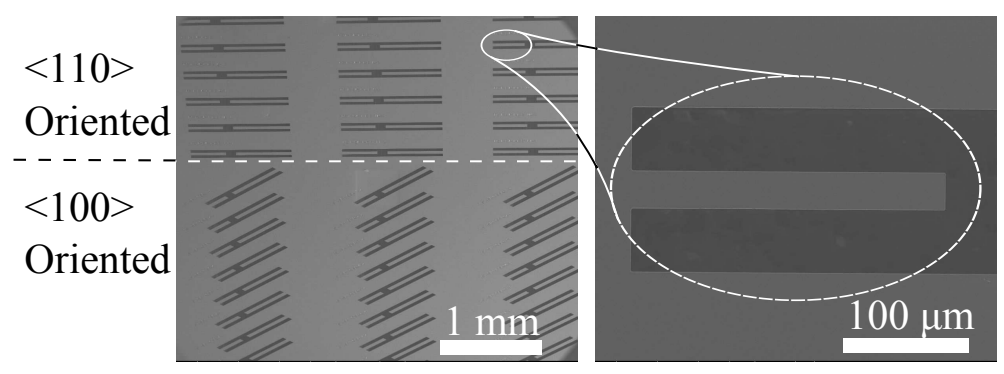

FIGURE 2.3 - Scanning electron micrographs of the fabricated cantilevers. The cantilevers vary in length from $250 \mu \mathrm{m}$ to $350 \mu \mathrm{m}$ in steps of $10 \mu \mathrm{m}$. The width and thickness of cantilevers are $30 \mu \mathrm{m}$ and $3 \mu \mathrm{m}$ respectively. The cantilevers are aligned parallel to the $\langle 110\rangle$ and $<100\rangle$ crystal orientations of the silicon wafer.

(VHF) (Anguita and Briones, 1998) (e). The vapour HF etching was stopped after an estimated isotropic etch length of $500 \mathrm{~nm}$. To measure resonance frequencies of the cantilevers in the $<110\rangle$ and $<100\rangle$ crystal directions of silicon, cantilevers were fabricated aligned parallel to the primary flat of wafers, which corresponds to the $\langle 110\rangle$ crystal direction of the silicon. For the $<100\rangle$ crystal direction of the silicon crystal lattice, cantilevers were rotated $45^{\circ}$ with respect to the primary flat of wafers. The obtained cantilevers were characterized and inspected by scanning electron and optical microscopy, see Figure 2.3.

\subsection{Measurements}

The resonance frequency of the cantilevers was measured under ambient conditions by using a MSA-40o Micro System Analyser scanning laser-Doppler vibrometer. The measured resonance frequencies for cantilevers of length around $250 \mu \mathrm{m}$, width around $30 \mu \mathrm{m}$, and thickness around $3 \mu \mathrm{m}$ are shown in Figure 2.4. Identical cantilevers are aligned parallel to the $<110\rangle$ and $<100\rangle$ crystal orientations of silicon. The difference in the fundamental resonance frequency for two differently oriented identical cantilevers can be seen clearly from Figure 2.4. This difference is solely caused by the different effective Young's modulus for the two crystal directions.

From Equation (2.1) we observed that the most critical dimensional parameters are thickness and length. Ideally, the fabricated cantilever should follow the geometrical dimensions as designed on mask, see Figure 2.5(a). Unfortunately, the DRIE process used for the release of cantilevers from the handle wafer introduces an undercut in the cantilevers. This undercut, shown in Figure 2.5(b), is caused by over-etching and increases the length of cantilevers.

Since undercut can not be avoided in this fabrication process, it must be included in the resonance frequency calculations using Equation (2.1). The effect of undercut is included by adding an effective undercut length $\triangle L^{\prime}$ to the length $L$ of the cantilevers (Babaei Gavan et al., 2009; Cleland et al., 2001). The effective 


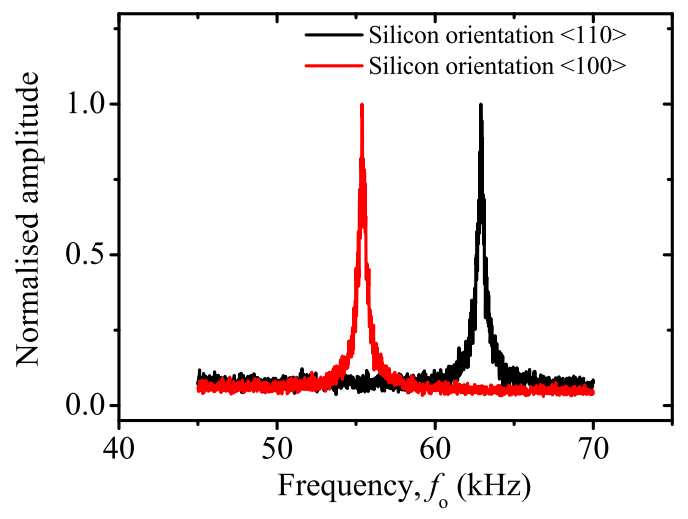

FIGURE 2.4 - The difference in resonance frequency of identical cantilevers, aligned in the $\langle 110\rangle$ and $\langle 100\rangle$ crystal directions of the silicon crystal lattice. The amplitude is normalised to the maximum value.

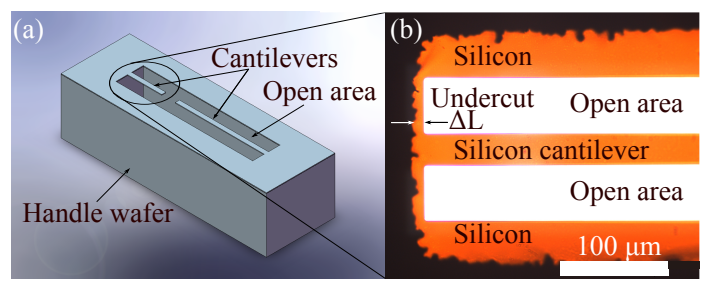

FIGURE 2.5 - An undesired undercut in the cantilevers was created by the back side etching of the handle wafer. (a) Pictorial representation of the ideal released cantilevers without undercut. (b) Optical micrograph of the $\langle 110\rangle$ cantilever showing undercut. The Rough sides of the undercut can be clearly seen.

length $L+\triangle L^{\prime}$ of cantilevers is determined by least square fitting of the measured resonance frequencies data for fabricated cantilevers with a range of length, see Figure 2.6. Equation (2.1) is used as a fitting function after replacing $L$ with $L+\triangle L^{\prime}$ and keeping $\triangle L^{\prime}$ as a free parameter in the fitting routine. The ratio of the measured resonance frequencies to their respective thickness are shown in Figure 2.6 for a range of cantilevers aligned parallel to the $\langle 110\rangle$ and $\langle 100\rangle$ crystal directions of silicon. The fitting curves are shown by solid lines in the Figure 2.6 whereas squares and circles represent the measured data for $\langle 110\rangle$ and $\langle 100\rangle$ cantilevers respectively. The effective undercut length $\triangle L^{\prime}$ determined from the fitting routine was found to be $5 \mu \mathrm{m}$ for the $<110>$ crystal direction and $1 \mu \mathrm{m}$ for the $<100\rangle$ crystal direction of silicon. The coefficients of determination were both 0.99 . 


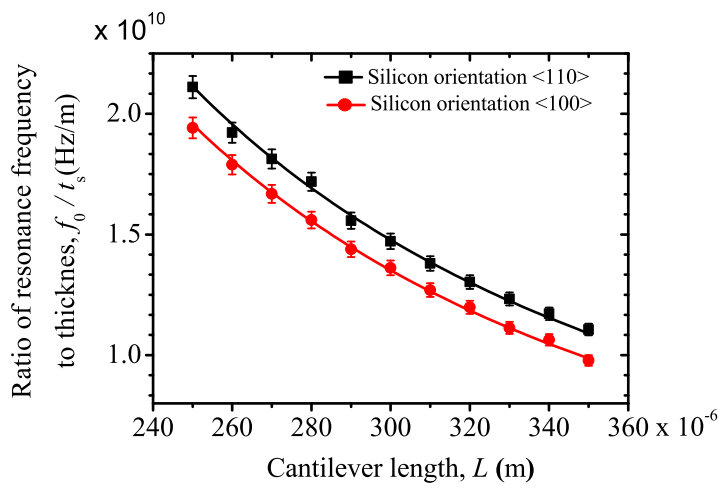

FIGURE 2.6 - Least square fitting of the fundamental resonance frequency of cantilevers. Ratio of the resonance frequency to their respective thickness was plotted against length. The effective undercut length $\triangle L^{\prime}$ was obtained by fitting the resonance frequency data points using least square method as shown by the solid lines. Squares are measured values for the $<110>$ cantilevers and circles represent $<100>$ aligned cantilevers.

\subsection{Results and discussion}

The experimentally measured resonance frequencies for the range of cantilevers length agree with the FE simulations and the analytically calculated values when using Young's modulus as the appropriate effective Young's modulus. We found a $3 \%$ variation between the FE simulations results and analytically calculated values of the resonance frequency in the $<100\rangle$ crystal direction of silicon when using the plate modulus approximation. Without a factor of $\left(1-v^{2}\right)$ in the denominator, the variation is only $0.7 \%$. Therefore the plate modulus approximation is not valid for the cantilevers used in this work. This is in agreement with the analysis by McFarland, who suggests use of the Searle parameter to differentiate between beams and plates (McFarland et al., 2005).

As an example of the determination the Young's modulus of the thin films, we deposited $100 \mathrm{~nm}$ thick PZT by PLD on these cantilevers. The Young's modulus of the PZT thin film is calculated by using the measured change in resonance frequency before and after the epitaxial deposition. The Young's modulus of PZT thin film was found to be $113.5 \mathrm{GPa}$. The value of the Young's modulus of the PZT thin film deposited by PLD is in the same order as values quoted in literature for sol-gel (Piekarski et al., 2001) and sputter deposited (Fang et al., 2003) PZT. Details of the Young's modulus measurement of the PZT thin films are discussed in Chapter 3. 


\subsection{Conclusion}

We demonstrated a method to determine the best approximation for the effective Young's modulus of cantilevers. This method is generally applicable for arbitrary cantilever dimensions. Furthermore, we determined that the analytical relation for resonance frequency calculations using $E^{*}=E$ for silicon cantilevers is very precise in both the $<110\rangle$ and $<100>$ directions. When using a plate modulus approximation for the $\langle 100\rangle$ direction, the deviation of the analytical values compared to the FE simulations is $3 \%$. As an example we utilised these cantilevers to determine the Young's modulus of the epitaxially grown PZT thin film deposited by PLD. The Young's modulus of PZT is found to be $113.5 \mathrm{GPa}$ with a standard error of $\pm 1.5 \mathrm{GPa}$. 


\section{Chapter 3}

\section{Measurement of Young's modulus}

\subsection{Introduction}

In the micro electromechanical systems (MEMS) industry, a strong interest exists in highly sensitive sensors and powerful actuators. To this end, $\mathrm{PbZr}_{0.52} \mathrm{Ti}_{0.48} \mathrm{O}_{3}$ (PZT) is widely used for both piezoelectric actuation and sensing purposes. Printer manufacturers are, for instance, trying to incorporate PZT as an active device layer in inkjet printheads (Murata et al., 2009). It is also a preferred choice for robotics applications (Bronson et al., 2009), biosensors (Lee et al., 2004), and probe based data storage devices (Nam et al., 2007) because of its high piezoelectric and ferroelectric properties. To support the use of this material in MEMS applications, information is needed on the mechanical properties in the thin film domain, certainly since these properties can differ from those of bulk materials (Delobelle et al., 2004). Moreover, a large variation in the values of the PZT thin film Young's modulus was published in literature, for instance, in reference (Deshpande and Saggere, 2007) the range was mentioned from 37 to $400 \mathrm{GPa}$.

PZT films can be deposited by processes like sol-gel (Ledermann et al., 2004), sputter (Fang et al., 2003) and pulsed laser deposition (PLD) (Dekkers et al., 2009). Recently, excellent ferroelectric properties have been reported for PZT deposited by PLD (Dekkers et al., 2009). However, accurate determination of the mechanical properties of PZT is being hampered by the fact that up to now only mm-square areas can be deposited uniformly using PLD. Mechanical characterization using full wafer techniques can therefore not be applied. Micrometer sized measurement devices provide a solution to this limitation. Many micro-sized structures such as cantilevers, membranes and bridges have been employed as test structures for determining the mechanical properties of thin films (Isarakorn et al., 2010; Ræder et al., 2007; Schweitz, 1991). In particular, cantilevers are among the most widely used test structures for this purpose (Finot et al., 2008; Nguyen et al., 2010). We devised a method to accurately determine the effective Young's modulus of PZT thin film by using the shift in resonance frequency of micro cantilevers before and after deposition of thin film of PZT. Our demonstrated technique yields results with 
much higher accuracy compared to the similar methods reported in literature (Rúa et al., 2009; Wang and Cross, 1998)

Accurate determination of the effective Young's modulus of PZT thin films from this resonance frequency method relies on the use of the appropriate effective Young's modulus of the cantilever material (Van Kampen and Wolffenbuttel, 1998). Since the epitaxial growth of the PZT by PLD on single crystal silicon might lead to in-plane anisotropy in the Young's modulus (Matin et al., 2010), cantilevers oriented along the $\langle 110\rangle$ and $<100\rangle$ crystal directions of silicon were analyzed. This analysis is discussed in section 3.2. In section 3.3, the fabrication of silicon cantilevers and the deposition of PZT thin films by PLD is explained. The determination of the effective Young's modulus of PZT depends on precise information about the geometrical dimensions of the cantilevers. In calculations, any uncertainty in these geometrical dimensions will propagate to the uncertainty in the final value of the Young's modulus of the PZT thin film. Therefore precise measurement of the thickness of cantilevers is an important parameter that reduces the uncertainty in the final result. This measurement is discussed in section 3.4. We observed an undesired undercut, which results from the deep reactive ion etching (DRIE) process that is used for the release of the cantilevers from the handle wafer. This undercut increases the effective length of the cantilevers (Babaei Gavan et al., 2009; Cleland et al., 2001). The effect of the undercut is incorporated in the calculation of the resonance frequency of cantilevers (Nazeer et al., 2011b). In section 3.4, we also present the orientation of PZT and resonance frequency measurements of the PZT deposited cantilevers. Finally, in section 3.5, the Young's modulus of the PZT thin film deposited by PLD was determined using the effective length and appropriate effective Young's modulus relation valid for our cantilever dimensions.

\subsection{Theory}

\subsubsection{Analytical relation for the resonance frequency of cantilevers}

The resonance frequency of a cantilever without PZT is calculated by using the Equation (2.1), explained in section 2.2.

\subsubsection{Analytical model for the Young's modulus of PZT}

Addition of PZT thin films on cantilevers affects their flexural rigidity and increases their mass. Both effects result in a change in the resonance frequency of the cantilevers. The effective Young's modulus of the PZT thin film is calculated using the resonance frequency both before and after deposition of the PZT thin film. We developed an analytical relation for the determination of Young's modulus of PZT as described in Equation (3.1). The equation is based on a shift of the neutral axis and on the assumptions that the cantilever has a uniform cross section, and that 
the cantilever deflection is small (Gere, 2006; Volterra and Zachmanoglou, 1965):

$$
\begin{aligned}
& E_{\mathrm{f}}^{*}=\frac{1}{t_{\mathrm{f}}^{3}}\left[6\left(t_{\mathrm{s}} \rho_{\mathrm{s}}+t_{\mathrm{f}} \rho_{\mathrm{f}}\right) B-2 E_{\mathrm{s}}^{*} t_{\mathrm{s}}^{3}-3 t_{\mathrm{f}} E_{\mathrm{s}}^{*} t_{\mathrm{s}}^{2}-2 E_{\mathrm{s}}^{*} t_{\mathrm{s}} t_{\mathrm{f}}^{2}\right.
\end{aligned}
$$

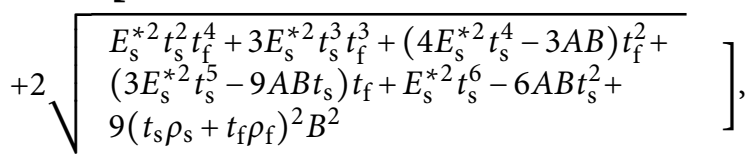

where

$$
A=E_{\mathrm{s}}^{*} t_{\mathrm{s}}\left(t_{\mathrm{s}} \rho_{\mathrm{s}}+t_{\mathrm{f}} \rho_{\mathrm{f}}\right)
$$

and

$$
B=\left(\sqrt{\frac{E_{\mathrm{s}}^{*} t_{\mathrm{s}}^{3}}{12 t_{\mathrm{s}} \rho_{\mathrm{s}}}}-0.568 \pi \Delta f_{0} L^{2}\right)^{2} .
$$

The symbols $E^{*}, t, L$ and $\rho$ are the effective Young's modulus, thickness, length and density, respectively. Subscripts 's' and 'f denote the silicon and PZT thin film. $\Delta f_{0}$ is the difference in the fundamental resonance frequency of the cantilever before and after the deposition of PZT. By taking this difference, any potential uncertainties in the thickness of the cantilever can be eliminated and a more accurate result is obtained (Schweitz, 1991).

\subsubsection{Analysis of uncertainties}

Any uncertainty in measurement of the geometrical dimensions, frequency and physical parameters will affect the final calculated value of the Young's modulus of the PZT thin film. The uncertainty in the Young's modulus of thin film was calculated using Equation (3.2).

$$
\frac{\Delta E_{\mathrm{f}}^{*}}{E_{\mathrm{f}}^{*}}=\frac{\partial E_{\mathrm{f}}}{\partial x}\left[\frac{x}{E_{\mathrm{f}}}\right]\left[\frac{\Delta x}{x}\right],
$$

where $x$ is any of the parameters $L, t_{\mathrm{s}}, t_{\mathrm{f}}$ or $\rho_{\mathrm{f}}$ used in the right hand-side of Equation (3.1). The cumulative error in the value of the effective Young's modulus of the PZT thin film is then calculated by the root mean square of the errors (Taylor, 1997) calculated by using Equation (3.2).

\subsection{Fabrication}

\subsubsection{Fabrication of silicon cantilevers}

Fabrication details and geometrical dimensions of the silicon cantilevers are similar to what is explained in section 2.3. 


\subsubsection{Deposition of PZT by PLD}

Deposition of PZT material on the front side of wafers started with depositing 10 nm thick buffer layers of yttria-stabilized zirconia (YSZ) and of strontium ruthenate (SRO) by PLD. These layers act as a barrier against lead diffusion during PZT film deposition and prevent the formation of an excessive $\mathrm{SiO}_{2}$ amorphous layer on the surface of the silicon substrate. Moreover, these layers also act as a crystallization template for the PZT epitaxial layer growth. After the deposition of buffer layers, $100 \mathrm{~nm}$ thick PZT film was deposited by PLD. The PLD parameters with which epitaxial growth of PZT was achieved are listed in Table 3.1 (Nguyen et al., 2010). These PLD parameters, and the use of buffer layers, ensured the epitaxial growth of PZT which is confirmed by phi-scan plots from x-ray diffraction (Nguyen et al., 2010).

TABLE 3.1 - PLD parameters for achieving the required deposition conditions.

\begin{tabular}{|c|c|c|c|}
\hline Parameters & YSZ & SRO & PZT \\
\hline $\mathrm{O}_{2}$ Pressure (mbar) & 0.021 & 0.13 & 0.1 \\
\hline Ar Pressure (mbar) & 0.020 & - & - \\
\hline Temperature $\left({ }^{\circ} \mathrm{C}\right)$ & 800 & 600 & 600 \\
\hline Fluence $\left(\mathrm{J} / \mathrm{cm}^{2}\right)$ & 2.1 & 2.5 & 3.5 \\
\hline Area of ablation spot $\left(\mathrm{mm}^{2}\right)$ & $3 \cdot 35$ & 1.9 & 3 \\
\hline
\end{tabular}

\subsection{Experimental details}

\subsubsection{Resonance frequency measurements}

The resonance frequency of the cantilevers was measured using thermally excited vibration in ambient conditions by using a MSA-40o micro system analyzer scanning laser-Doppler vibrometer. The free resonance frequency was calculated by curve fitting with the theoretical expression for a second order mass-spring system with damping.

\subsubsection{Thickness of cantilevers}

Uncertainty in the thickness of cantilevers makes the calculation for the effective Young's modulus of PZT unreliable. The supplier of the SOI wafers specifies an error of $\pm 0.5 \mu \mathrm{m}$ for the thickness of the device layer, which is a $17 \%$ uncertainty in the $3 \mu \mathrm{m}$ device layer. In order to determine the thickness of the individual cantilevers with higher precision, we measured each cantilever by high resolution scanning electron microscopy. We found that there is a $4 \%$ difference in the thickness of the first and last cantilevers, which are $10 \mathrm{~mm}$ apart from each other, see Figure 3.1(a). The thickness measurement was corrected for the applied tilt as shown 
in Figure 3.1(b) to obtain the final value of the thickness. The cumulative error in the thickness measurement of individual cantilevers was found to be $\pm 2.2 \%$.
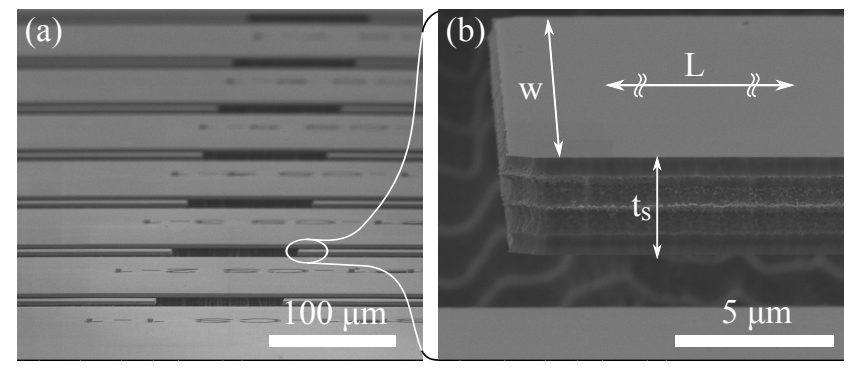

FIGURE 3.1 - Scanning electron micrograph of cantilevers with applied tilt for non destructive thickness measurement. (a) Wafer tilted in the SEM to locate a particular cantilever. (b) Zoom-in image of the individual cantilever tilted at $5^{\circ}$ for thickness measurement.

\subsubsection{XRD measurements}

In order to reveal the crystal structure and the epitaxial growth of the PZT, x-ray diffraction (XRD) measurements were performed. The $\theta-2 \theta$ scan of Figure 3.2 clearly indicates the growth of a PZT thin film with a (110) preferred orientation. The epitaxial growth of our PZT films can be confirmed by phi-scan plots from the similar samples, reported previously by the authors in (Dekkers et al., 2009; Nguyen et al., 2010).

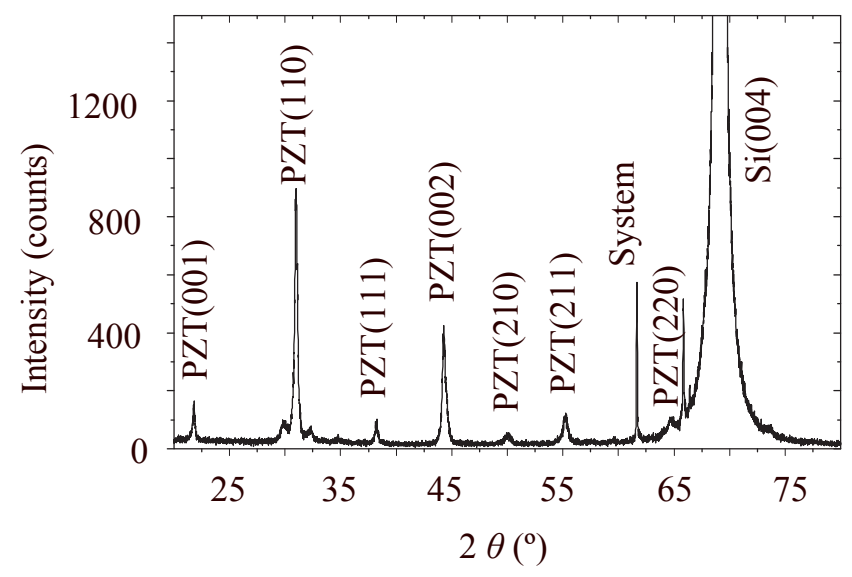

FIGURE 3.2 - Measured $x$-ray diffraction pattern of pulsed laser deposited $\mathrm{PbZr}_{0.52} \mathrm{Ti}_{0.48} \mathrm{O}_{3}$. The (110) is the predominant orientation of the deposited PZT. 


\subsubsection{PZT measurements}

The second measurement of the cantilever resonance frequency was performed after the deposition of PZT. The difference in the fundamental resonance frequency of a cantilever of length around $250 \mu \mathrm{m}$, width around $30 \mu \mathrm{m}$, and thickness around $3 \mu \mathrm{m}$ measured both before and after the deposition of $100 \mathrm{~nm}$ PZT thin film is shown in Figure 3.3. Due to the addition of the PZT thin film on the cantilevers, the resonance frequency was decreased as expected.

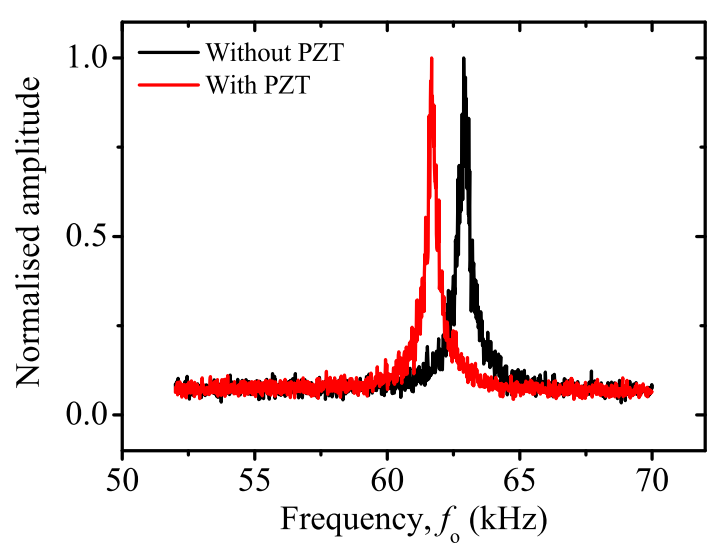

FIGURE 3.3-Measured resonance frequency before and after deposition of the PZT. The amplitude is normalised to the maximum value. The resonance frequency with PZT is lower compared to the cantilevers without PZT, which is as expected.

\subsection{Discussion}

In (Nazeer et al., 2011b) we have shown that finite element (FE) simulations validate the use of the Young's modulus $E$ instead of the plate modulus $E /\left(1-v^{2}\right)$ as the effective Young's modulus in the analytical relation of the resonance frequency for our cantilever dimensions. The ratio of the resonance frequency to the cantilever thickness was plotted against $\left(L+\Delta L^{\prime}\right)^{-2}$ in Figure 3.4. The analytical, FE (COM$\mathrm{SOL}$ ) and experimental results are shown in the plot for easy comparison. The experimentally measured values agree well with the analytically calculated values, which confirms that the Young's modulus without a factor of $\left(1-v^{2}\right)$ in the denominator is the appropriate effective Young's modulus for our cantilever dimensions. The agreement between FE and the analytical approximation is particularly good for the $<110>$ silicon direction. A small deviation is found for the $<100>$ direction. 


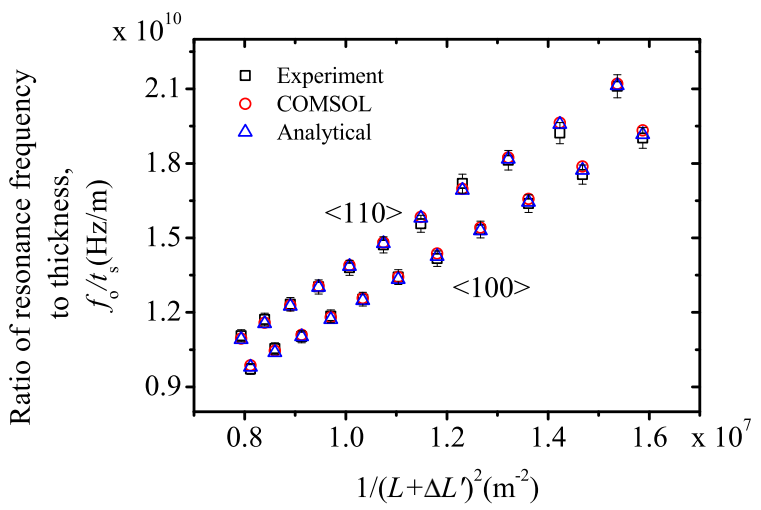

FIGURE 3.4 - Analytically calculated, simulated and measured resonance frequencies shown as $f_{o} / t_{s}$ for cantilevers of varying length. The cantilevers are aligned parallel to the $\langle 110\rangle$ and $\langle 100\rangle$ crystal directions of silicon.

According to Equation (2.1), the fundamental resonance frequency has a linear relation with inverse of the cantilever length squared. From Figure 3.5, we see that this linear relation is maintained for the experimental results of our $<110\rangle$ and $\langle 100\rangle$ oriented cantilevers when using the effective length $\left(L+\Delta L^{\prime}\right)$ of these cantilevers. The difference in the fundamental resonance frequency of cantilevers before and after the deposition of PZT thin film is also clear from Figure 3.5.

The Young's modulus of PZT, calculated from Equation (3.1) by using the measured change in resonance frequency, was found to be $113.5 \mathrm{GPa}$ with a standard error of $\pm 1.5 \mathrm{GPa}$, see Figure 3.6. This value is obtained from cantilevers of varying lengths aligned parallel to the $\langle 110\rangle$ crystal direction of silicon. The value for the cantilevers aligned parallel to the $\langle 100\rangle$ crystal direction of silicon was found to be $103.5 \mathrm{GPa}$, with a standard error of $\pm 1.9 \mathrm{GPa}$, see Figure 3.7. No significant influence of the cantilever length was observed on the Young's modulus of PZT thin film, as expected. The value of the Young's modulus of PZT thin film deposited by the PLD is in the same order as values quoted in literature, such as $25 \mathrm{GPa}$ for sol-gel (Piekarski et al., 2001) and 109 GPa for sputter deposited (Fang et al., 2003) PZT.

A thorough error analysis was performed to calculate the propagation of errors in the parameters to the calculated values for the effective Young's modulus using Equation (3.2). The cumulative error found in the calculated value of the effective Young's modulus is in the order of 6 to $8 \mathrm{GPa}$ for individual cantilevers. Uncertainty about the thickness of the PZT thin film was found to be the dominant source of error, as is shown in Table 3.2 . 


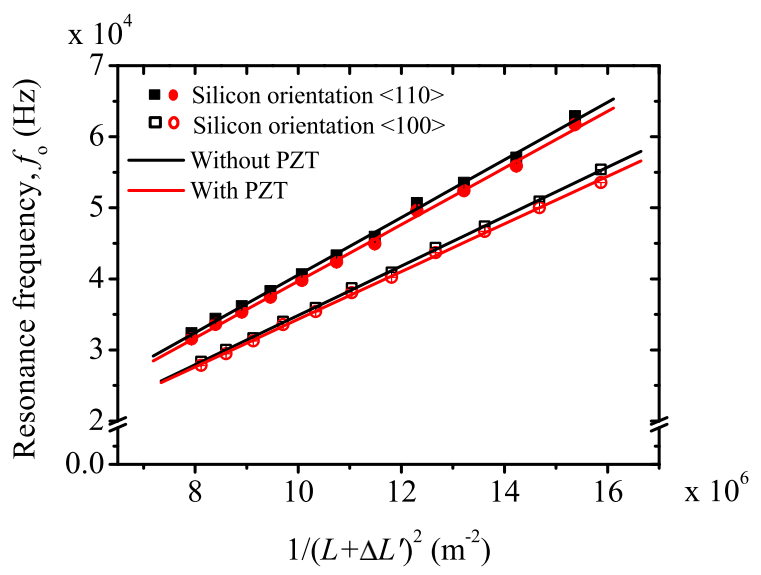

FIGURE 3.5 - Fundamental resonance frequency versus inverse of effective length squared of the cantilevers, follows a straight line in both the $\langle 110\rangle$ and $\langle 100\rangle$ crystal orientation of silicon.

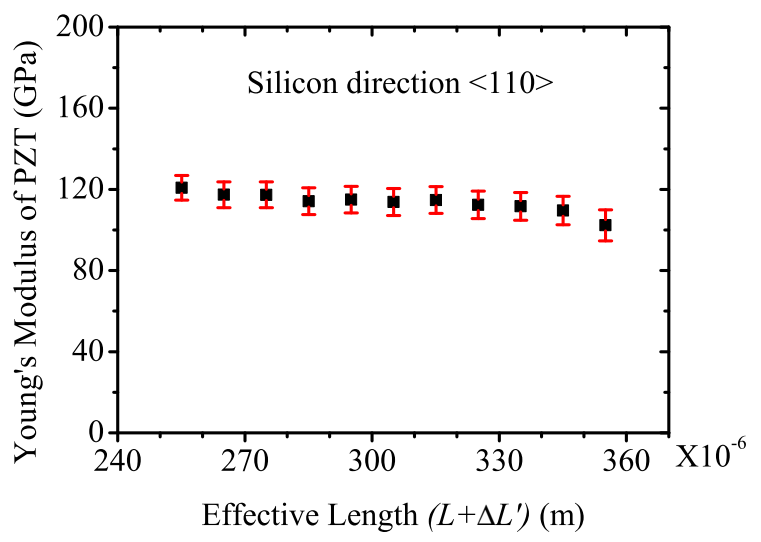

FIGURE 3.6 - Young's modulus of PZT, calculated for individual cantilevers oriented in the $\langle 110\rangle$ crystal direction of silicon along with respective error bars. The mean value was determined to be $113.5 \mathrm{GPa}$ with a standard error of $\pm 1.5 \mathrm{GPa}$. 


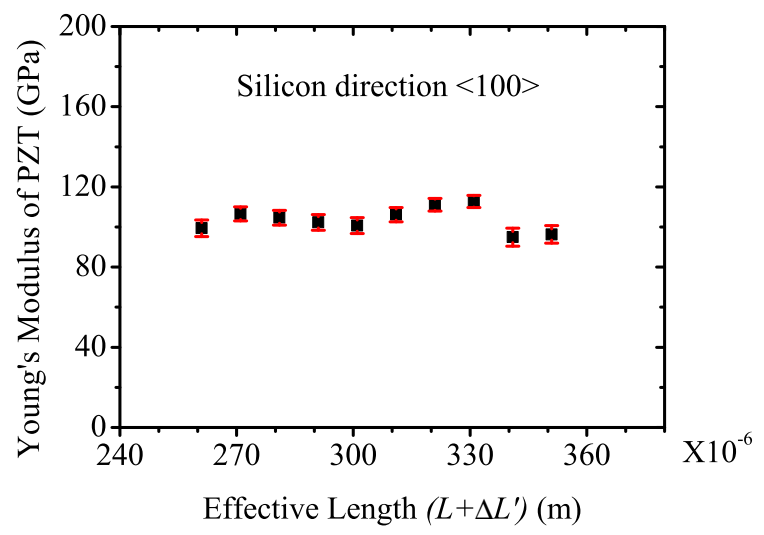

FIGURE 3.7 - Young's modulus of PZT calculated for individual cantilevers oriented in the $\langle 100\rangle$ crystal direction of silicon along with respective error bars. The mean value was determined to be $103.5 \mathrm{GPa}$ with a standard error of $\pm 1.9 \mathrm{GPa}$.

TABLE 3.2 - Error analysis for Young's modulus of PZT. Results of a $250 \mu \mathrm{m}$ long cantilever are used as an example. The error in the film thickness $t_{f}$ is the largest and has the maximum contribution to the cumulative error.

\begin{tabular}{|c|c|c|}
\hline Parameters & $\begin{array}{c}\text { Error in } \\
\text { parameter }(\%)\end{array}$ & $\begin{array}{c}\text { Error in } \\
\text { Young's modulus (\%) }\end{array}$ \\
\hline$L$ & 0.5 & 0.6 \\
\hline$t_{\mathrm{s}}$ & 2.2 & 0.2 \\
\hline$t_{\mathrm{f}}$ & 10 & 5.2 \\
\hline$\rho_{\mathrm{f}}$ & 1 & 1.6 \\
\hline
\end{tabular}

\subsection{Conclusion}

We determined the Young's modulus of PLD deposited epitaxial PZT thin films using the resonance frequencies of a range of cantilevers, measured both before and after deposition. From the shift in resonance frequency of the cantilevers and taking into account their effective undercut length, the thickness of the individual cantilevers, and applying a rigorous error analysis, we successfully determined that the in-plane Young's modulus of PZT thin films is anisotropic. The measured Young's modulus of the PZT thin film is $113.5 \mathrm{GPa}$ with a standard error of $\pm 1.5 \mathrm{GPa}$ for the $<110\rangle$ crystal direction of silicon and $103.5 \mathrm{GPa}$ with a standard error of $\pm 1.9 \mathrm{GPa}$ for the $<100\rangle$ silicon direction.

The value and anisotropy of the Young's modulus is of major importance for the design of MEMS sensors and actuators based on this advanced PLD PZT material. 
Furthermore, the high accuracy method of determining the Young's modulus of thin films in different in-plane crystal directions of silicon we describe here is generally applicable to any thin film that can be deposited on silicon cantilevers. 


\section{Chapter 4}

\section{PZT films with (110) orientation}

\subsection{Introduction}

In the micro- and nano industry, the ever-growing demand for powerful actuators and sensitive sensors is addressed by the use of piezo-based transducers (Bronson et al., 2009; Nam et al., 2007). $\mathrm{Pb}\left(\mathrm{Zr}_{x} \mathrm{Ti}_{1-x}\right) \mathrm{O}_{3}$ (PZT) thin films are often used as piezo-materials because they have excellent ferroelectric and piezoelectric properties. These properties can be tuned by controlling the composition of the material by changing the $\mathrm{Zr} / \mathrm{Ti}$ ratio (Isarakorn et al., 2011; Zhuang et al., 1989). For instance, the composition $\mathrm{Pb}\left(\mathrm{Zr}_{0.52} \mathrm{Ti}_{0.48}\right) \mathrm{O}_{3}$ is used in different types of applications due to its higher piezoelectric properties (Xu et al., 2000). Recently Isarakorn et al. (2011) discussed the use of a Ti-rich composition $(x=0.2)$ in energy-harvesting devices. They combined the high piezoelectric coefficient $e$ and low dielectric constant $\varepsilon$ of $\mathrm{Pb}\left(\mathrm{Zr}_{0.2} \mathrm{Ti}_{0.8}\right) \mathrm{O}_{3}$ to obtain a high figure of merit for power and voltage generation. A similar trade-off can be achieved for the piezoelectric coefficient $d$ and the Young's modulus of the material, which are analyzed in this chapter.

If one looks at micro-electromechanical systems (MEMS), it is apparent that with the development of various types and applications, such as sensors and actuators, the requirement for materials with specific properties is getting very strict. It is realized that because of their tunable properties, PZT thin films are very suitable for such micro- and nano systems (Piekarski et al., 2002). However, in order to efficiently use PZT thin films in these systems a better understanding of the piezoelectric and ferroelectric properties, as well as the mechanical behaviour of PZT thin films of various compositions, is necessary. For instance, the compositional dependence of these properties is dissimilar from their ceramic counterparts due to reasons like clamping of the films to the substrates and the different orientation of the films (Hiboux et al., 1999; Taylor and Damjanovic, 2000).

PZT thin films can be obtained through different processes like sol-gel (Ledermann et al., 2004), sputter- (Fang et al., 2003) and pulsed laser deposition (PLD) (Dekkers et al., 2009) techniques. Excellent ferroelectric properties of PLDPZT with a (110) preferred orientation are reported in (Nguyen et al., 2010). In 
this chapter, we investigate the compositional dependence of the effective longitudinal piezoelectric coefficient $\left(d_{33, \mathrm{f}}\right)$, the Young's modulus $E$, dielectric constant $\varepsilon$ and coupling coefficient $k$ of these PLD-PZT thin films in order to efficiently use these films as active device layers in MEMS devices. We used micrometer-sized measurement devices to characterize these dependencies.

The $d_{33, \mathrm{f}}$ was determined by measuring the out-of-plane displacement of PZT thin film capacitors, as described in section 4.2.1. The Young's modulus of the PZT thin films was determined by measuring the change in the resonance frequency of cantilevers before and after deposition of the PZT thin films. In sections 4.3.1 and 4.3.2, the fabrication of capacitor structures and silicon cantilevers and the deposition of PZT thin films by PLD are explained. The Young's modulus and the $d_{33, \mathrm{f}}$ depend on the orientation of the PZT thin films. Therefore X-ray diffraction (XRD) measurements were performed. These measurements and the techniques used to measure the Young's modulus and $d_{33, \mathrm{f}}$ are described in sections 4.3.3, 4.3.4 and 4.3.5. Finally, the compositional dependence of the $d_{33, \mathrm{f}}$, the Young's modulus, the dielectric constant and the coupling coefficient of the PLD-PZT thin films are discussed in section 4.4 .

\subsection{Theory}

\subsubsection{Longitudinal piezoelectric coefficient $d_{33, \mathrm{f}}$}

The $d_{33, \text { f }}$ can be determined by either measuring the charge generated due to an applied external mechanical stress (direct piezoelectric effect) or by measuring the displacement in the PZT caused by the application of an electric field (converse piezoelectric effect). Homogeneous uniaxial stress is required in the direct piezoelectric effect measurements, which is difficult to apply. Bending in the film due to application of the non-homogeneous stress results in a large amounts of charge due to the transverse piezoelectric effect (Yao and Tay, 2003). For this reason, we measured the $d_{33 \text {, f }}$ using the converse piezoelectric effect. Applying an ac voltage on the top and bottom electrodes of the PZT capacitors, as shown in Figure 4.1, results in a piezoelectric displacement. The $d_{33, \mathrm{f}}$ is then determined by measuring the out-of-plane displacement of these capacitors by using this relation (Lefki and Dormans, 1994):

$$
d_{33, \mathrm{f}}=\frac{S_{3}}{V / t_{\mathrm{f}}} .
$$

Here $d_{33, \mathrm{f}}$ is the effective longitudinal piezoelectric coefficient ('effective' means that the thin film is clamped to the substrate which reduces $d_{33}$ with respect to a system that is not clamped), $S$ is strain, $V$ is the voltage over the capacitor and $t_{\mathrm{f}}$ is the thickness of the film. 


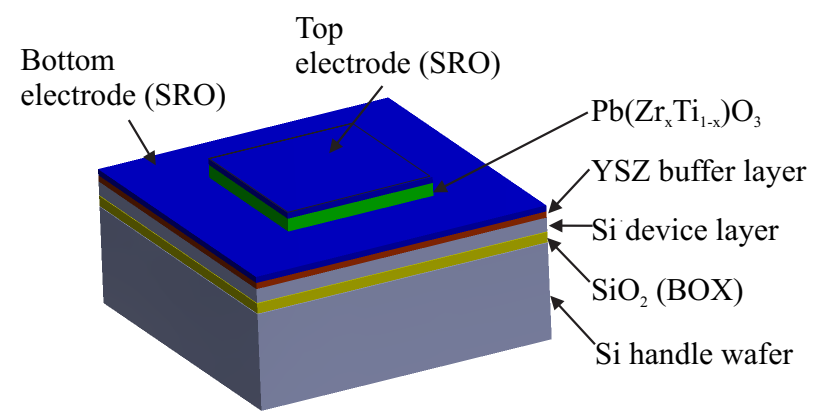

FIGURE $4.1-P Z T$ capacitors are fabricated to measure the $d_{33, f}$. These capacitors are formed with a $250 \mathrm{~nm}$ thick PZT film. The thicknesses of both the SRO top and bottom electrodes and YSZ are $100 \mathrm{~nm}$ each.

\subsubsection{Analytical model for the Young's modulus of PZT thin films}

The analytical model to determine the in-plane Young's modulus of PZT thin films is explained in section 3.2.2.

\subsection{Experimental details}

\subsubsection{Fabrication of PZT capacitors}

To measure the $d_{33, \mathrm{f}}$ and dielectric constant of PLD-PZT, capacitors were fabricated on (oo1) silicon wafers, as shown in Figure 4.2. To obtain epitaxial growth of the PZT thin films, a $100 \mathrm{~nm}$ thick buffer layer of yttria-stabilized zirconia (YSZ) was first deposited on silicon by PLD. This layer prevents the diffusion of lead into the silicon during PZT deposition and also acts as a crystallization template for epitaxial growth of the PZT thin films. Next, $100 \mathrm{~nm}$ of strontium ruthenate (SRO) was deposited as a bottom electrode. The PLD process then continued with the PZT thin film until the desired thickness of $250 \mathrm{~nm}$ was achieved. The parameters for the process used are given in (Nguyen et al., 2010). Deposition of the stack was completed with a $100 \mathrm{~nm}$ thick top electrode of SRO, as seen in Figure 4.2. The $200 \times 200 \mu \mathrm{m}^{2}$ capacitors were patterned by a standard photolithographic process, followed by argon-ion beam milling of the top SRO electrodes with an etching rate of $10 \mathrm{~nm} / \mathrm{minute}$ and a wet etch to remove the PZT layer in a diluted $\mathrm{HF}: \mathrm{HNO}_{3}: \mathrm{H}_{2} \mathrm{O}$ solution.

\subsubsection{Fabrication of cantilevers}

Silicon cantilevers of varying lengths from $250 \mu \mathrm{m}$ to $350 \mu \mathrm{m}$ in steps of $10 \mu \mathrm{m}$ were fabricated using the process steps similar to what is explained in section 2.3. The thickness of the cantilevers was defined by a $3 \pm 0.5 \mu \mathrm{m}$ thick device layer of (oo1) single crystal silicon on insulator (SOI) wafers. The width of the cantilevers 


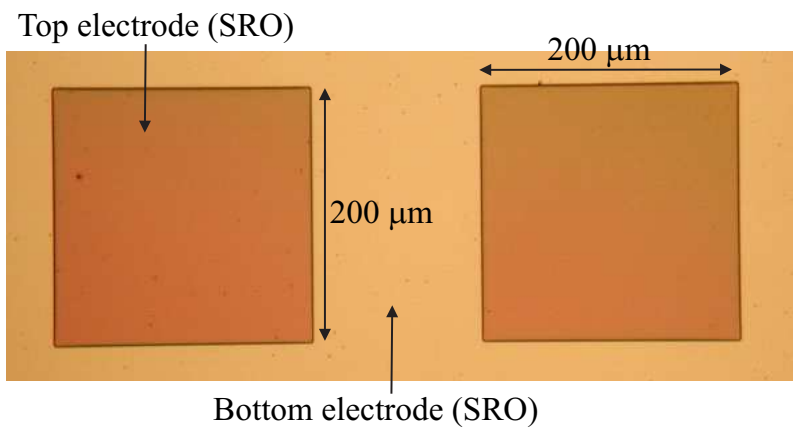

FIGURE 4.2 - Optical micrograph of the fabricated PZT capacitors using $100 \mathrm{~nm}$ thick SRO as top and bottom electrodes. The bottom electrode was deposited on the complete wafer for easy access. The PZT layer and top electrode were etched to form the capacitors. Surface dimensions of the PZT are $200 \times 200 \mu^{2}$ with a thickness of $250 \mathrm{~nm}$.

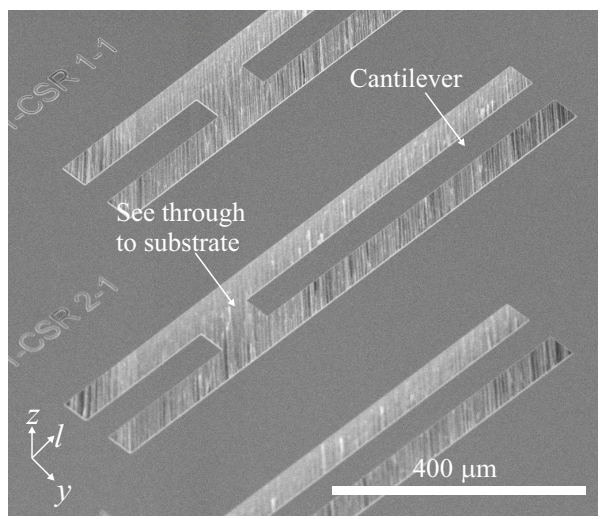

FIGURE 4.3 - Scanning electron micrograph of fabricated cantilevers. Cantilevers were fabricated from a $3 \mu \mathrm{m}$ thick silicon device layer. The length of the cantilevers varies from $250 \mu \mathrm{m}$ to $350 \mu \mathrm{m}$ in steps of $10 \mu \mathrm{m}$. The cantilevers have a constant width of $30 \mu \mathrm{m}$. See-through to substrate shows rough walls due to DRIE from the back side of the wafers.

was fixed at $30 \mu \mathrm{m}$. Scanning electron micrographs (SEM) and optical images were used to characterize these cantilevers; see Figure 4.3. After characterization of the fabricated silicon cantilevers, $10 \mathrm{~nm}$ thick buffer layers of YSZ and SRO and $100 \mathrm{~nm}$ thick PZT thin films of different compositions were deposited on separate wafers. In contrast to the capacitor structures, we deposited thin buffer layers of YSZ and SRO and omitted the top electrode, to prevent the influence of the additional layer on the resonance frequency. 


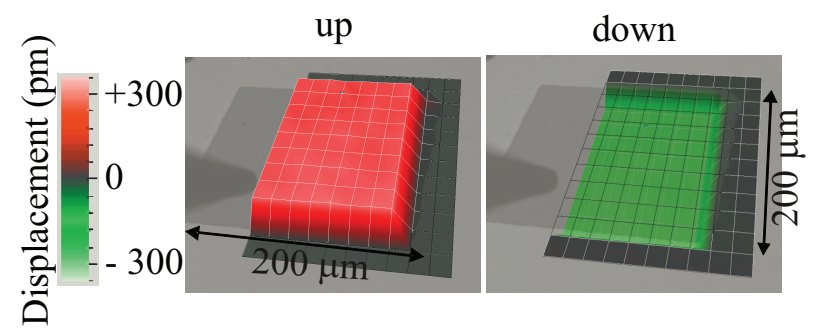

FIGURE 4.4 - Scanning laser-Doppler vibrometer measurements of a $250 \mathrm{~nm}$ thick $\mathrm{PbZr}_{0.52} \mathrm{Ti}_{0.48} \mathrm{O}_{3}$ film. The $d_{33, f}$ was calculated by applying an $8 \mathrm{kHz}$ and $6 \mathrm{~V}$ (peak to peak) ac voltage and measuring the maximum displacement of the top electrode.

\subsubsection{XRD measurements}

The orientation of the deposited PZT thin films was analyzed by $\theta-2 \theta$ X-ray diffraction (XRD) scans (XRD, Bruker D8 Discover) with a $\mathrm{Cu} \mathrm{K} \alpha$ cathode in the Bragg-Brentano geometry. The $\theta-2 \theta$ scans were performed for all compositions of the PZT thin films $(x=0.2-0.8)$. Both types of fabricated devices, capacitors and cantilevers were analyzed separately to determine the preferred orientation of the PZT thin films. The results are reported in Figure 4.6.

\subsubsection{Measurements of the longitudinal piezoelectric coefficient $d_{33, \mathrm{f}}$}

The piezoelectric displacement of the PZT thin film capacitors was measured to determine the $d_{33, \mathrm{f}}$. A MSA-400 micro system analyzer scanning laser-Doppler vibrometer was used for measuring the displacement of the capacitors. An acvoltage of magnitude $6 \mathrm{~V}_{\mathrm{p} \text {-p }}$ (peak to peak) was applied to the top and bottom electrodes at a frequency of $8 \mathrm{kHz}$. This voltage actuates the PZT and the resulting displacement of the top electrode was measured. Figure 4.4 shows the 3 -D scan of the top electrode caused by the piezoelectric response of the $200 \times 200 \mu \mathrm{m}^{2}$ $\mathrm{PbZr}_{0.52} \mathrm{Ti}_{0.48} \mathrm{O}_{3}$ film capacitor. This film has a thickness of $250 \mathrm{~nm}$. Similar measurements were conducted to measure the $d_{33, \mathrm{f}}$ of PZT compositions ranging from $x=0.2$ to 0.8 using identical structures.

\subsubsection{Measurements of the Young's modulus}

To determine the in-plane Young's modulus of PZT thin films, the resonance frequencies of cantilevers were measured by using a MSA-40o micro system analyzer scanning laser-Doppler vibrometer. Thermally excited vibrations of the cantilevers were measured in ambient conditions. Curve fitting with a theoretical expression for a second-order mass-spring system with damping was used to calculate the free resonance frequencies. The resonance frequency measurements were conducted both before and after the deposition of the PZT thin films for cantilevers of varying length and for different compositions. As an example, the measurements 
for a cantilever of length $\sim 250 \mu \mathrm{m}$, width $\sim 30 \mu \mathrm{m}$, and thickness $\sim 3 \mu \mathrm{m}$ before and after deposition of the $\mathrm{Pb}\left(\mathrm{Zr}_{0.2} \mathrm{Ti}_{0.8}\right) \mathrm{O}_{3}$ thin film are shown in Figure 4.5. The Young's modulus can be calculated from the shift in resonance frequency using Equation (3.1). To reduce the uncertainty in the calculated value of the Young's modulus, we measured the thickness of the cantilevers by using high-resolution SEM. As a result we could measure the Young's modulus with a standard error of less than $\pm 1.8 \mathrm{GPa}$.

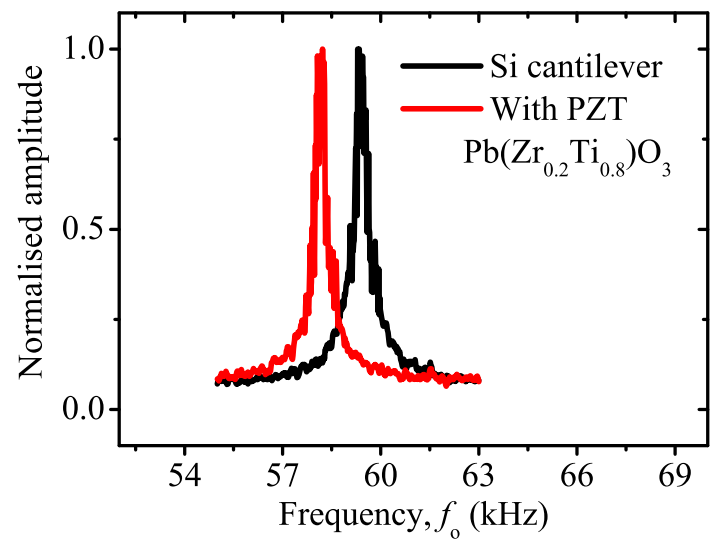

FIGURE 4.5 - The measured resonance frequencies of a cantilever before and after PZT deposition. Normalised amplitude shows a decrease in the resonance frequency of the cantilever measured after deposition of the $\mathrm{Pb}\left(\mathrm{Zr}_{0.2} \mathrm{Ti}_{0.8}\right) \mathrm{O}_{3}$. This expected decrease is attributed to the addition of the PZT thin film on the cantilever.

\subsubsection{Measurements of the dielectric constant $\varepsilon$}

The polarization hysteresis (P-E) loop was measured at $\pm 200 \mathrm{kV} / \mathrm{cm}$ amplitude and $1 \mathrm{kHz}$ frequency, using a ferroelectric tester system (aixACCT TF-200o Analyzer). The relative dielectric constant of the PZT thin films was obtained by the slope of the corresponding P-E loop using the same capacitor structures as used for the $d_{33, \mathrm{f}}$ measurements.

\subsection{Results and Discussion}

\subsubsection{Crystal structure}

It is known that the piezoelectric and mechanical properties of PZT thin films depend on the crystal orientation (Corkovic et al., 2008; Wang et al., 2005). X-ray 
diffraction (XRD) measurements reveal that all PZT thin films investigated in this study grow with a (110) preferred orientation; see Figure 4.6. Therefore, if there are any variations in the $d_{33}$, f values and the Young's modulus, then these can not be caused by the crystal orientation but must be due to a difference in composition.

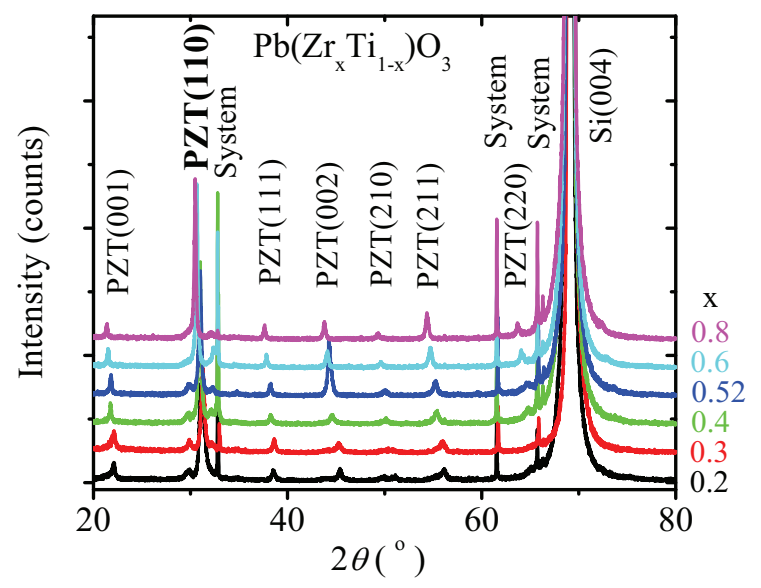

FIGURE 4.6 - Measured X-ray diffraction patterns of pulsed laser deposited $\mathrm{Pb}\left(\mathrm{Zr}_{x} \mathrm{Ti}_{1-x}\right) \mathrm{O}_{3}$ thin films, plotted for different compositions. The PZT films display a preferred (110) orientation.

\subsubsection{Piezoelectric coefficient}

The composition of PZT has a strong effect on the $d_{33, f}$ value, see Figure 4.7. For a film thickness of $250 \mathrm{~nm}$, a maximum $d_{33, \mathrm{f}}$ value of $93 \mathrm{pm} / \mathrm{V}$ was observed at a composition of $\mathrm{Pb}\left(\mathrm{Zr}_{0.52} \mathrm{Ti}_{0.48}\right) \mathrm{O}_{3}$. The optimum composition is in agreement with bulk PZT ceramics in unclamped condition (Jaffe et al., 1971), but the value is $58 \%$ lower. For this there are two reasons: clamping and domain switching. Clamping of the thin film with the substrate causes a reduction in the $d_{33, \mathrm{f}}$ value as compared to the corresponding bulk material $\left(d_{33}\right)$ (Muralt, 2000). The relation between the $d_{33, \mathrm{f}}$ and $d_{33}$ using the compliance coefficients data of the bulk $\mathrm{Pb}\left(\mathrm{Zr}_{0.52} \mathrm{Ti}_{0.48}\right) \mathrm{O}_{3}$ ceramic is given in (Xu et al., 1999) as

$$
d_{33, \mathrm{f}}=d_{33}+1.19 d_{31}
$$

Since relevant compliance coefficient data are not available for all PZT ceramic compositions, we used Equation (4.1) and $d_{33}$ and $d_{31}$ of the corresponding composition (Jaffe et al., 1971) to calculate the $d_{33, \mathrm{c}}^{\text {ceramic }}$ values of PZT ceramics in clamped 
condition (Figure 4.7). It is evident from the comparison of the compositional dependence of the PZT ceramics in clamped condition $d_{33, \mathrm{c}}^{\text {ceramic }}$ and the measured $d_{33, \mathrm{f}}$ that the $d_{33, \mathrm{f}}$ value of PLD-PZT thin film is $16 \%$ lower for $x=0.52$, whereas it shows higher values for other compositions.

Secondly, the orientation of the crystal axis is random in ceramics, therefore rotation of the ferroelectric domains is much easier as compared to single crystal PZT. It might therefore be possible that domain switching is much more difficult in our epitaxially grown PZT thin films. As a result the $d_{33}$ of the pulsed laser deposited film would be lower than the bulk PZT ceramics. It should be noted, however, that domain switching is heavily dependent on composition and difficult to estimate.

The maximum of $d_{33, \mathrm{f}}$ at $x=0.52$ composition is in agreement with the piezoelectric response reported in literature for PZT thin films obtained by a sol-gel method (Kim et al., 2003). However, the effect is more pronounced in our PZT thin films, with a shallow maximum at $x=0.52$.

We measured an increase in the $d_{33}$, f value of $123 \mathrm{pm} / \mathrm{V}$ at film thickness of $1 \mu \mathrm{m}$ and a composition of $x=0.52$. This increase is attributed to the insulating non-ferroelectric interfacial layer at the film/substrate interface (Tagantsev et al., 1995). Since the influence of the interfacial layer decreases with increasing film

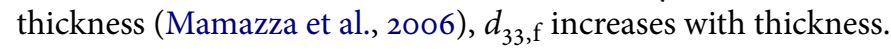

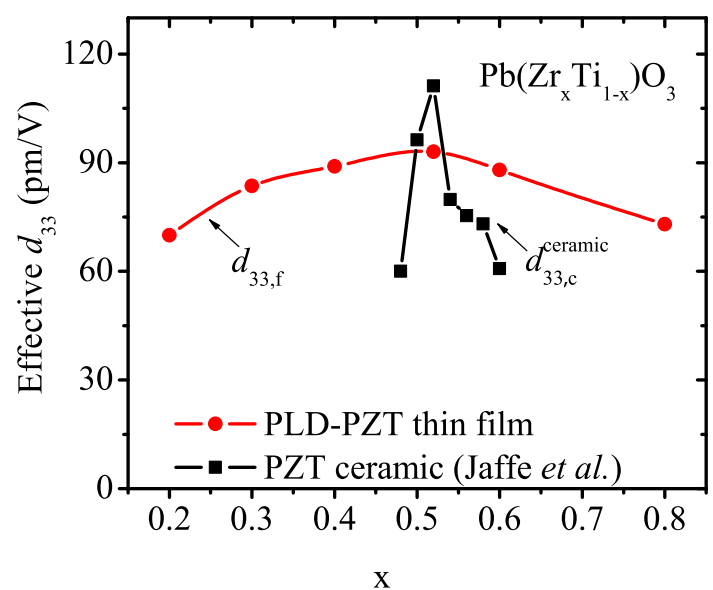

FIGURE 4.7 - The $d_{33, f}$ values as a function of $Z r$ content $(x)$ for different PZT compositions. Based on our measurements we find a maximum value of $d_{33, f}$ at $x=0.52$. The trend of the $d_{33, f}$ values for PZT thin films is compared with the bulk PZT ceramics (Jaffe et al., 1971) in clamped condition. The lines are guides to the eye. 


\subsubsection{Young's modulus}

The Young's modulus strongly depends on the film composition, as is shown in Figure 4.8. The dependence of Young's modulus on the PZT composition shows an increase in value for the $\mathrm{Zr}$-rich compositions, which is in agreement with the published data for bulk PZT ceramics (Jaffe et al., 1971), also shown in Figure 4.8. The value of the Young's modulus for the composition with the maximum $d_{33, \mathrm{f}}(x=0.52)$ was found to be $113.5 \mathrm{GPa}$ with a standard error of $\pm 1.5 \mathrm{GPa}$ at $x=0.52$. This value is $57 \%$ higher than for bulk PZT ceramic. It is also much higher than values reported in literature for sol-gel films (25 GPa (Piekarski et al., 2001)), but has the same order as values reported for sputter deposited PZT (109 GPa (Fang et al., 2003)). The dip in the Young's modulus lies at a lower Zr content than found for bulk PZT ceramics $(x=0.52$, see Figure 4.8). A similar discrepancy between piezoelectric coefficients $d_{33, \mathrm{f}}$ and $e_{31, \mathrm{f}}$ was also observed for sol-gel PZT thin films (Dubois et al., 1998; Ledermann et al., 1999).

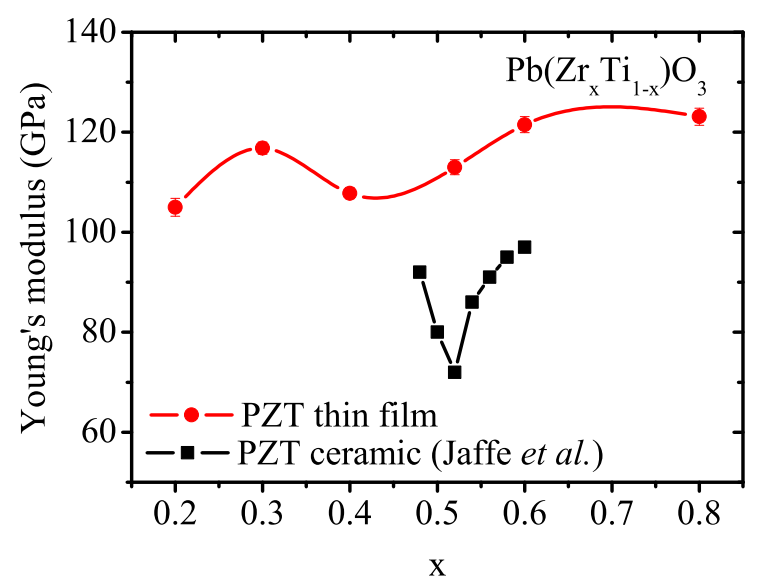

FIgURE 4.8 - Composition dependence of Young's modulus of the PZT thin films plotted as a function of $Z r$ content $(x)$ in $\mathrm{Pb}\left(Z r_{x} \mathrm{Ti}_{1-x}\right) \mathrm{O}_{3}$ thin films. The trend is compared with the the data published by Jaffe et al. (Jaffe et al., 1971) for bulk PZT ceramics. The lines are guides to the eye.

\subsubsection{Dielectric constant}

The compositional dependence of the dielectric constant shows a peak at $x=0.52$, see Figure 4.9. Such dependence was also reported previously (Du et al., 1998). A distinct peak was observed for the dielectric constant of the bulk PZT ceramics at $x=0.50$ (Jaffe et al., 1971) (Figure 4.9). Compared to bulk PZT ceramics, the PLD- 
PZT film shows a much broader peak with lower values of dielectric constant for Ti-rich compositions and higher values for $\mathrm{Zr}$-rich compositions. The electromechanical coupling factor $k$, which is an extremely useful figure of merit, is defined as $k_{33}=d_{33} \sqrt{E_{33} / \varepsilon}$ where $\varepsilon=\varepsilon_{o} \varepsilon_{r}$ (Jaffe et al., 1971). We measured the in-plane Young's modulus, not the $E_{33}$; for this reason we compared the term $k_{33}, \mathrm{f} / \sqrt{E_{33}}$ of the PLD-PZT with the one obtained from the bulk ceramics data $k_{33, \mathrm{c}}^{\mathrm{ceramic}} / \sqrt{E_{33}}$, as seen in Figure 4.10. We obtained the electromechanical coupling factor $k_{33, \mathrm{f}} / \sqrt{E_{33}}$ from the measured $d_{33, \mathrm{f}}$ and $\varepsilon$, whereas the $k_{33, \mathrm{c}}^{\mathrm{ceramic}} / \sqrt{E_{33}}$ was calculated using the $d_{33, \mathrm{c}}^{\text {ceramic }}$ and $\varepsilon$ of bulk PZT ceramics (Jaffe et al., 1971). The in-plane Young's modulus of the PLD-Pb( $\left(\mathrm{Zr}_{0.52} \mathrm{Ti}_{0.48}\right) \mathrm{O}_{3}$ thin film is $57 \%$ higher than the bulk ceramic counterpart; if the same is true for the $E_{33}$, then we can expect much higher coupling coefficients as compared to the bulk PZT ceramic material, which makes our PLD-PZT thin films much more efficient.

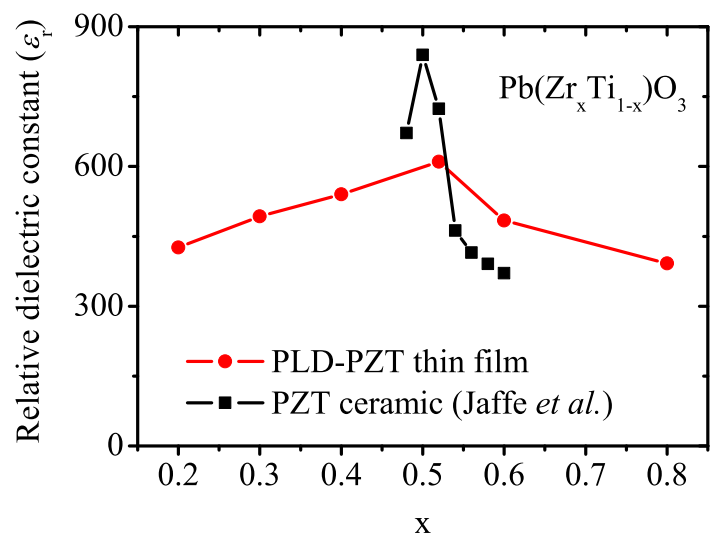

FIGURE 4.9-Compositional dependence of the relative dielectric constant $\varepsilon / \varepsilon_{o}$ of the PLD-PZT thin films compared with the bulk PZT ceramics data obtained from Jaffe et al. (Jaffe et al., 1971). The peak in thin films as well as bulk PZT ceramics was observed near the composition of $x=0.52$. The lines are guides to the eye.

\subsection{Conclusion}

We report on the compositional dependence of the effective longitudinal piezoelectric coefficient, the Young's modulus, dielectric constant and coupling coefficient of $\mathrm{Pb}\left(\mathrm{Zr}_{x} \mathrm{Ti}_{1-x}\right) \mathrm{O}_{3}$ thin films, grown on micromachined silicon cantilevers by pulsed laser deposition. This epitaxial deposition process yields a (110) preferred orientation for the range of compositions investigated $(x=0.2-0.8)$. 


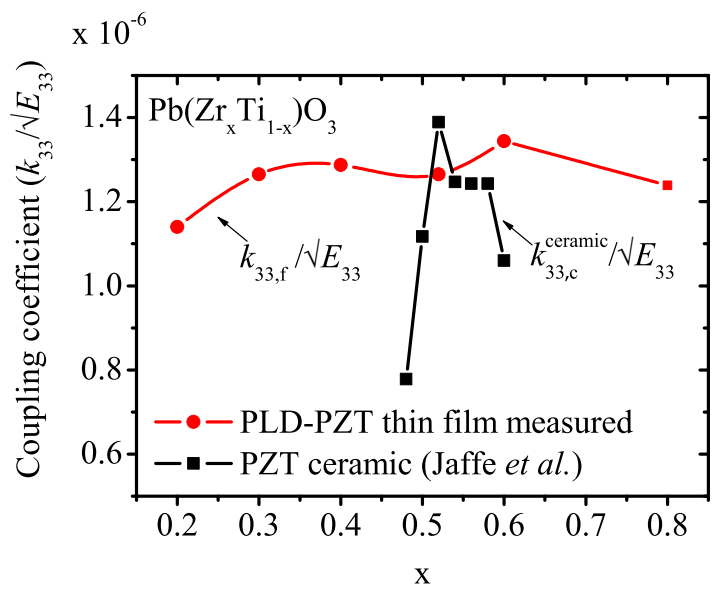

FIGURE 4.10 - Compositional dependence of the ratio of coupling coefficient $k$ to the square root of the Young's modulus E obtained from the measured $d_{33}$ and calculated dielectric constant $\varepsilon$. We observed higher values of the $k_{33} / \sqrt{E_{33}}$ for most of the PLD-PZT thin films as compared to the bulk PZT material in clamped condition. The lines are guides to the eye.

The $d_{33, \mathrm{f}}$ shows a maximum value of $93 \mathrm{pm} / \mathrm{V}$ at a $\mathrm{Zr}$ content of $x=0.52$ for a film thickness of $250 \mathrm{~nm}$. At the same composition and a film thickness of $1 \mu \mathrm{m}$ the piezoelectric coefficient is $123 \mathrm{pm} / \mathrm{V}$. The dependence of the piezoelectric coefficient of PLD-PZT on composition is much weaker than in bulk PZT ceramics material, which has a sharp peak at $x=0.52$. When correcting for the clamping effect, the $d_{33, \mathrm{f}}$ in bulk ceramics exceeds the PLD-PZT thin film value by $16 \%$ at this composition. At other compositions the PLD-PZT has a substantially higher value.

The Young's modulus of films at $x=0.52$ composition is $113.5 \mathrm{GPa}$ with a standard error of $\pm 1.5 \mathrm{GPa}$. When further increasing the $\mathrm{Zr}$ content, the Young's modulus increases, which is in agreement with data published for bulk PZT ceramics (Jaffe et al., 1971). For lower Zr content, the Young's modulus does not appear to follow the curves measured for ceramics, showing a minimum of $105 \mathrm{GPa}$ at $x=0.2$. The data suggest a second minimum for the Young's modulus in the region of $x=0.4$ to $x=0.52$.

The compositional dependence of the dielectric constant of the PLD-PZT thin films follows the same trend as predicted by bulk PZT ceramics. Instead of a distinct peak as observed in ceramics, we found a broader maximum at the $x=0.52$ composition. A comparison of the electromechanical coupling factor $k_{33}$ of the PLD-PZT thin films and bulk PZT ceramics in clamped condition reveals that our PLD-PZT thin films have a much higher coupling factor because of higher Young's 
modulus values.

Epitaxially grown PZT by pulsed laser deposition shows excellent piezoelectric and mechanical properties, which can be exploited in MEMS sensors and actuators. The results reported in this chapter facilitate the choice for the correct composition, based for instance on an optimization of figures of merit specific for the intended application, such as the coupling coefficient. 


\section{Chapter 5}

\section{Comparison of $(110)$ and (oo1) oriented PZT}

\subsection{Introduction}

$\mathrm{Pb}\left(\mathrm{Zr}_{x} \mathrm{Ti}_{1-x}\right) \mathrm{O}_{3}$ (PZT) thin films show excellent ferroelectricity, pyroelectricity and piezoelectricity, and therefore are widely used in MEMS actuators and sensors (Tadigadapa and Mateti, 2009; Trolier-Mckinstry and Muralt, 2004). The range of applications utlizing PZT thin films as an active device layer are, but not limited to, energy harvesting devices (Beeby et al., 2006), memory elements (Dawber et al., 2005; Setter et al., 2006), ultrasonic image sensors, surface acoustic wave filters (Choi et al., 2008), micro-pumps and print-heads (Cui et al., 2007).

Requirements on the properties of the PZT depend on the specific application. The advantage of PZT thin films is that these properties can be tuned by changing the $\mathrm{Zr}$ /Ti ratio (Zhuang et al., 1989). For instance, $\mathrm{Pb}\left(\mathrm{Zr}_{0.52} \mathrm{Ti}_{0.48}\right) \mathrm{O}_{3}(x=0.52)$ thin films are most widely used for higher piezoelectric response applications $(\mathrm{Xu}$ et al., 2000), whereas $\mathrm{Pb}\left(\mathrm{Zr}_{0.2} \mathrm{Ti}_{0.8}\right) \mathrm{O}_{3}$ thin films are used in energy harvesting devices (Isarakorn et al., 2011).

PZT thin films can be deposited by different processes like sol-gel (Reaney et al., 1998), sputter- (Fang et al., 2003) and pulsed laser deposition (PLD) (Nguyen et al., 2010). Recently, excellent ferroelectric properties were reported for epitaxial PZT thin films grown on the silicon by means of PLD (Dekkers et al., 2009). In order to integrate PLD-PZT thin films as active device layers in the devices, it is imperative that next to the ferroelectric properties, also the mechanical and piezoelectric properties are investigated. These properties depend on various factors, such as composition (Zhuang et al., 1989) and orientation (Dekkers et al., 2009; Ledermann et al., 2003).

The epitaxial growth of the PZT films by PLD results in an anisotropic in-plane Young's modulus. In this chapter this anisotropic behaviour of (001) oriented PZT thin films is investigated by depositing the PZT thin films on silicon cantilevers aligned along the $<110>$ and $<100>$ crystal direction of silicon. 
Furthermore, the compositional dependence of the Young's modulus of epitaxial PZT thin films with (oo1) preferred orientation grown by PLD is investigated. The results are compared with (110) oriented PZT thin films. In addition the dielectric constant $\varepsilon$ and effective longitudinal piezoelectric coefficient $d_{33 \text {,f }}$ of a $\mathrm{Pb}\left(\mathrm{Zr}_{0.52} \mathrm{Ti}_{0.48}\right) \mathrm{O}_{3}$ thin film was determined and the coupling coefficient $k_{33}$, $\mathrm{f}$ was calculated and compared on the basis of orientation.

The in-plane Young's modulus of the PZT thin films was determined by measuring the change in the resonance frequency before and after the deposition of the PZT thin films. To analyse the effect of silicon orientation on the resonance frequency of the cantilevers and the Young's modulus of the PZT thin films, cantilevers were fabricated along two different crystal directions of silicon. This fabrication scheme is described in section 5.3.1. Epitaxial growth of the PZT thin films by PLD requires the application of buffer layers on the silicon substrate. These layers are described in section 5.3.2. In the same section fabrication of the PZT capacitor for determining the $d_{33, \mathrm{f}}$ and dielectric constant is explained. X-ray diffraction (XRD) measurements were conducted to find the orientation of the PZT thin films, see section 5.3.3. The resonance frequency measurements and $d_{33, \mathrm{f}}$ measurements are explained in section 5.3.4 and 5.3.5 respectively. The measurements results are reported in section 5.4 and discussed in section 5.5 .

\subsection{Theory}

\subsubsection{Analytical model}

The in-plane Young's modulus of PZT thin films can be determined by using the theory explained in section 3.2.

\subsection{Experimental details}

\subsubsection{Fabrication of cantilevers}

Figure 5.1 shows the fabrication scheme for the cantilevers using a dedicated SOI/MEMS fabrication process. The process is described briefly as follows. (a) A double side polished silicon on insulator (SOI) wafer was selected. The substrate has a $380 \mu \mathrm{m}$ handle wafer and a $3 \mu \mathrm{m}$ thick device layer. The device layer defines the thickness of the cantilevers. A layer of $500 \mathrm{~nm}$ buried oxide (BOX) serves as an etch stop during the etching of the device layer and handle wafer. A photoresist mask was designed with cantilevers that have varying lengths from $250 \mu \mathrm{m}$ to $350 \mu \mathrm{m}$ in steps of $10 \mu \mathrm{m}$. The cantilevers have a fixed width of $30 \mu \mathrm{m}$. ( $b$ and $c$ ) The front side of the (001) single crystal silicon device layers was patterned by conventional UV photolithography using the prepared mask that defines the shape of the cantilevers. The used photoresist was Oling07-17 with a thickness of $1.7 \mu \mathrm{m}$. $(d)$ Subsequently the cantilevers were anisotropically etched by deep reactive ion etching (DRIE) using $\mathrm{SF}_{6}, \mathrm{O}_{2}$ and $\mathrm{C}_{4} \mathrm{~F}_{8}$ gases (Jansen et al., 2009). The cantilevers were released from the handle wafer by making through holes from the back side of the wafers 
using the following process steps. ( $e$ and $f$ ) A layer of $3.5 \mu \mathrm{m}$ thick photoresist (908-35) was applied on the back side of the wafer and patterned to define the holes. ( $g$ ) DuPont MX-5020 foil was applied on the front side of the wafers to protect the cantilevers from damage and prevent leakage of the helium during the wafer through etching. Application of this foil was required to ensure stable temperature control of the wafer during the back side DRIE process (Brookhuis et al., 2011). (h) Etching of the handle wafer from the back side was then performed by DRIE using $\mathrm{SF}_{6}, \mathrm{O}_{2}$ and $\mathrm{C}_{4} \mathrm{~F}_{8}$ gases (Jansen et al., 2009). This fabrication process is an improved version of what we reported in section 2.3. The main improvement is that we used a different recipe for the back side etch, which enables us to use foil on the front side instead of polyimide pyralin. After etching, the foil on the front side and photoresist material from the back side of the wafer were removed using $\mathrm{O}_{2}$ plasma (TeplazooE). Subsequently, the cantilevers were released by etching the BOX layer using buffered-hydrofluoric acid. See Appendix B for a detailed description of the fabrication process.

In order to analyse the effect of the in-plane crystal directions of silicon on the PZT thin films, the fabricated cantilevers were aligned parallel to the primary flat of wafers, which corresponds to the $<110>$ crystal direction of the silicon. For the $<100>$ crystal direction of the silicon crystal lattice, the cantilevers were rotated $45^{\circ}$ with respect to the primary flat of the wafers. Scanning electron micrographs (SEM) as shown in Figure 5.2 were used to inspect and characterise the fabricated cantilevers.

\subsubsection{PZT deposition}

To determine the Young's modulus, PZT thin films of different compositions were deposited by PLD on separate wafers containing fabricated cantilevers (see Figure 5.3(a)). The process started with the deposition of a $15 \mathrm{~nm}$ thick buffer layer of yttria-stabilized zirconia (YSZ), followed by an $8 \mathrm{~nm}$ thick cerium oxide $\left(\mathrm{CeO}_{2}\right)$ layer. Without breaking the vacuum in the PLD chamber, the process was continued with the deposition of a $12 \mathrm{~nm}$ thick strontium ruthenate (SRO) film. These buffer layers serve as a crystallization template and ensure epitaxial growth of the PZT thin films with a (oo1) preferred orientation. The deposition process was continued with PZT until the desired thickness of $100 \mathrm{~nm}$ was achieved (Dekkers et al., 2009).

A similar PLD process was used to fabricate a $\mathrm{Pb}\left(\mathrm{Zr}_{0.52} \mathrm{Ti}_{0.48}\right) \mathrm{O}_{3}$ thin film capacitor on a (oo1) silicon wafer. This capacitor is used to measure the $d_{33, \mathrm{f}}$ and dielectric constant. For the capacitor, the thickness of the deposited $\mathrm{YSZ}$ and $\mathrm{CeO}_{2}$ buffer layers were adjusted to $50 \mathrm{~nm}$ and $100 \mathrm{~nm}$ respectively. The SRO bottom electrode in the capacitor has a thickness of $100 \mathrm{~nm}$. After depositing the $250 \mathrm{~nm}$ thick $\mathrm{Pb}\left(\mathrm{Zr}_{0.52} \mathrm{Ti}_{0.48}\right) \mathrm{O}_{3}$ thin film, a $100 \mathrm{~nm}$ thick top electrode of SRO was deposited for electrical contacts, which is not present in the cantilever stack. The capacitors were defined by patterning $200 \times 200 \mu \mathrm{m}^{2}$ squares using standard photolithography and etching of the SRO film by argon-ion beam milling. Subsequently the PZT 
(a)

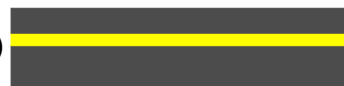

(b)

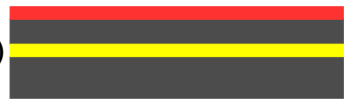

(c)

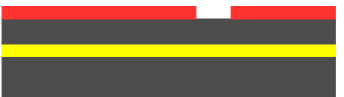

(d)

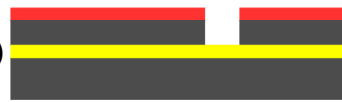

(e)

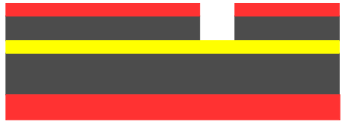

Silicon $\mathrm{SiO}_{2}$ (f)

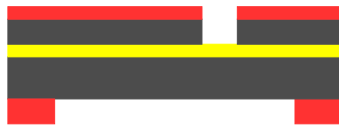

(g)

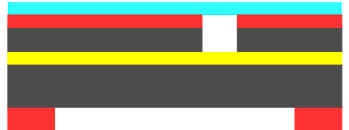

(h)

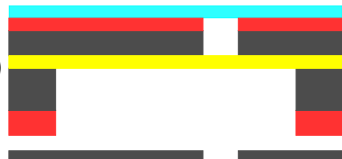

(i)

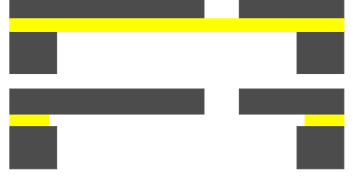

Photoresist

DuPont foil

FIGURE 5.1 - Fabrication flow of the silicon cantilevers. (a) A SOI wafer with a $3 \mu \mathrm{m}$ thick device layer and a $500 \mathrm{~nm}$ thick BOX was selected. (b and c) Application and patterning of the photoresist (Olin 907-17) on the front side of the wafer. (d) Silicon device layer was etched by DRIE. (e and f) Thick photoresist (Olin 908-35) was applied and patterned on the back side of the wafer. $(g)$ Application of the foil (DuPont MX5020) on the front side for stable temperature control and avoid helium leakage. (h) Through holes from the back side were etched by DRIE. (i) Photoresist and foil was removed from the front and back side using oxygen plasma. ( $j$ ) Cantilevers were released by etching the BOX layer using BHF.

thin film was etched by a wet process in a diluted $\mathrm{HF}: \mathrm{HNO}_{3}: \mathrm{H}_{2} \mathrm{O}$ solution (see Figure 5.3(b)).

\subsubsection{XRD measurements}

X-ray diffraction measurements were performed on a Bruker D8 Discover X-ray diffractometer with a $\mathrm{Cu} \mathrm{K} \alpha$ cathode in the Bragg-Brentano geometry to investigate the orientation of the PZT thin films. X-ray radiation of $0.15 \mathrm{~nm}$ wavelength was used at $40 \mathrm{kV}$ and $40 \mathrm{~mA}$. We measured $\theta-2 \theta$ scans in the range of $20-50^{\circ}$ at $0.01^{\circ} / \mathrm{sec}$. The JCPDS database was used to identify the peaks in the diffraction patterns of the PZT thin films.

\subsubsection{Resonance frequency measurements}

Resonance frequency measurements of the cantilevers were performed both before and after deposition of the PZT thin films $(x=0.2-0.8)$ using a microscope scanning 


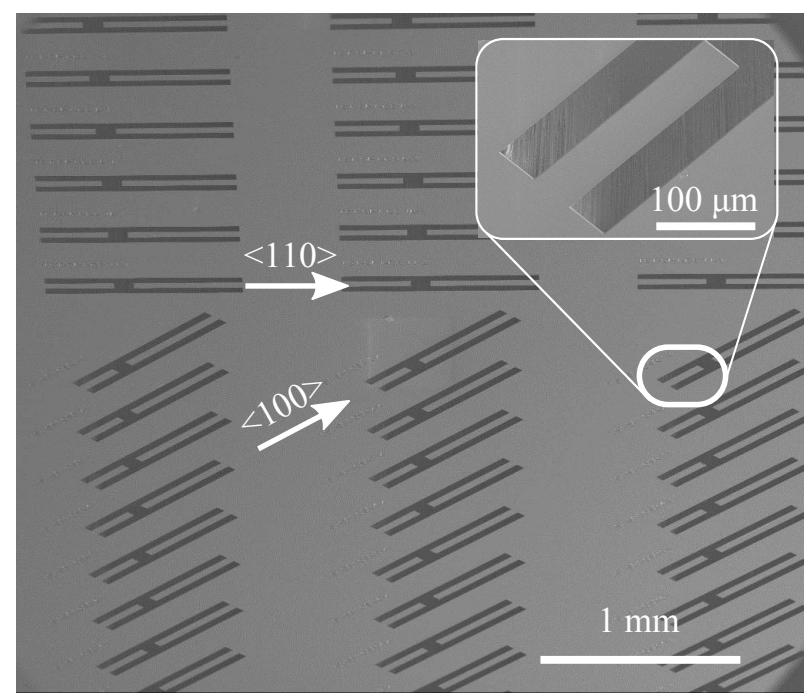

FIGURE 5.2 - Scanning electron micrograph of the fabricated cantilevers, aligned along the $\langle 110\rangle$ and $\langle 100\rangle$ crystal directions of silicon. The through hole from the back side of the wafer can be clearly identified in the inset of the image.

(a)

(b)

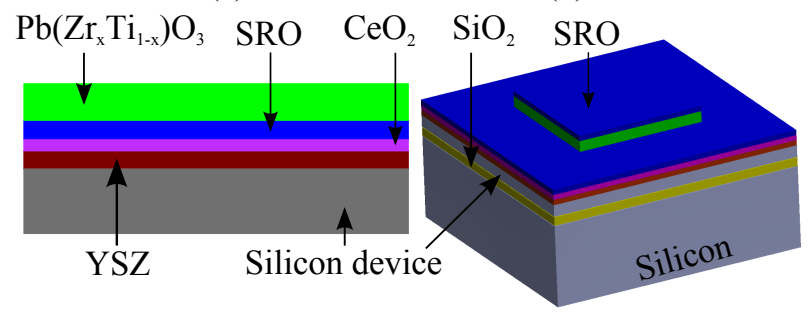

FIGURE 5.3 - Fabrication process of the epitaxial $\mathrm{Pb}\left(\mathrm{Zr}_{0.52} \mathrm{Ti}_{0.48}\right) \mathrm{O}_{3}$ thin films using a PLD process. Buffer layers of $Y S Z, \mathrm{CeO}_{2}$ and $\mathrm{SRO}$ were deposited on the SOI wafer before the deposition of the PZT to obtain a (oo1) preferred orientation of the PZT thin films. (a) Top electrode was not deposited on the cantilever stack. (b) SRO top electrode and PZT were etched to form $200 \times 200 \mu \mathrm{m}^{2}$ capacitor. (Dimensions not according to scale.) 
laser Doppler vibrometer (MSA-400, micro system analyzer from Polytec). The thermal excitation of the cantilevers at ambient conditions was used to obtain the resonance amplitude spectrum. Subsequently, the resonance frequency was obtained by curve fitting with a theoretical expression for a second order mass-spring system with damping.

\subsubsection{Measurements of piezoelectric coefficient}

The $d_{33, \mathrm{f}}$ of the $\mathrm{Pb}\left(\mathrm{Zr}_{0.52} \mathrm{Ti}_{0.48}\right) \mathrm{O}_{3}$ thin film was determined from the piezoelectric displacement of the capacitor structures (Lefki and Dormans, 1994). The displacement of the capacitors was measured by using a MSA-40o micro system analyzer scanning laser-Doppler vibrometer. An $8 \mathrm{kHz}$ ac-voltage of magnitude $6 \mathrm{~V}_{\mathrm{p}-\mathrm{p}}$ (peak to peak) was applied to the top and bottom SRO electrodes. Subsequently, the resulting displacement of the top electrode was measured.

\subsection{Measurement Results}

\subsubsection{Crystal structure}

The crystal structure of a PZT thin film is one of the factors that influences the piezoelectric and mechanical properties, such as the dielectric constant (Gong et al., 2004), piezoelectric coefficient (Du et al., 1998; Park et al., 2009), Young's modulus (Wang et al., 2005) and residual stress (Corkovic et al., 2008; Lian and Sottos, 2004). XRD patterns reveal that the growth of the PZT thin films follows a (001) preferred orientation. As an example, the XRD pattern of a $\mathrm{Pb}\left(\mathrm{Zr}_{0.52} \mathrm{Ti}_{0.48}\right) \mathrm{O}_{3}$ thin film deposited on a $\mathrm{SRO} / \mathrm{CeO}_{2} / \mathrm{YSZ} /$ silicon substrate is shown in Figure 5.4. The (0o1) preferred orientation can be clearly identified (label PZT(Oo1) in the graph).

\subsubsection{Young's modulus}

Equation (3.1) is used to determine the in-plane Young's modulus from the difference in measured resonance frequencies of the cantilevers before and after deposition of the PZT thin films. As an example, the shift in the resonance frequency of two identical cantilevers aligned along the $\langle 110\rangle$ and $\langle 100\rangle$ silicon directions is shown in Figure 5.5. The length, width and thickness of the cantilevers were $290 \mu \mathrm{m}, 30 \mu \mathrm{m}$ and $3 \mu \mathrm{m}$ respectively.

This specific situation is instructive since the resonance frequency of the $<110>$ aligned silicon cantilever decreased after the deposition of the PZT thin film, whereas it increased for the $<100\rangle$ aligned cantilevers. This difference in behaviour is caused by the fact that the Young's moduli of silicon and of PZT are different along these two crystal orientations. For the <110 $>$ alignment the Young's modulus of silicon $(168.9 \mathrm{GPa})$ is higher, whereas for the $<100>$ it is lower $(130.2 \mathrm{GPa})$ compared to the Young's modulus of the PZT. 


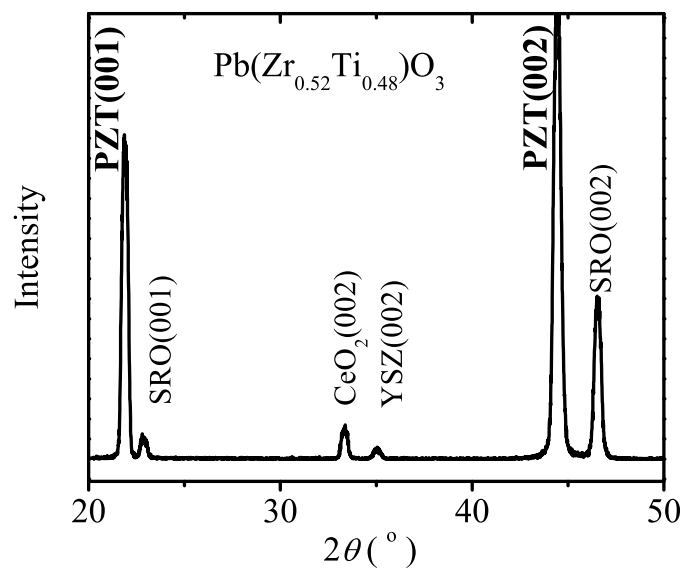

FIGURE 5.4 - Measured XRD pattern of the $\mathrm{Pb}\left(\mathrm{Zr}_{0.52} \mathrm{Ti}_{0.48}\right) \mathrm{O}_{3}$ thin film grown on a silicon substrate with buffer layers using pulsed laser deposition. The peaks confirm the growth of a PZT thin film with a (oo1) preferred orientation.

Figure 5.6 shows that the in-plane Young's modulus of epitaxial PZT thin films is anisotropic and strongly dependent on composition. The Young's modulus measured along the $\langle 100\rangle$ crystal direction of silicon was found to be higher than along the $<110>$ direction, for all compositions measured. A maximum anisotropy in the Young's modulus of $46 \%$ was found at a composition of $x=0.2$. At this composition, the values are 201.9 (2.2) GPa and 139.7 (0.5) GPa. (The value in brackets indicate the standard error from 11 cantilevers of varying length).

\subsection{Discussion}

\subsubsection{Young's modulus compared to bulk PZT ceramic}

The minimum in the Young's modulus was found to be 120.1 (1.2) GPa at a composition of $x=0.52$ for (001) oriented PZT deposited on <110 > oriented cantilevers. The presence of a minimum at this compositions agrees well with results reported in literature for bulk PZT ceramics (Jaffe et al., 1971), but the value is $67 \%$ higher (Figure 5.7, labelled PZT ceramic). It is also much higher compared to values reported in literature for sol-gel films (25 GPa (Piekarski et al., 2001)), but has the same order of magnitude as values reported for sputter deposited PZT (109 GPa (Fang et al., 2003)). A broader minimum in the Young's modulus for compositions ranging from $x=0.3$ to 0.52 was observed for cantilevers aligned along the $<100\rangle$ silicon direction (Figure 5.7, labelled PLD-PZT (oo1) along $\mathrm{Si}<100>$ ). 


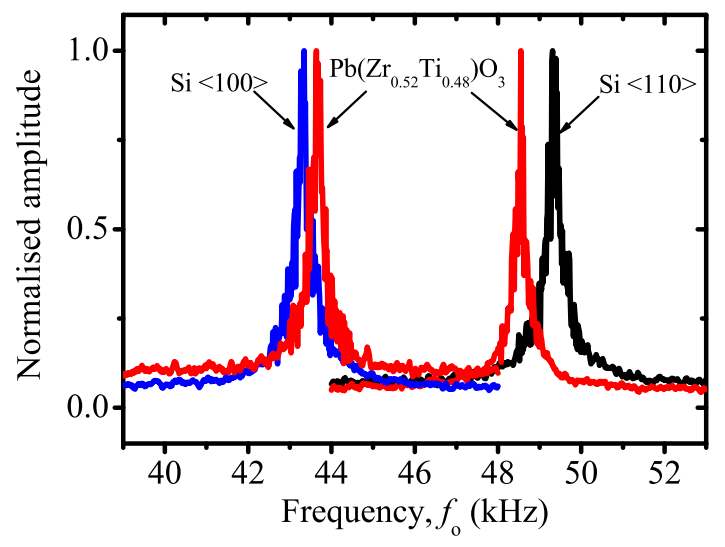

FIGURE 5.5 - Resonance spectra of two silicon cantilevers aligned along the $<110>$ and $\langle 100\rangle$ silicon directions, with and without $\mathrm{Pb}\left(\mathrm{Zr}_{0.52} \mathrm{Ti}_{0.48}\right) \mathrm{O}_{3}$ thin films. The resonance frequency of the $<110>$ silicon cantilever decreases after the deposition of the PZT, whereas it increases for the $<100>$ aligned cantilever. The difference is caused by a difference in Young's modulus of both the silicon and PZT along both directions.

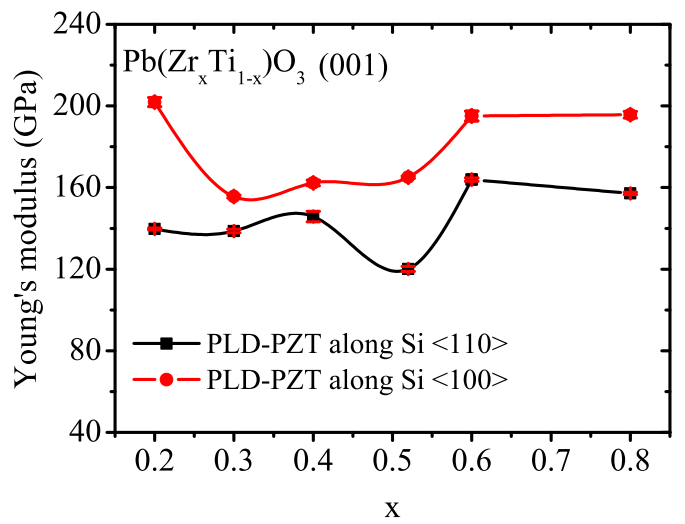

FIGURE 5.6 - Compositional dependence of the Young's modulus of PZT thin films with a (oo1) preferred orientation. The Young's modulus is consistently higher for PZT thin films deposited on $a<100>$ aligned silicon cantilever than those on $a<110\rangle$ aligned cantilever. The lines are guides to the eye. 


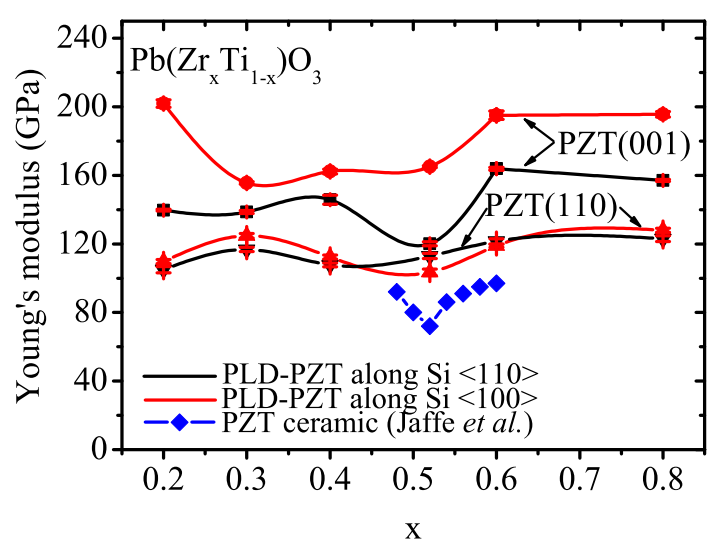

Figure 5.7 - Compositional dependence of the Young's modulus of PZT thin films with (001) and (110) preferred orientations. The anisotropy in the in-plane Young's modulus is higher for the (oo1) oriented PZT compared to the (110) orientation. The determined Young's modulus of PLD-PZT is compared with the bulk PZT ceramic data obtained from the literature (Jaffe et al., 1971). The dip in the Young's modulus at $x=0.52$ is most prominent in the (oo1) oriented PZT when measured along the $<110>$ silicon direction. The lines are guides to the eye.

\subsubsection{Young's modulus compared to (110) PZT}

The compositional dependence of the in-plane Young's modulus of the PZT thin films with (110) and (001) orientations show quite a distinct behaviour (see Figure 5.7). The Young's modulus of the (oo1) oriented PZT thin films was found to be higher than the films with (110) orientation for all the composition from $x=0.2$ to o.8. The higher Young's modulus of the (oo1) orientation is in agreement with the results published in literature (Delobelle et al., 2006; Liu et al., 2009; Wang et al., 2005). This might be due to the fact that grain boundaries in (001) oriented PZT are less pronounced than in (110) oriented films (Dekkers et al., 2009).

Apart from the different absolute values of the Young's modulus, the amount of anisotropy in the two orientations is also quite different. The maximum difference between the Young's modulus of the (110) oriented PZT in two different crystal directions of silicon $(<110>$ and $<100\rangle)$ is $8.5 \%$ for a composition of $x=0.52$. At the same composition, the anisotropy is $37 \%$ for the (oo1) oriented PZT. The maximum anistropy in the (001) PZT is $45 \%$ at $x=0.2$. We believed that the higher anisotropy in the Young's modulus of the (oo1) oriented PZT is caused by the absence of twin domains which we observed in (110) oriented PZT (Dekkers et al., 2009). 


\subsubsection{Piezoelectric properties}

The $d_{33, \mathrm{f}}$ of the $\mathrm{Pb}\left(\mathrm{Zr}_{0.52} \mathrm{Ti}_{0.48}\right) \mathrm{O}_{3}$ thin film with a (oo1) orientation was found to be $86 \mathrm{pm} / \mathrm{V}$, which is $61 \%$ lower compared to bulk PZT ceramic (Jaffe et al., 1971). Clamping of the thin film with the substrate and domain switching are the two main reasons for this reduction (Nazeer et al.). The reduction due to clamping can be calculated from (Xu et al., 1999)

$$
d_{33, \mathrm{f}}=d_{33}+1.19 d_{31}
$$

Please note that $\mathrm{d}_{31}$ is negative. From this equation, the $d_{33, \mathrm{c}}^{\text {ceramic }}$ of the PZT ceramic in clamped condition can be calculated to be $111 \mathrm{pm} / \mathrm{V}$ (Nazeer et al.), which is now only $22 \%$ higher than for PLD-PZT. Secondly, the orientation of the crystal axis is random in ceramics, therefore rotation of the ferroelectric domains is much easier as compared to single crystal PZT. It might therefore be possible that domain switching is much more difficult in our epitaxially grown PZT thin films. This could account for the remaining $22 \%$ difference. It should be noted, however, that domain switching is heavily dependent on composition and difficult to estimate.

The effective longitudinal piezoelectric coefficient of PZT thin films depends on their orientation (Du et al., 1998; Park et al., 2009). For our films, the $d_{33, \text { f }}$ of $\mathrm{Pb}\left(\mathrm{Zr}_{0.52} \mathrm{Ti}_{0.48}\right) \mathrm{O}_{3}$ for the (110) orientation was found to be $8 \%$ higher than for (oo1) oriented films. This does not necessarily mean that the (110) orientation is better suited for applications. For this, the coupling coefficient of the material is also important (Jaffe et al., 1971), which is a combination of piezoelectric coefficient, Young's modulus and dielectric constant:

$$
k_{33}=d_{33} \sqrt{\frac{E_{33}}{\varepsilon_{o} \varepsilon_{r}}} .
$$

The relative dielectric constant $\varepsilon_{r}$ was obtained from polarization hysteresis (P-E) loop measurements using an aixACCT TF-20oo ferroelectric measurement system at $\pm 200 \mathrm{kV} / \mathrm{cm}$ amplitude and $1 \mathrm{kHZ}$ frequency (see Figure 5.8). We used the same capacitor structures as used for the $d_{33}$, f measurements. The relative dielectric constant is 665 for (oo1) and 610 for (110) oriented $\mathrm{Pb}\left(\mathrm{Zr}_{0.52} \mathrm{Ti}_{0.48}\right) \mathrm{O}_{3}$. The higher dielectric constant and the lower $d_{33, \mathrm{f}}$ of the (oo1) orientation results in a lower ratio of coupling coefficient to the Young's modulus $\left(k_{33, \mathrm{f}} / \sqrt{E_{33}}\right)$, compared to the (110) orientation. Since we measured the in-plane Young's modulus, instead of $E_{33}$, therefore we compared the ratio of coupling coefficient to the Young's modulus. The in-plane Young's modulus is higher for the (oo1) orientation, and if the $E_{33}$ is also higher with the same ratio, even than the coupling coefficient is found to be lower for the (oo1) composition. Indeed, for applications the (110) oriented PLD-PZT has a preference over the (0o1) orientation. 


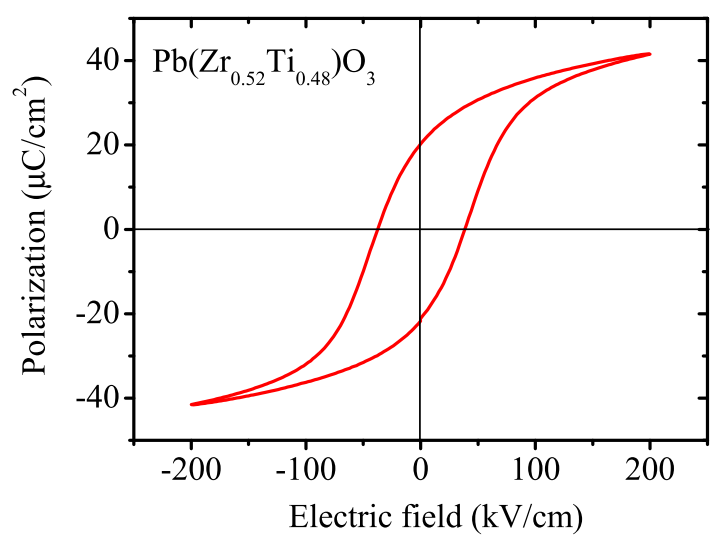

Figure 5.8 - Polarization as a function of applied electric field ( $P$-E loop) of a (oo1) oriented $\mathrm{Pb}\left(\mathrm{Zr}_{0.52} \mathrm{Ti}_{0.48}\right) \mathrm{O}_{3}$ thin film. The $\mathrm{P}-\mathrm{E}$ loop was measured at $\pm 200 \mathrm{kV} / \mathrm{cm}$ amplitude and $1 \mathrm{kHz}$ frequency.

\subsection{Conclusion}

By means of pulsed laser deposition, we have grown $\mathrm{Pb}\left(\mathrm{Zr}_{x} \mathrm{Ti}_{1-x}\right) \mathrm{O}_{3}$ thin films with compositions ranging from $x=0.2$ to $x=0.8$ and (oo1) or (110) preferred orientations on silicon cantilevers oriented along the $\langle 110\rangle$ and $\langle 100\rangle$ direction.

The in-plane Young's modulus of PZT thin films with (001) preferred orientation was found to be strongly dependent on the composition. The Young's modulus is anisotropic (up to $46 \%$ ) and higher along the $<100>$ than along the $<110>$ silicon direction for all compositions.

The Young's modulus was observed to be minimal for a composition of $x=0.52$ and along the silicon $<110>$ direction. This agrees well with the dip reported for bulk PZT ceramic at the same composition. However, no distinct minimum was observed along the $<100\rangle$ silicon direction, which shows only a shallow valley from $x=0.3$ to 0.52 .

Both the Young's modulus and anisotropy of films with (110) orientation is lower than those with (oo1) orientation, for all compositions and both directions of the silicon cantilever.

The coupling coefficient $\left(k_{33, \mathrm{f}} / \sqrt{E_{33}}\right)$ for the (110) oriented $\mathrm{Pb}\left(\mathrm{Zr}_{0.52} \mathrm{Ti}_{0.48}\right) \mathrm{O}_{3}$ thin film was found to be $11.5 \%$ higher than the (oo1) orientation. As the $d_{33, \mathrm{f}}$ at $x=0.52$ is highest in all compositions therefore (110) oriented $\mathrm{Pb}\left(\mathrm{Zr}_{0.52} \mathrm{Ti}_{0.48}\right) \mathrm{O}_{3}$ thin film has the best coupling coefficient.

The fact that (110) orientated PZT is less anisotropic and has a higher coupling coefficient, suggest that it is better suited for applications. 



\section{Chapter 6}

\section{Measurement of residual stress}

\subsection{Introduction}

Lead zirconate titanate $\mathrm{Pb}\left(\mathrm{Zr}_{x} \mathrm{Ti}_{1-x}\right) \mathrm{O}_{3}$ (PZT) is an eminent material that has been identified for MEMS devices because of its excellent ferroelectric and piezoelectric properties (Dekkers et al., 2009; Muralt, 2000). Recent advancements can be observed by the usage of PZT thin films in MEMS which ranges from micro pumps (Laser and Santiago, 2004) to probe based data storage (Nam et al., 2007), from micro-machined ultrasonic transducers (Choi et al., 2008) to ferroelectric random access memory (Kim and Lee, 2006) and from accelerometers (Kobayashi et al., 2010) to energy harvesting devices (Shen et al., 2008). The properties of $\mathrm{PZT}$ thin films can be tuned by changing the $\mathrm{Zr} / \mathrm{Ti}$ ratio to make it suitable for a particular application (Zhuang et al., 1989). For instance, Ti-rich PZT $(x=0.2)$ is used in energy harvesting devices (Isarakorn et al., 2011), whereas the composition $\mathrm{Pb}\left(\mathrm{Zr}_{0.52} \mathrm{Ti}_{0.48}\right) \mathrm{O}_{3}$ is suitable for wide variety of applications requiring high piezoelectric response (Xu et al., 200o). This control of properties by varying the $\mathrm{Zr} / \mathrm{Ti}$ ratio is accompanied by a variation in the mechanical properties of the PZT thin films, of which the residual stress is investigated in this chapter.

Sol-gel (Ledermann et al., 2004), sputter- (Fang et al., 2003) and pulsed laser deposition (PLD) (Dekkers et al., 2009) are used in the fabrication of PZT thin films. These processes result in the built up of the residual stress, depending on the process parameters and deposition process itself. Residual stress also depends on the properties of the substrate used because of the very different mechanical and thermal properties of the substrate as compared to the PZT thin films. These two effects when combined result in residual stress, with values reported in literature from one to several hundred MPa (Yao et al., 2003).

The functionality and reliability of the PZT thin film devices depends, among other factors, on the residual stress in the PZT thin films. For instance strain induced modification of dielectric properties of thin films was discussed by Horwitz et al. (2000). Similarly, piezoelectric and electromechanical properties vary with the residual stress (Berfield et al., 2007; Lian and Sottos, 2004). Controlling the crystal 
orientation by utilizing stresses is discussed in (Kim et al., 2005; Ogawa et al., 1991), whereas Desu et al. (1999) discussed the effect of residual stress on the electrical properties like resistivity. In order to fabricate reliable MEMS devices utilizing PZT thin films as an active device layer, it is therefore necessary to investigate the compositional dependence of residual stress.

Single crystal silicon is an elastically anisotropic material. We also found an anisotropy in the Young'modulus of $\mathrm{Pb}\left(\mathrm{Zr}_{0.52} \mathrm{Ti}_{0.48}\right) \mathrm{O}_{3}$ thin film deposited on silicon cantilevers aligned in the $<110>$ and $<100>$ crystal directions of silicon (Nazeer et al., 2011a). Therefore, we investigate the compositional dependence of residual stress in PZT thin films deposited on the $<110>$ and $<100>$ silicon cantilevers, taking into account the anisotropic Young's modulus of PZT thin films and silicon.

The residual stress of pulsed laser deposited PZT was determined by measuring the changes in static deflection of cantilevers on which the films were deposited. This residual stress was compared to stress calculated from the $\mathrm{x}$-ray diffraction (XRD) measurements and Young's modulus, as well stress originating from a mismatch in thermal expansion coefficients between PZT and the silicon substrate. The theoretical background of these methods are explained in section 6.2. In sections 6.3.1 and 6.3.2, the fabrication of micron sized measurement devices and deposition of the PZT thin films are explained. Residual stress in the PZT thin films depends on the orientation, therefore XRD measurements to analyse the crystal orientation of different compositions of PZT thin films are treated in section 6.3.3. Resonance frequency and static deflection measurements were performed to determine the in-plane Young's modulus and residual stress in PZT thin films, see section 6.3.4 and 6.3.5. Measurement results are reported in section 6.4. Finally, a comparison between the different methods to determine residual stress is discussed in section 6.5 .

\subsection{Theory}

\subsubsection{Stress determined from cantilever bending}

PZT thin films of various compositions were deposited by PLD on separate wafers after the release of the cantilever from the substrate. Tension or compression in the PZT thin film leads to a curvature of the cantilever on which it is deposited (see Figure 6.1). Static deflection of the free end of the cantilever was measured both before and after deposition. The residual stress in the thin film was determined by using Stoney's Equation (6.1), which is valid when the thickness of film is very small in comparison to the thickness of substrate (Jeon and Thundat, 2004; Stoney, 1909):

$$
\sigma_{\mathrm{f}}=\frac{1}{6} \frac{E_{\mathrm{s}} t_{\mathrm{s}}^{2}}{\left(1-v_{\mathrm{s}}\right) R t_{\mathrm{f}}}, \quad \text { with } R=\frac{L^{2}}{2 \xi},
$$

the symbols $\sigma, E, t, L, R$ and $\xi$ are the residual stress, Young's modulus, thickness, length, radius of curvature and deflection, respectively. Subscripts ' $s$ ' and ' $\mathrm{f}$ denote 


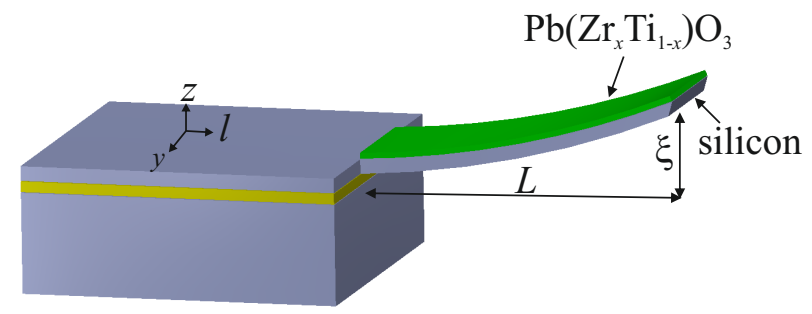

FIGURE 6.1 - Schematical representation of a cantilever fabricated from a silicon on insulator wafers. The upward static deflection is due to the tensile residual stress in the PZT thin film that was deposited on the cantilever.

the silicon and PZT thin film.

The residual stress is a combination of stress caused by the PZT film itself and to some extent due to the bottom electrode YSZ and buffer layer SRO. However, the PZT film is much thicker than the underlying layers, therefore the contribution of the underlying layers in the cantilever curvature is ignored.

\subsubsection{Stress originating from thermal expansion differences}

There are two main mechanisms for stress contribution in the PZT thin films: stress developed during growth of the film and stress caused by cooling down from the deposition temperature due to a difference in thermal expansion of the film and the substrate. By taking into account only the thermal mismatch effect, the residual stress in the PZT thin films can be calculated using the average CTE of the PZT thin films and silicon in the temperature range between room temperature and deposition temperature $\left(600^{\circ} \mathrm{C}\right)$ from Equation (6.2).

$$
\sigma_{\mathrm{f}}=\left(\alpha_{\mathrm{f}}-\alpha_{\mathrm{s}}\right) \Delta T \frac{E_{\mathrm{f}}}{1-v_{\mathrm{f}}},
$$

the symbols $\alpha, v$ and $\Delta T$ are the average CTE, poisson's ratio and difference in deposition $\left(600^{\circ} \mathrm{C}\right)$ and room temperature $\left(20^{\circ} \mathrm{C}\right)$ respectively. We used published

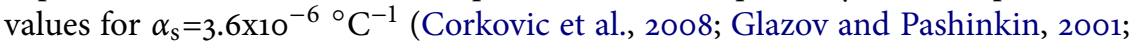
Okada and Tokumaru, 1984) and $v_{\mathrm{f}}=0.3$ (Bruchhaus et al., 1998; Shepard Jr. et al., 1998).

\subsubsection{Stress determined from lattice strain}

From the $\mathrm{x}$-ray diffraction (XRD) data one can estimate the in-plane strain in the film, taking the values of bulk PZT ceramic as a non-strained reference. In combination with the measured in-plane Young's modulus, residual stress can be calculated using 


$$
\sigma_{\mathrm{f}}=\left(a_{\mathrm{ip}, \mathrm{c}}-a_{\mathrm{ip}, \mathrm{f}}\right) \frac{E_{\mathrm{f}}}{1-v_{\mathrm{f}}}
$$

In the above equation $a_{\mathrm{ip}, \mathrm{c}}$ and $a_{\mathrm{ip}, \mathrm{f}}$ are the in-plane lattice parameters of the bulk PZT ceramics and PLD-PZT thin films respectively. The lattice parameters of the PLD-PZT thin films for different compositions ( $x=0.2-0.8)$ were calculated using the XRD patterns whereas for bulk PZT ceramics we used published data (Shirane and Suzuki, 1952) .

\subsection{Experimental details}

\subsubsection{Fabrication of cantilevers}

Fabrication of the cantilevers from double side polished single crystal silicon on insulator (SOI) wafers is discussed in detail in section 2.3

\subsubsection{PZT deposition}

The pulsed laser deposition technique allows us to epitaxially grow PZT on silicon substrates, as explained in (Nguyen et al., 2010). Deposition starts with $10 \mathrm{~nm}$ thick buffer layers of yttria-stabilized zirconia (YSZ) and strontium ruthenate (SRO), followed by the deposition of a $100 \mathrm{~nm}$ thick PZT without breaking the vacuum. Different $\mathrm{Zr} / \mathrm{Ti}$ compositions of $\mathrm{Pb}\left(\mathrm{Zr}_{x} \mathrm{Ti}_{1-x}\right) \mathrm{O}_{3}(x=0.2,0.3,0.4,0.52,0.6$ and 0.8$)$ were deposited on individual dies containing 66 cantilevers, of which 22 cantilevers in two identical sets of 11 cantilevers of varying lengths and oriented along the $<110>$ $<100>$ crystal directions of silicon were measured.

\subsubsection{XRD measurements}

A Bruker D8 Discover X-ray diffractometer with a $\mathrm{Cu} \mathrm{K} \alpha$ cathode in the BraggBrentano geometry was used to investigate the orientation of the PZT thin films. $\mathrm{X}$-ray radiation of $0.15 \mathrm{~nm}$ wavelength was used at $40 \mathrm{kV}$ and $40 \mathrm{~mA}$. We measured $\theta-2 \theta$ scans in the range of $20-80^{\circ}$ with the $0.01^{\circ} / \mathrm{sec}$ for all compositions of the PZT thin films $(x=0.2-0.8)$. The peaks in the diffraction patterns of the different compositions of PZT thin films were identified using the JCPDS database.

\subsubsection{Resonance frequency measurements}

The resonance frequency of cantilevers was measured both before and after deposition of the PZT. From the frequency shift we can determine the Young's modulus of the deposited thin film (Nazeer et al., 2011a), provided that we know the density and film thickness. Cantilevers of varying length, aligned parallel to the $<110\rangle$ and $<100>$ crystal directions of silicon, were measured by a MSA-40o micro system analyzer scanning laser-Doppler vibrometer. Measurements were taken at ambient conditions, using only thermal excitation of the resonance. From the amplitude 


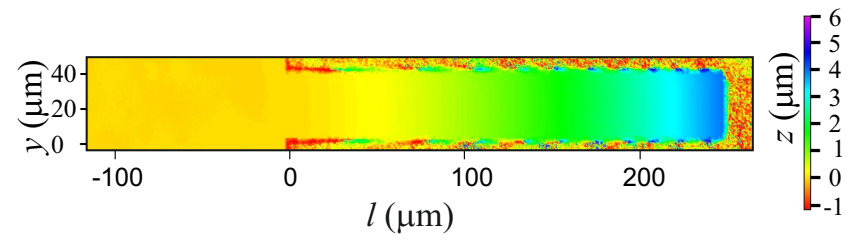

FIGURE 6.2 - White light interferometry measurement of the static deflection of a $250 \mathrm{~m}$ long cantilever after deposition of a $\mathrm{Pb}\left(\mathrm{Zr}_{0.52} \mathrm{Ti}_{0.48}\right) \mathrm{O}_{3}$ thin film.

Coordinates along the length and width of the cantilever are represented by $l$ and $y$. The variable $z$ represents the out of plane deflection of the cantilever.

spectrum, the resonance frequency was obtained by curve fitting with a theoretical expression for a second order mass-spring system with damping.

\subsubsection{Static deflection measurements}

The residual stress of the deposited PZT thin films can be determined from the static deflection of the cantilevers, which we measured by white light interferometry. In all cases, the profile of the cantilevers measured before the deposition of the PZT thin films was straight within measurement error, so only the curvature after deposition needs to be determined. A measurement of a $250 \mu \mathrm{m}$ long cantilever after deposition of PZT is shown in Figure 6.2. From this measurement we obtained the maximum deflection of the free end of the cantilever, as shown in Figure 6.3. This information was used to calculate the curvature $R$ of the cantilevers, so that we can determine the residual stress using Equation (6.1).

As an example, residual stress in a $\mathrm{Pb}\left(\mathrm{Zr}_{0.4} \mathrm{Ti}_{0.6}\right) \mathrm{O}_{3}$ film calculated from static deflection of cantilevers of varying length aligned parallel to the $<110>$ crystal direction of silicon is shown in Figure 6.4. As expected, the residual stress is independent on cantilever length. The mean value of the residual stress was found to be $263 \mathrm{MPa}$ with a standard error of $\pm 1 \mathrm{MPa}$. A thorough error analysis was performed to calculate the propagation of errors to the calculated value of the residual stress of the PZT and presented as error bars for each single cantilever.

\subsection{Measurement Results}

\subsubsection{Crystal structure}

X-ray diffraction (XRD) patterns (Figure 6.5) show that all compositions of PZT thin films $(x=0.2-0.8)$ grow with a (110) preferred orientation. There is a clear shift in the (110) peak position with increasing Zr content, which can be related to a variation in lattice parameters. The out of plane lattice parameters were measured from $\theta-2 \theta$ XRD scans. Reciprocal space mapping was used to determine the in-plane lattice parameters. With increasing $\mathrm{Zr}$ content, the out-of-plane lattice parameter 


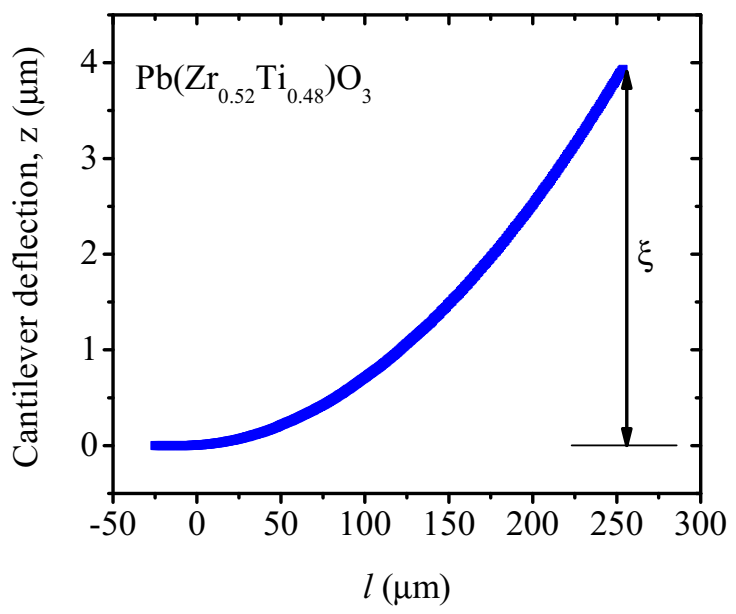

FIGURE 6.3 - Profile of the cantilever after the deposition of PZT $(x=0.52)$. The maximum upward displacement $\xi$ of the free end of the cantilever (at $l=250 \mu \mathrm{m}$ ) is almost $4 \mu \mathrm{m}$, and is used to determine the radius of curvature.

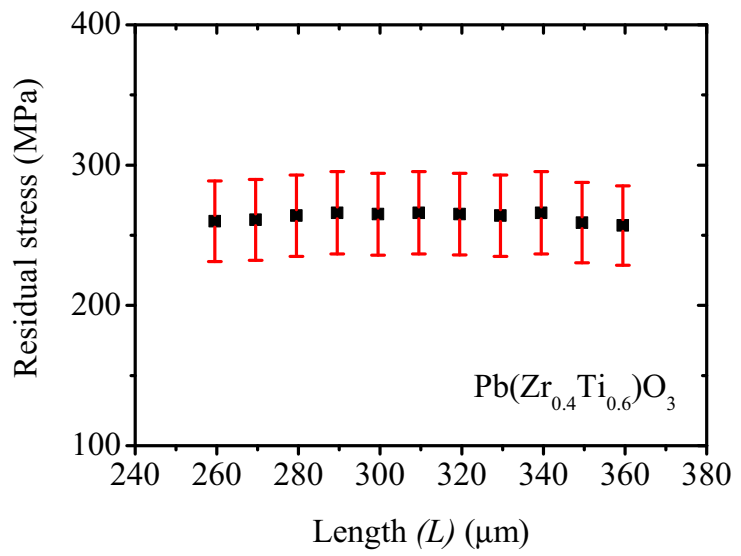

Figure 6.4 - Measured residual stress in the $\mathrm{Pb}\left(\mathrm{Zr}_{0.40} \mathrm{Ti}_{0.60}\right) \mathrm{O}_{3}$ thin film as a function of cantilever length. The mean value was determined to be $263 \mathrm{MPa}$ with a standard error of $\pm 1 \mathrm{MPa}$. 


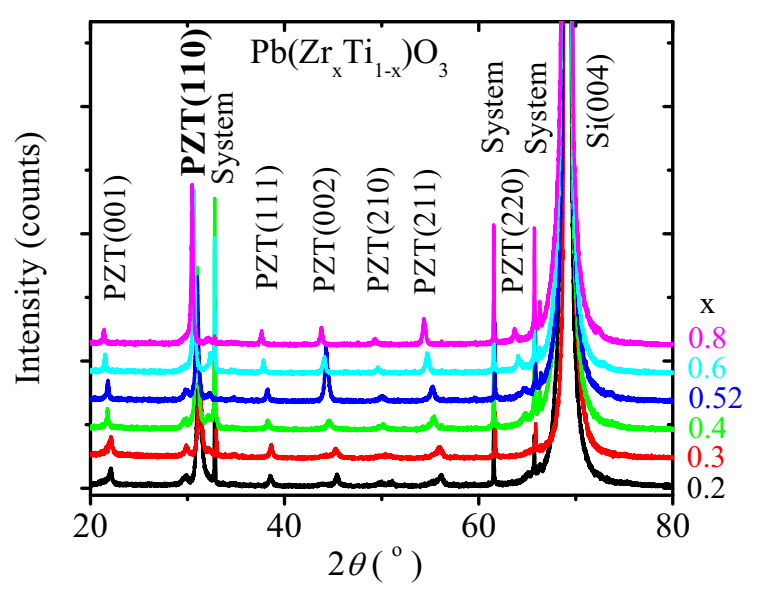

FIgURE 6.5-Measured $x$-ray diffraction patterns of pulsed laser deposited $\mathrm{Pb}\left(\mathrm{Zr}_{x} \mathrm{Ti}_{1-x}\right) \mathrm{O}_{3}$ thin films, plotted for different compositions. The PZT films display a preferred (110) orientation.

increases, whereas the in-plane lattice parameter decreases slightly (see Figure 6.6). The lattice parameters of bulk PZT ceramics (Shirane and Suzuki, 1952) are shown for comparison. The in-plane lattice parameters of PLD-PZT thin films are higher than those of PZT ceramics for $x<0.52$ and lower for $x>0.52$, whereas at $x=0.52$, in-plane lattice parameters are approximately equal.

The volume of a unit cell can be calculated from the lattice parameters and is shown as a function of composition in Figure 6.7. Compared to bulk PZT ceramics, the volume of a PLD-PZT unit cell is lower for the $\mathrm{Zr}$ rich compositions whereas it is higher for the Ti rich compositions.

\subsubsection{Young's modulus}

The in-plane Young's modulus of the PLD-PZT thin films is strongly dependent on composition (Figure 6.8). Moreover, there is a significant difference in Young's modulus for films deposited on cantilevers aligned parallel to the $\langle 100\rangle$ and $<110\rangle$ silicon directions, which clearly indicates that the in-plane Young's modulus is anisotropic. We believe the origin of this effect lies in the epitaxial growth of the PZT on the silicon crystal (Nazeer et al., 2011a).

The minimum value for the Young's modulus obtained from the cantilevers aligned parallel to the $\langle 100\rangle$ silicon direction is found to be $103.5 \mathrm{GPa}$ with a standard error of $\pm 1.9 \mathrm{GPa}$ for $x=0.52$. At the same composition for the $<110>$ aligned cantilevers, the Young's modulus value is $113.5 \mathrm{GPa}$ with a standard error of $\pm 1.5 \mathrm{GPa}$. 


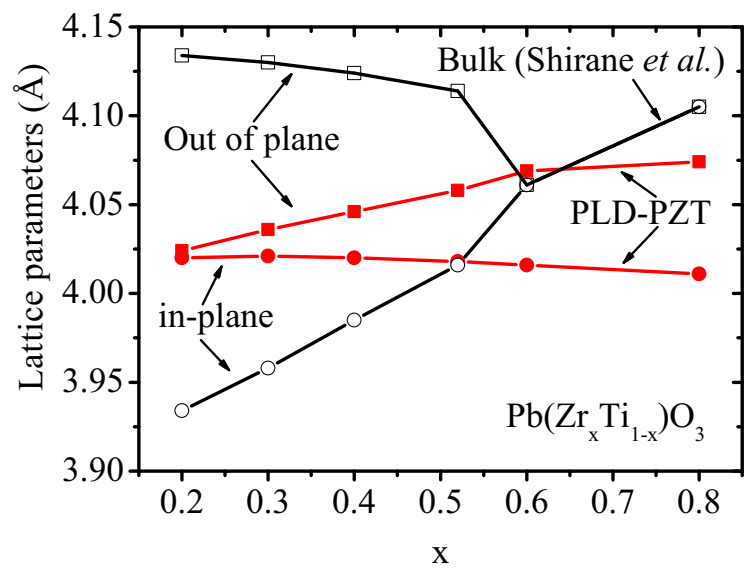

FIGURE 6.6 - Lattice parameters as a function of $\mathrm{Zr}$ content. The in-plane lattice parameter varies slightly with the increase in $\mathrm{Zr}$ content whereas the out-of-plane lattice parameter increases significantly. PLD-PZT lattice parameters are compared with the bulk PZT ceramic parameters published by Shirane and Suzuki (1952). The lines are guides to the eye.

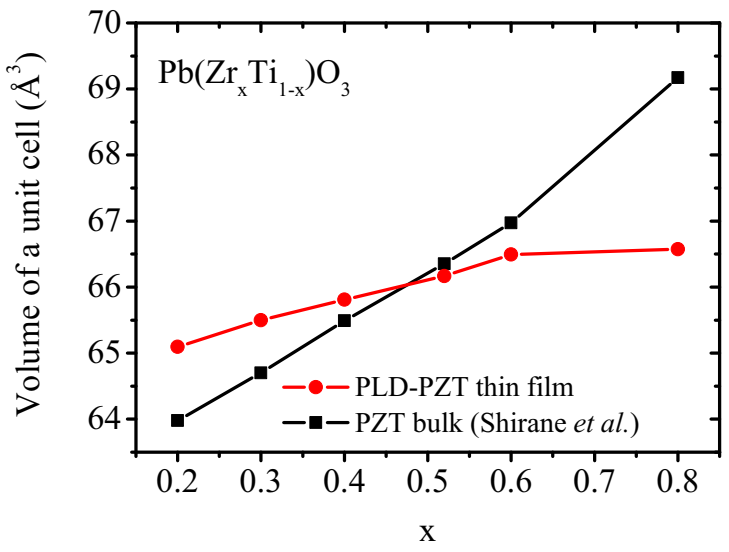

FIGURE 6.7 - Compositional variation of the volume of unit cells, calculated from the data in Figure 6.6. Compared to bulk PZT ceramic data, the volume of $P L D-P Z T$ thin film unit cells are lower for Zr rich compositions and higher for $\mathrm{Ti}$ rich compositions. The lines are guides to the eye. 


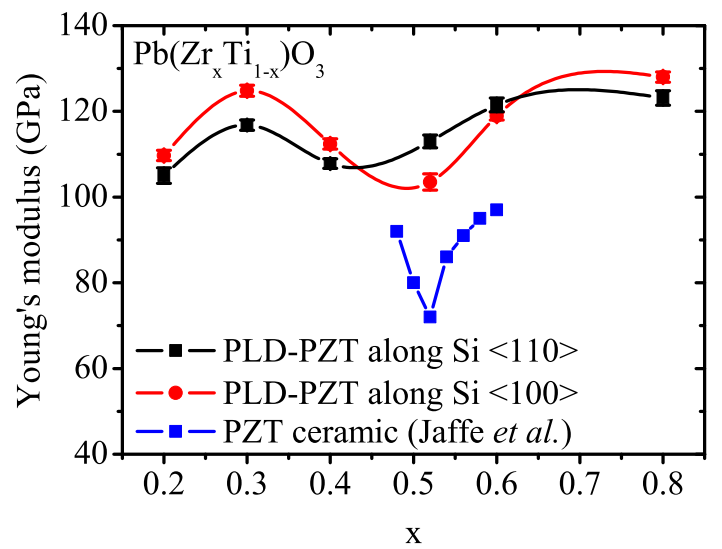

Figure 6.8 - Composition dependence of the Young's modulus of $\mathrm{Pb}\left(\mathrm{Zr}_{x} \mathrm{Ti}_{1-x}\right) \mathrm{O}_{3}$ thin films deposited on cantilevers aligned parallel to the $\langle 100\rangle$ and $\langle 110\rangle$ crystal direction of silicon. The trend is compared with the data published by Jaffe et al. (1971) for bulk PZT ceramics. The lines are guides to the eye.

For this cantilever orientation, the minimum Young's modulus is shifted towards Ti rich composition (Nazeer et al.).

The dip in the Young's modulus value at $x=0.52(<100>$ silicon $)$ is in agreement with the data published for bulk PZT ceramic, but the value is $44 \%$ higher (Jaffe et al., 1971). Reasons for the higher Young's modulus of the PLD-PZT thin films, such as clamping of the thin film, are discussed in detailed in (Nazeer et al.).

\subsubsection{Residual stress}

The residual stress of PZT thin films deposited on the two crystal directions of silicon $<110>$ and $<100>$ was determined to be tensile and strongly dependent on the film composition (see Figure 6.9). For Ti rich compositions of $x=0.2$ and 0.3 , the value of residual stress obtained from the $<110\rangle$ aligned silicon cantilevers is small compared to the compositions of $x=0.4$ and above. A similar trend was also observed from the cantilevers of varying length aligned parallel to the $<100>$ crystal direction of silicon. For Ti rich compositions from $x=0.2$ to $x=0.4$, the stress increases sharply and then remains constant within error bounds at a higher value of around $270 \mathrm{MPa}$ for PZT compositions of $x=0.4$ and above. On the $<110>$ oriented cantilever however, the residual stress still varies considerably at higher $\mathrm{Zr}$ values with a maximum of $291 \mathrm{MPa}$ at $x=0.52$. These variations cannot be attributed to measurement uncertainties.

The minimum in the Young's modulus at $x=0.52$, corresponds to a maximum 


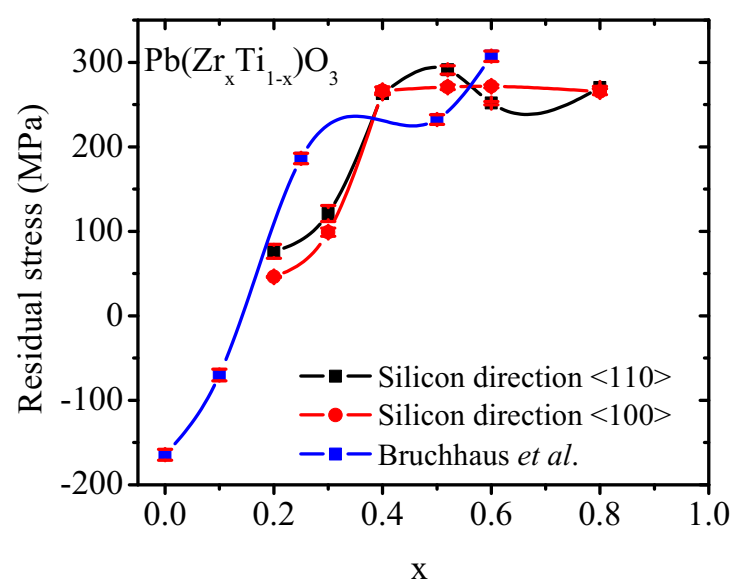

FIGURE 6.9 - Compositional distribution of the residual stress in PLD-PZT thin films deposited on cantilevers aligned along the $\langle 110\rangle$ and $\langle 100\rangle$ direction of silicon crystal lattice. Residual stress in the PZT thin film increases with the increasing $\mathrm{Zr}$ content for both silicon directions. Compared to data published for sputtered PZT (Bruchhaus et al., 1999), the stress in PLD-PZT is lower for Zr rich and Ti rich compositions whereas it is higher near $x=0.52$. The lines are guides to the eye.

in the piezoelectric coefficient $d_{33, \mathrm{f}}$, which we reported on earlier (Nazeer et al.). A maximum in the residual stress at $x=0.52$ was reported as well in literature for sol-gel derived PZT thin films on $\mathrm{Si} / \mathrm{SiO}_{2} / \mathrm{Pt}$ substrates (Corkovic et al., 2008), but at a lower maximum stress (90 $\mathrm{MPa}$ ). Residual stress in sol-gel PZT thin films $(x=0.52)$ on platinum electrodes was also reported as $108 \mathrm{MPa}$ and $180 \mathrm{MPa}$ by other authors (Ledermann et al., 2004; Shepard Jr. et al., 1996). Similar behaviour was also observed for sputtered PZT thin films on platinum electrodes that show compressive stress for $x=0$ and o.1, which changes into tensile stress at $x=0.25$ and above (Bruchhaus et al., 1999) (see Figure 6.9). Compared to sputtered PZT, our measured PLD-PZT thin films show lower stress values for all compositions except at $x=0.4-0.52$ (Bruchhaus et al., 1999).

\subsection{Discussion}

\subsubsection{Residual stress estimated from difference in thermal expansion}

The maximum in the residual stress at $x=0.52$ coincides with a maximum of the CTE of PZT thin films (Corkovic et al., 2008). This suggests that at least a part of the residual stress is caused by the difference in CTE between the PZT film and the 


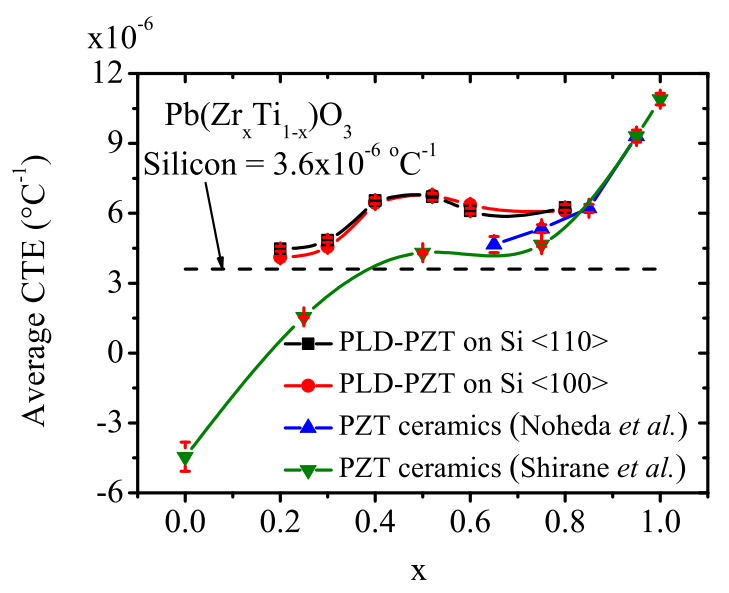

FIGURE 6.10 - Average coefficient of thermal expansion for cooling down from deposition temperature $\left(600^{\circ} \mathrm{C}\right)$ to room temperature as a function of composition. The average CTE is estimated from the residual stress calculated from the static deflection and the Young's modulus and compared with the data from (Noheda et al., 1997; Shirane et al., 1952). Note that this average CTE also includes volume changes due to changes in crystal structure.

silicon substrate. Average CTE data has not been published for PZT thin film over the temperature range of interest. Therefore, we extrapolated published thermal expansion data of bulk PZT ceramics (Noheda et al., 1997; Shirane et al., 1952) to $600^{\circ} \mathrm{C}$ (see Figure 6.10, curves labeled Noheda and Shirane). These values should be compared with the average CTE of silicon (dotted line).

Using Equation (6.2) we can now calculate the residual stress building up during cooling down from deposition temperature $\left(600^{\circ} \mathrm{C}\right)$ to room temperature, (see Figure 6.11, labelled RS-CTE). The trend is comparable to the residual stress calculated from cantilever deflection (curves labeled PLD-PZT), but there is a large negative offset. We suspect that this offset is caused by a tensile residual stress of 200 to $300 \mathrm{MPa}$ which is already present at the deposition temperature.

For comparison, we show the average CTE calculated from cantilever bending for our PLD-PZT films as well in Figure 6.10. The compositional variation of CTE follows the same trend as published in literature for bulk PZT ceramics, but the values are $75 \%$ higher for $x$ around 0.2 and $25 \%$ higher for $x$ around 0.8 (see Figure 6.10). The average CTE of our PLD-PZT is higher compared to sol-gel (3.7 - $5.3 \times 10^{-6}{ }^{\circ} \mathrm{C}^{-1}$ ) (Corkovic et al., 2008), and comparable to the range of values mentioned for the PLD $\left(6-7 \times 10^{-6}{ }^{\circ} \mathrm{C}^{-1}\right)$ in literature (Goh et al., 2005). 


\subsubsection{Residual stress estimated from lattice parameters}

From the XRD data one can estimate the in-plane strain in different compositions of the film, taking the values of bulk PZT ceramics as a non-strained reference. In combination with the measured in-plane Young's modulus of the corresponding PLD-PZT composition in two crystal directions of silicon (Figure 6.8), one can estimate the residual stress by using Equation (6.3). The strain in the PLD-PZT thin film varies from negative to positive value as the $\mathrm{Zr}$ content increases, with a transition around $x=0.52$. Therefore, the calculated residual stress also changes from compressive to tensile at $x$ around 0.52 , where the in-plane lattice parameters of the PLD-PZT matches with bulk PZT ceramics. This approach however leads to unlikely high values ranging from -3.2 to $+4.0 \mathrm{GPa}$, at least an order of magnitude higher than for the range of values observed from cantilever deflection, see Figure 6.11 (labelled RS-LP, note that the values are divided by 10!).

Discrepancy between the residual stress from XRD data and the curvature measurements was already reported in literature (Kim and Yu, 1998), although in their case the difference between XRD and curvature measurements was only a factor of two. We can therefore only assume that the peak shift in the XRD is not caused by strain alone, but also originates from other effects such as grain size variation and columnar growth of our epitaxial PLD-PZT.

It should be noted that residual stress estimates from thermal expansion differences or strain measured by XRD rely on bulk ceramic data and assumptions we made. For design purposes we suggest to use the actually measured data from cantilever curvature as reported in Figure 6.9.

\subsection{Conclusion}

We studied the effect of the $\mathrm{Zr} / \mathrm{Ti}$ ratio on the Young's modulus and residual stress of the $\mathrm{Pb}\left(\mathrm{Zr}_{x} \mathrm{Ti}_{1-x}\right) \mathrm{O}_{3}$ thin films with a (110) preferred orientation deposited on silicon cantilevers aligned along the $\langle 110\rangle$ and $\langle 100\rangle$ silicon crystal direction.

The Young's modulus was found to be in the range of 100-120 GPa. The values and the variation with composition are different for both cantilever orientations. We believe this anisotropy is caused by the epitaxial growth of our PZT on silicon.

The residual stress measured from static deflection was found to be tensile for all compositions measured ( $x=0.2$ to 0.8 ) and shows a sharp increase from about 50 to over $250 \mathrm{MPa}$ for compositions from $x=0.2$ to 0.4 . These values are higher than commonly found for sol-gel deposited films (9o to $180 \mathrm{MPa}$ ). Compared to sputter deposited PZT, the residual stress in our PLD-PZT is lower for all compositions except for $x=0.4-0.52$.

The residual stress for films deposited on $<100>$ cantilevers remains constant for compositions of $x=0.4$ and above, whereas it reaches a maximum value for the $<110>$ oriented cantilevers at $x=0.52$, followed by a slight reduction. This effect is larger than the experimental error, and might again be connected to the epitaxial growth of the films. 


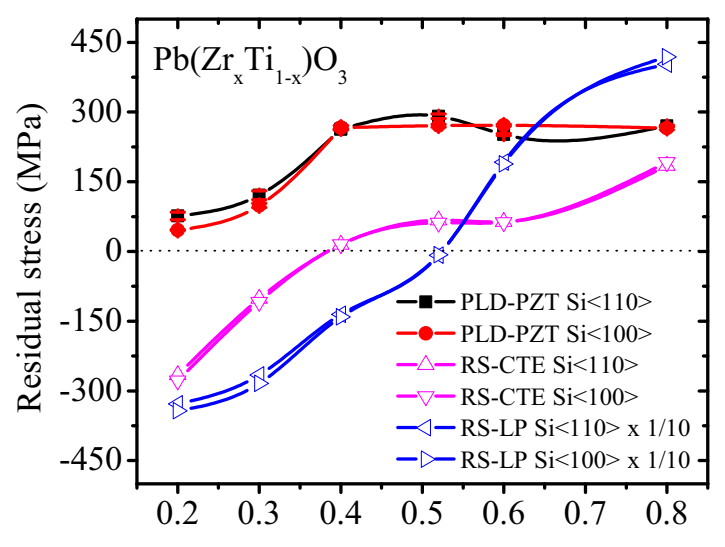

$\mathrm{X}$

FIGURE 6.11 - Compositional distribution of the residual stress in the PZT thin films from the cantilevers aligned along the $\langle 110\rangle$ and $\langle 100\rangle$ direction of silicon crystal lattice. The residual stress measured from the static deflection of cantilevers (labelled $P L D-P Z T)$, estimated from the lattice parameters mismatch (RS-LP, divided by 10!) and mismatch of thermal expansion coefficients (RS-CTE) are shown together for comparison. The lines are guides to the eye.

A maximum residual stress of $291.1 \mathrm{MPa}$ with a standard error of $\pm 4.9 \mathrm{MPa}$ was measured for the $\mathrm{Pb}\left(\mathrm{Zr}_{0.52} \mathrm{Ti}_{0.48}\right) \mathrm{O}_{3}$ thin film deposited on the silicon cantilever directed along the $<110\rangle$ silicon crystal direction. For identical cantilevers but aligned parallel to the $<100\rangle$ crystal direction of silicon, we found $270.6 \mathrm{MPa}$ with a standard error of $\pm 2.9 \mathrm{MPa}$.

Using thermal expansion coefficients for bulk PZT ceramics and silicon, we estimated the residual stress caused by cooling down from deposition to room temperature. The variation in stress with composition is predicted qualitatively, but at a large negative offset. We suspect this is due to a 200-300 MPa intrinsic tensile stress which is already present at the deposition temperature.

The in-plane and out-of-plane lattice parameters measured by XRD on PLDPZT show a remarkably different behaviour with composition as compared to bulk PZT ceramics. From the difference we estimated the residual stress, which was found to be at least an order of magnitude higher than measured by cantilever bending. We suspect that the peak shifts in the XRD measurement are not only caused by strain variation, and conclude that XRD measurements are not suitable to estimate residual stress in this material. 



\section{Chapter 7}

\section{Mechanical properties of GeSbTe phase-change thin films}

\subsection{Introduction}

Mechanical properties of thin films, notably their Young's modulus, can be accurately determined by means of microcantilevers (Isarakorn et al., 2010; Poelma et al., 2011; Ræder et al., 2007). The method relies on a change in resonance frequency caused by the deposition of the thin film on the cantilever. The extra mass of the thin film will decrease the resonance frequency, whereas the added rigidity of the structure by adding the film will cause an increase. Up to now we have been using thin films from different deposition runs, for instance to determine the variation of the Young's modulus with film composition (Nazeer et al., 2011a,b). In this chapter we illustrate the method on GeSbTe (GST) phase change films, which has the advantage that the Young's modulus of the film can be changed when it is on the cantilever, without changing its mass. The sole reason for a change in resonance frequency will therefore be the change in the Young's modulus of the phase change film.

The class of GST phase change materials has received considerable attention because of its use in non-volatile memory devices. Applications using the optical properties of this material date back to 1990, and passing through different generations led to the Blu-ray disk in 2004 (Wuttig and Yamada, 2007). The growing and dynamic market of electronic memories is the driving force to explore new material technologies with superior properties. In this application, the difference in the electrical resistance between the amorphous and crystalline state is exploited (Burr et al., 2010).

Phase change materials based on the Ge-Sb-Te (GST) alloy are found to exhibit excellent electrical and phase change properties and can endure large numbers of read write cycles (Carria et al., 2011). From the family of GST alloys, the compositions $\mathrm{Ge}_{1} \mathrm{Sb}_{2} \mathrm{Te}_{4}$ (GST124) and $\mathrm{Ge}_{2} \mathrm{Sb}_{2} \mathrm{Te}_{5}$ (GST225) are widely studied because of their superior combination of properties (Krbal et al., 2008; Matsunaga and 
Yamada, 2004; Tomforde et al., 2011). These materials were mostly investigated on the basis of their optical, electrical and phase change properties. To support the use of these materials as an active device layer, information is needed on the mechanical properties, like Young's modulus and residual stress. These properties have not been extensively investigated and a large variation of reported values can be found in literature (Jong et al., 2001; Marmier et al., 2011). Knowledge on the compositional dependence of these properties and their variation with temperature facilitates the choice for the correct composition for a particular application.

In addition to the determination of the Young's modulus, the residual stress of the GST thin films was obtained from the change in static deflection of the cantilevers. Crystallization of the GST thin films is accompanied by a volume reduction (Weidenhof et al., 1999), which results in an abrupt change in the cantilever deflection. For comparison, the decrease in sheet resistance of the GST thin films upon crystallization was measured as well.

The theoretical relations for the properties investigated in this study are explained in section 7.2. Cantilevers were fabricated with standard MEMS fabrication process and GST thin films were sputtered on these cantilevers (see section 7.3). In this section, we explain the annealing treatment and measurements of the Young's modulus, residual stress and sheet resistance. The measurement results are compiled in section 7.4 and discussed in section 7.5 .

\subsection{Theory}

\subsubsection{Analytical model for the Young's modulus of GST thin films in amorphous and crystalline states}

A dynamic approach, based on the Euler-Bernoulli beam equation and the dependence of the resonance frequency on the flexural rigidity of composite cantilever, was used to develop an analytical model for determination of the Young's modulus (Nazeer et al., 2011a). Due to the addition of a thin film on the cantilever, the flexural rigidity of the composite cantilever increases and its neutral axis shifts to a new position. In addition the film will add to the mass of the composite cantilever. These three effects result in a change in the resonance frequency. By measuring this change before and after deposition of the thin film, one can obtain its Young's modulus from Equation (7.1).

$$
\begin{aligned}
& E_{\mathrm{f}}^{*}=\frac{1}{t_{\mathrm{f}}^{3}}\left[6\left(\gamma_{\mathrm{s}}+\gamma_{\mathrm{f}}\right) B-2 E_{\mathrm{s}}^{*} t_{\mathrm{s}}^{3}-3 t_{\mathrm{f}} E_{\mathrm{s}}^{*} t_{\mathrm{s}}^{2}-2 E_{\mathrm{s}}^{*} t_{\mathrm{s}} t_{\mathrm{f}}^{2}\right.
\end{aligned}
$$

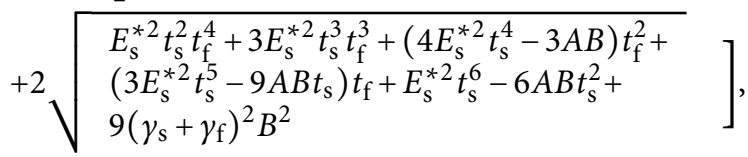

where 


$$
A=E_{\mathrm{s}}^{*} t_{\mathrm{s}}\left(\gamma_{\mathrm{s}}+\gamma_{\mathrm{f}}\right)
$$

and

$$
B=\left(\sqrt{\frac{E_{\mathrm{s}}^{*} t_{\mathrm{s}}^{3}}{12 t_{\mathrm{s}} \rho_{\mathrm{s}}}}-0.568 \pi \Delta f_{0} L^{2}\right)^{2}
$$

In the above equation $L, t$ and $E^{*}$ are the length, thickness and the effective Young's modulus respectively and $\gamma=\rho t$. Subscripts ' $s$ ' and ' $f$ ' denote the silicon and the thin film. The measured difference in the fundamental resonance frequency of the cantilevers before and after the deposition of the thin film is denoted by $\Delta f_{0}$. By taking this difference, any potential uncertainties in the thickness of the cantilever can be eliminated and a more accurate result is obtained (Schweitz, 1991).

The resonance frequency of the cantilever is a function of the Young's modulus of the GST film and its mass, which is the product of density and thickness. In principle, the mass does not change during a transition from the amorphous to crystalline phase. The change in resonance frequency therefore is in first order only caused by a change in Young's modulus. The neutral line (of no strain) in the cantilever however shifts down toward the cantilever axis with decreasing GST film thickness. From Equation (7.1) we can calculate that for a $200 \mathrm{~nm}$ GST film deposited on a $3 \mu \mathrm{m}$ silicon cantilever, the product of Young's modulus and film thickness only changes by $0.3 \%$ when reducing the film thickness by $6.5 \%$ Therefore, we can consider the product of GST Young's modulus and film thickness to be independent on a reduction in film thickness due to the crystallization process.

\subsubsection{Residual stress}

Crystallization of the GST thin films at elevated temperature leads to a reduction in volume. When deposited on cantilevers, this reduction causes the cantilevers to bend upwards. By measuring the static deflection of these cantilevers before and after the deposition at every annealing step, we can determine the residual stress in GST thin films at different temperatures. Since the GST film thickness is small compared to the substrate thickness, we can use Stoney's approximation 7.2 (Jeon and Thundat, 2004; Stoney, 1909).

$$
\sigma_{\mathrm{f}}=\frac{1}{3} \frac{E_{\mathrm{s}} t_{\mathrm{s}}^{2} \xi}{\left(1-v_{\mathrm{s}}\right) t_{\mathrm{f}} L^{2}},
$$

the symbols $\sigma, E, t, L$, and $\xi$ are the residual stress, Young's modulus, thickness, length and deflection respectively. Subscripts 's' and ' $\mathrm{f}$ denote the silicon and thin film. Again, the product of residual stress and film thickness is independent on the film thickness itself. 


\subsubsection{Coefficient of thermal expansion}

The average coefficient of thermal expansion (CTE) of the GST thin films depends on the composition as well as the phase of the material (Li et al., 2008). We determined the average CTE of the GST thin films in amorphous and crystalline state by using the residual stress calculated from the cantilever deflection (Equation (7.3)). The average CTE was calculated in the temperature range between room temperature $\left(20^{\circ} \mathrm{C}\right)$ and the annealing temperature.

$$
\alpha_{\mathrm{f}}=\frac{\sigma_{\mathrm{f}}}{\Delta T}\left(\frac{1-v_{\mathrm{f}}}{E_{\mathrm{f}}}\right)+\alpha_{\mathrm{s}},
$$

the symbols $\alpha, v$ and $\Delta T$ are the average CTE, poisson's ratio and difference in the annealing and room temperature $\left(20^{\circ} \mathrm{C}\right)$ respectively. We used published values of $\alpha_{\mathrm{s}}$ at the particular annealing temperature (Glazov and Pashinkin, 2001; Okada and Tokumaru, 1984), and $v_{\mathrm{f}}$ was assumed to be 0.3 (Leervad Pedersen et al., 2001).

\subsection{Experimental details}

\subsubsection{Fabrication of cantilevers}

The cantilevers are fabricated from a double side polished single-crystal silicon on insulator wafer (SOI). Length of the cantilevers varies from $250 \mu \mathrm{m}$ to $350 \mu \mathrm{m}$ in steps of $10 \mu \mathrm{m}$ with a constant width of $30 \mu \mathrm{m}$. The thickness is defined by the thickness of the (001) silicon device layer $(3 \pm 0.5 \mu \mathrm{m})$. Details of the fabrication process are similar to what is explained in section 5.3.1.

\subsubsection{GST deposition}

The $200 \mathrm{~nm}$ films of compositions $\mathrm{Ge}_{1} \mathrm{Sb}_{2} \mathrm{Te}_{4}$ (GST124) and $\mathrm{Ge}_{2} \mathrm{Sb}_{2} \mathrm{Te}_{5}$ (GST225) were deposited directly on the Si cantilevers by DC magnetron sputtering in an argon plasma at a sputtering power of $300 \mathrm{~W}$ and deposition rate of $6 \mathrm{~nm} / \mathrm{s}$. A $5 \mathrm{~nm} \mathrm{ZnS}-\mathrm{SiO}_{2}$ capping layer was deposited to protect the films from oxidation at a sputtering power of $1 \mathrm{~kW}$ at a rate of $3.4 \mathrm{~nm} / \mathrm{s}$.

\subsubsection{Annealing of GST}

Compositional and phase dependence of the Young's modulus, residual stress and sheet resistance of the GST225 and GST124 thin films were investigated at different temperatures. Samples were annealed from room temperature to the desired temperature with a ramping rate of $3^{\circ} \mathrm{C} / \mathrm{min}$ in a vacuum furnace with nitrogen environment at a pressure of 1 mbar. The chips were kept at the desired temperature for 15 minutes and then cooled down to room temperature with even lower rate.

Measurements for the Young's modulus, residual stress and sheet resistance were conducted at room temperature after each annealing step. Samples identified by GST225 and GST124 were passed through an identical annealing procedure up 
to $180^{\circ} \mathrm{C}$ with reduced temperature steps around $150^{\circ} \mathrm{C}$. In order to investigate the behaviour of the properties around crystallization temperature of GST124, another sample with a $\mathrm{Ge}_{1} \mathrm{Sb}_{2} \mathrm{Te}_{4}$ composition (which we will refer to as GST124*) was annealed with extra temperature steps around $130^{\circ} \mathrm{C}$. The annealing history of the samples is summarized in Table 7.1.

TABLE 7.1 - Annealing history of the GST thin films. GST124* passed through more annealing steps before reaching $140^{\circ} \mathrm{C}$.

\begin{tabular}{|c|c|c|c|c|c|c|c|c|c|c|}
\hline \multirow[b]{2}{*}{ Sample } & \multicolumn{10}{|c|}{ Annealing temperature $\left({ }^{\circ} \mathrm{C}\right)$} \\
\hline & 60 & 100 & 110 & 120 & 130 & 140 & 150 & 160 & 170 & 180 \\
\hline GST225 & $\mathrm{x}$ & $\mathrm{x}$ & & & & $\mathrm{x}$ & $\mathrm{x}$ & $\mathrm{x}$ & $\mathrm{x}$ & $\mathrm{x}$ \\
\hline GST124 & $\mathrm{x}$ & $\mathrm{x}$ & & & & $\mathrm{x}$ & $\mathrm{x}$ & $\mathrm{x}$ & $\mathrm{x}$ & $\mathrm{x}$ \\
\hline GST $124^{*}$ & $\mathrm{x}$ & $\mathrm{x}$ & $\mathrm{x}$ & $\mathrm{x}$ & $\mathrm{x}$ & $\mathrm{x}$ & $\mathrm{x}$ & $\mathrm{x}$ & $\mathrm{x}$ & $\mathrm{x}$ \\
\hline
\end{tabular}

\subsubsection{Resonance frequency measurements}

The resonance frequency of the cantilevers was measured by using a MSA-400 micro system analyzer scanning laser Doppler vibrometer. Measurements of the resonance frequency were conducted both before and after the deposition and each annealing step. Thermal excitation of the cantilevers in ambient conditions was used to measure the amplitude spectrum, which is then fitted to the theoretical expression of mass-spring system with damping to calculate the resonance frequency (see Figure 7.3).

\subsubsection{Static deflection measurements}

Static deflection $\xi$ of the cantilevers was measured at room temperature by using white light interferometry (WLIF) of a Polytec MSA-40o analyzer. From the deflection, the residual stress in the GST thin films was determined using Equation (7.2). As expected, all cantilevers were found to be straight before deposition of the GST thin films. After annealing at certain temperature, all cantilevers bent upwards, indicating that the GST films are under tensile residual stress. A 2-D white light interference microscopic image of a $250 \mu \mathrm{m}$ long cantilever with GST225 after annealing at $150^{\circ} \mathrm{C}$ is shown in Figure 7.1. The profile of the cantilever obtained from this image shows that the cantilever was bent upward (see Figure 7.2). Similarly, cantilevers of varying length deposited with GST225 and GST124 were measured after each annealing step to reduce the error. All the static deflection measurements were conducted at room temperature.

\subsubsection{Sheet resistance measurements}

The sheet resistance of the GST thin films was measured by a four-point probe. The measurements were taken after the deposition of the GST thin films and after each 


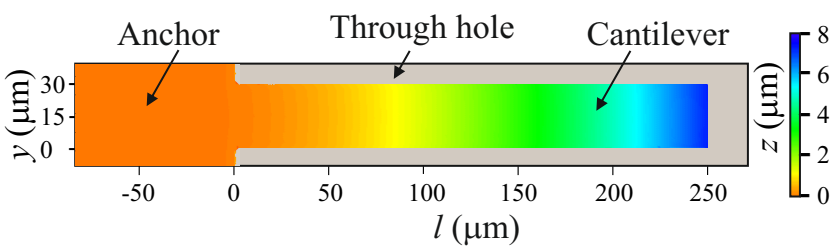

FIGURE 7.1 - Top view of the reconstructed image from a white light interference measurement of $a \sim 290 \mu \mathrm{m}$ long, $\sim 30 \mu \mathrm{m}$ wide and $\sim 3 \mu \mathrm{m}$ thick silicon cantilever, with $200 \mathrm{~nm}$ thick GST225. As an example, measurement conducted after annealing at $150^{\circ} \mathrm{C}$ are shown here. Length and width axes of the cantilever are denoted by $l$ and $y$, whereas the out of plane displacement is represented by $z$.

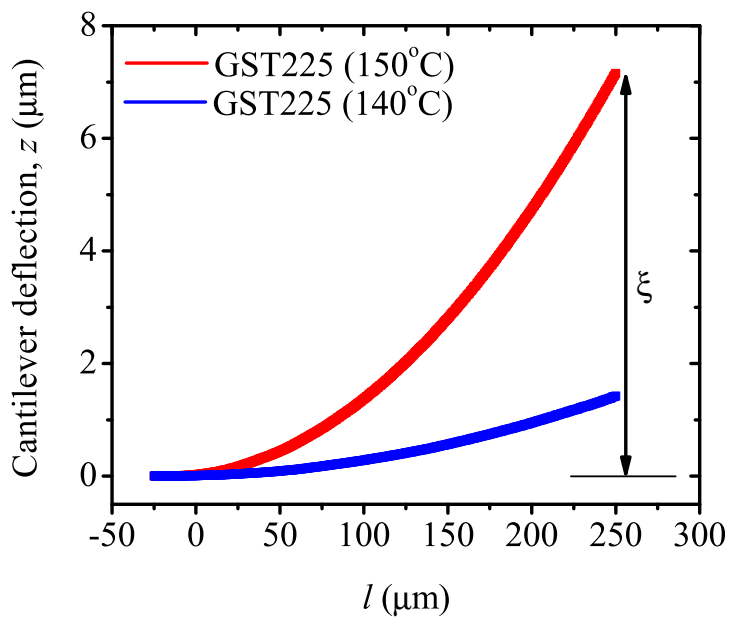

FIGURE 7.2 - Cantilever profile obtained from Figure 7.1. The maximum upward static deflection at room temperature after $150^{\circ} \mathrm{C}$ annealing is high compared to the one measured at $140^{\circ} \mathrm{C}$ because of the built up of tensile residual stress. 
annealing step at room temperature (see Figure 7.6).

\subsection{Measurement Results}

\subsubsection{Young's modulus}

The in-plane Young's modulus of the GST thin films is shown in Figure 7.4 as a function of composition and annealing step. In the amorphous state, below the crystallization temperature, the Young's modulus is lower than that of the corresponding crystalline phase (Weaire et al., 1971).

During crystallization the thickness of the GST reduces, leading to an equal increase in film density. The product of both, which is the mass of the film, remains constant. The same is true, to a good approximation, for the product of Young's modulus and thickness. To be able to give absolute values, we have taken the thickness reduction to be $6.5 \%$ for the GST225 composition (Elliott and Hegedus, 2008; Njoroge et al., 2002) (leading to an increase in density from $5870 \pm 50 \mathrm{~kg} / \mathrm{m}^{3}$ to $6270 \pm 20 \mathrm{~kg} / \mathrm{m}^{3}$ ), and a reduction of $4 \%$ for GST124 (Blachowicz et al., 2007) (with density increasing from $5900 \mathrm{~kg} / \mathrm{m}^{3}$ to $6200 \mathrm{~kg} / \mathrm{m}^{3}$ ).

The measured Young's modulus of the GST225 thin film as deposited in amorphous state was found to be $18.9 \mathrm{GPa}$ with a standard error of $\pm 0.7 \mathrm{GPa}$ (0.7). The Young's modulus increased sharply above the crystallization temperature of $150^{\circ} \mathrm{C}$ to a value of 38.2 (o.3) GPa. The crystallization temperature agrees well with the range of values quoted in literature (Kalb et al., 2003 $b$; Krusin-Elbaum et al., 2007; Njoroge et al., 2002; Tomforde et al., 2011). The increase in the Young's modulus from amorphous to crystalline state is consistent with results published in literature (Kalb et al., 2003a; Leervad Pedersen et al., 2001). We assumed a typical value of $v_{\mathrm{f}}$ of 0.3 , in order to compare with the biaxial modulus values published in literature.

The Young's modulus of the GST124 thin film was found to be 15.9 (0.2) GPa and 31.3 (0.3) GPa in the amorphous and crystalline state respectively. The crystallization temperature of $130^{\circ} \mathrm{C}$ is consistent with the range of temperature values reported elsewhere (Blachowicz et al., 2007; Kalkan et al., 2011). The fact that the crystallization temperature of GST124 is lower than GST225 agrees with measurements by Carria (Carria et al., 2011) and Kalb (Kalb et al., 2007). The measured Young's modulus is slightly lower than reported by Blachowicz (Blachowicz et al., 2007), who found 24.8 GPa for the amorphous and $39.5 \mathrm{GPa}$ for the crystalline phase.

\subsubsection{Residual stress}

The residual stress in the GST thin films strongly depends on the annealing temperature as well as the composition of the GST material (see Figure 7.5). We observed a sharp increase in the residual stress, when the GST thin films were annealed above the crystallization temperature. This increase in the residual stress is attributed 

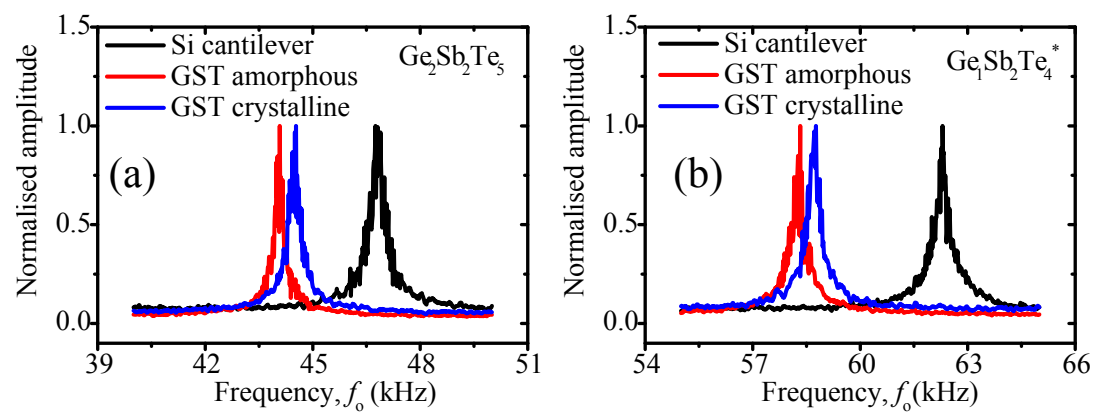

FIGURE 7.3 - Measured resonance frequencies of the silicon cantilever without (black) and with GST thin films in amorphous (red) and crystalline state (blue). The resonance frequency decreases after deposition, whereas it increases upon annealing. This increase is attributed to the higher Young's modulus of the GST thin films in crystalline state. Figure (a) $\mathrm{Ge}_{2} \mathrm{Sb}_{2} \mathrm{Te}_{5}$ on a $310 \mu \mathrm{m}$ long cantilever. Figure (b) $\mathrm{Ge}_{1} \mathrm{Sb}_{2} \mathrm{Te}_{4}$ on a $260 \mu \mathrm{m}$ long cantilever.

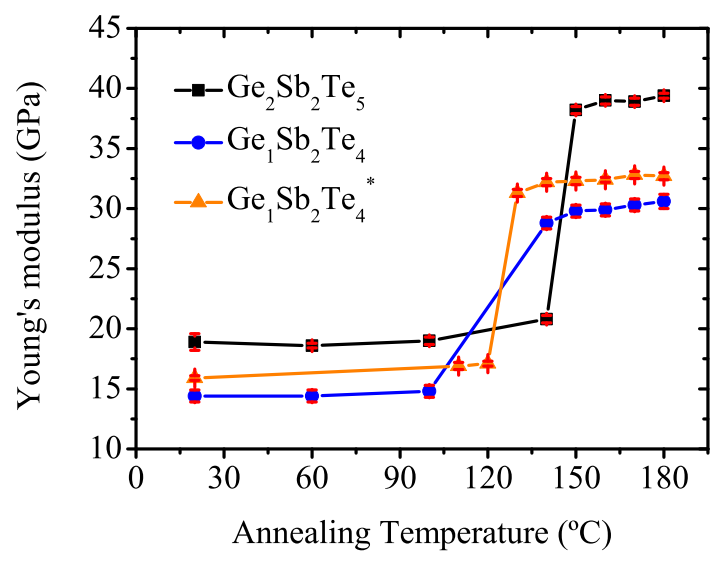

FIGURE 7.4 - The Young's modulus of the GST225 and GST124 thin films plotted as a function of the annealing temperature. We observed the rise in the Young's modulus value above the crystallization temperature for both the GST225 and GST124 thin films. The Young's modulus of the GST225 film is 30\% higher than that of GST124. The lines are guides to the eye. 
to an increase in the density as well as an increase in CTE of the GST upon to crystallization.

There is no residual stress in the as-deposited GST225 thin film. The stress increases slowly to a value of 49.7 (0.3) $\mathrm{MPa}$ at $140^{\circ} \mathrm{C}$, just before the crystallization temperature. A sharp increase in residual stress to a value of 331.6 (1.5) MPa was observed after annealing at $150^{\circ} \mathrm{C}$. The crystallization temperature determined from the stress measurements is consistent with the Young's modulus results. Annealing above the crystallization temperature up to $180^{\circ} \mathrm{C}$ shows some stress relaxation, see Figure 7.5. The trend in the temperature dependence of the residual stress in GST225 agrees with results published by others (Leervad Pedersen et al., 2001; Park et al., 2008). Krusin-Elbaum et al. (2007) observed a similar stress release, and showed it to be dependant on the material composition.

Residual stress in the GST124 and GST124* thin films were also found to be negligible in the as-deposited state. The stress for GST124* increased to a value of $46.8 \mathrm{MPa}(0.2)$ at $120^{\circ} \mathrm{C}$. When measured after annealing at the crystallization temperature $\left(130^{\circ} \mathrm{C}\right)$, the residual stress increased to a higher value of 238.6 (1.0) MPa. The GST124 and GST124* sample show surprisingly distinct residual stress values at annealing temperatures after the crystallization (see Figure 7.5). We observed a strong effect of the annealing history on the residual stress of the GST thin films. The GST124* sample, which passed through more annealing steps (see Table 7.1) shows a $45 \%$ higher residual stress than GST124 sample at $140^{\circ} \mathrm{C}$. Stress relaxation in the GST124 thin films at elevated annealing temperatures is not present, as we observed for the GST225 thin film.

\subsubsection{Sheet resistance}

The annealing temperature dependence of the sheet resistance is shown in Figure 7.6. The sheet resistance of both the GST225 and GST124 thin films in the as-deposited amorphous state is high (in the range of 1100 to $1200 \mathrm{k} \Omega / \mathrm{sq}$ ) as compared to the crystalline state. Annealing with increasing temperature reduces the sheet resistance monotonously, without a sudden drop at the crystallization temperature. A sudden drop is reported however by Jang et al. (2009), from $90^{\circ} \mathrm{C}$ to $170^{\circ} \mathrm{C}$ for the $\mathrm{Ge}_{2} \mathrm{Sb}_{2} \mathrm{Te}_{5}$ composition. Njoroge et al. (2002) also observed a sudden drop around $150^{\circ} \mathrm{C}$ when measuring during annealing.

At the temperature of $150^{\circ} \mathrm{C}$, where we observed a sharp increase in the Young's modulus and residual stress, the sheet resistance was $74 \mathrm{k} \Omega / \mathrm{sq}$ for the GST225 thin film, which is in the same order of magnitude as reported in literature. However, the sheet resistance in amorphous state is one order of magnitude less than reported values in literature. We suspect that these lower values, and the absence of a sudden drop, are caused by the low resistivity silicon device layer underneath the GST thin films. A short-cut current through this layer might reduce the sheets resistance and obscure a sudden drop in sheet resistance in the four-point measurement. The sheet resistance of the GST124 and GST124* samples at $140^{\circ} \mathrm{C}$ was found to be $184 \mathrm{k} \Omega / \mathrm{sq}$ and $164 \mathrm{k} \Omega / \mathrm{sq}$ respectively (see Figure 7.6). 


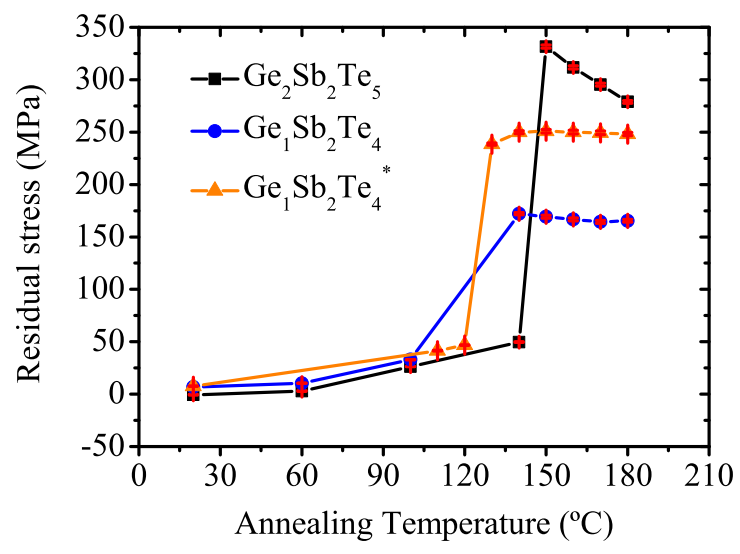

FIGURE 7.5 - Residual stress dependence of $\mathrm{Ge}_{2} \mathrm{Sb}_{2} \mathrm{Te}_{5}$ and $\mathrm{Ge}_{1} \mathrm{Sb}_{2} \mathrm{Te}_{4}$ films on temperature. The $\mathrm{Ge}_{1} \mathrm{Sb}_{2} \mathrm{Te}_{4}$ films shows lower values of residual stress as compared to $\mathrm{Ge}_{2} \mathrm{Sb}_{2} \mathrm{Te}_{5}$. There is a clear difference in residual stress values for two identical $\mathrm{Ge}_{1} \mathrm{Sb}_{2} \mathrm{Te}_{4}$ samples, which were annealed through different steps (see Table 7.1). Stress relaxation as seen in the $\mathrm{Ge}_{2} \mathrm{Sb}_{2} \mathrm{Te}_{5}$ film after $150^{\circ} \mathrm{C}$ was not observed for $\mathrm{Ge}_{1} \mathrm{Sb}_{2} \mathrm{Te}_{4}$ films. The lines are guides to the eye.

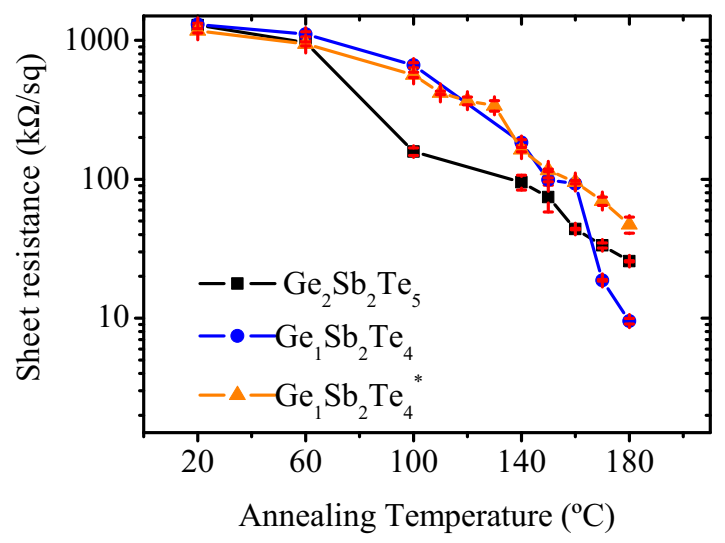

FIGURE 7.6 - Change in the sheet resistance of the GST225 and GST124 films as a function of temperature. The sheet resistance was measured using a four-point probe at room temperature. The lines are guides to the eye. 


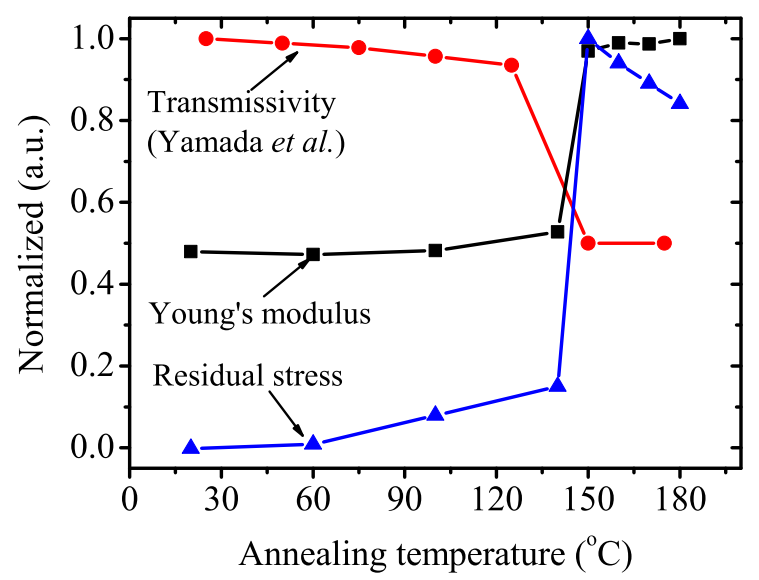

FIGURE 7.7 - Young's modulus and residual stress of the GST225 thin film compared to the change in transmissivity at the crystallization temperature (Yamada et al., 1991). The lines are guides to the eye.

\subsection{Discussion}

At the crystallization temperature a sharp increase in the residual stress and Young's modulus of the GST thin films is observed. The variation in the Young's modulus and residual stress of the GST225 thin films with annealing temperature is compared with changes in the transmissivity data obtained from literature (Yamada et al., 1991) in Figure 7.7. The observed dip in the transimissivity coincides well with the rise of the Young's modulus and residual stress. This crystallization temperature of $150^{\circ} \mathrm{C}$ film agrees well with data published for $\mathrm{Ge}_{2} \mathrm{Sb}_{2} \mathrm{Te}_{5}$ (Friedrich et al., 2000; Kalb et al., 2003a).

From the residual stress and the Young's modulus, we can calculate the strain in the film, and therefore the average CTE between room temperature and the annealing temperature. The result is plotted in Figure 7.8. The drop in the residual stress of the GST225 thin film after the crystallization temperature (Figure 7.5) is also reflected in an even more steep drop in the average CTE values. Likewise, even though the stress remains constant after the crystallization temperature for the GST125 films, the average CTE decreases with higher annealing temperature.

\subsection{Conclusion}

We have deposited $200 \mathrm{~nm}$ GST films on $3 \mu \mathrm{m}$ silicon cantilevers to determine their change in Young's modulus and residual stress when passing from the amorphous to crystalline state. Calculations show that the effect of a change in neutral line 


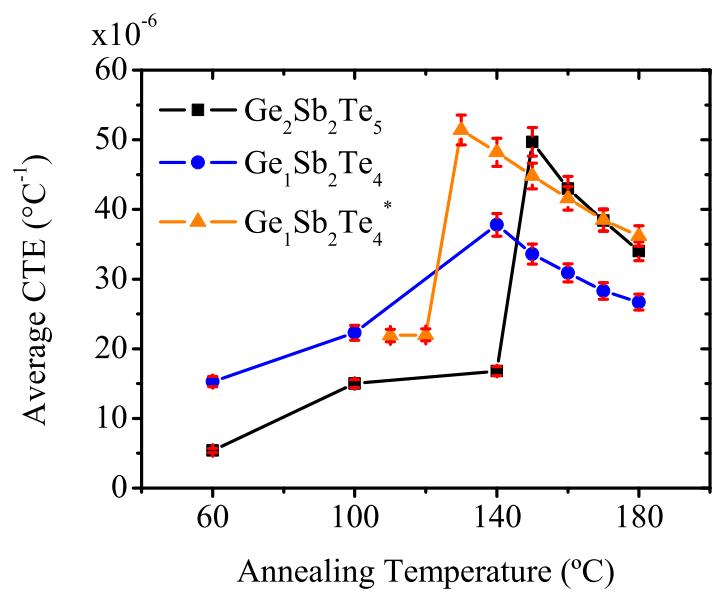

FIGURE 7.8 - Average coefficient of thermal expansion calculated between the annealing temperature and room temperature. The average CTE is estimated from the measured Young's modulus and residual stress at the corresponding annealing temperature.

when the thickness of the GST film changes by $6.5 \%$ is negligble. Therefore, we can consider the product of GST Young's modulus and film thickness, as well as the product of residual stress and film thickness, to be independent on a reduction in film thickness due to the crystallization process.

The in-plane Young's modulus of the GST thin films depends on the physical state, amorphous or crystalline, as well as the composition. The Young's modulus of the GST films increases sharply from 18.9 (o.7) GPa to 38.2 (0.3) GPa (GST225) and 15.9 (0.2) GPa to 31.3 (0.3) GPa (GST124) after annealing above the crystallization temperature. Distinct values exists for the crystallization temperature of GST225 and GST124 as $150^{\circ} \mathrm{C}$ and $130^{\circ} \mathrm{C}$ respectively. This phase transition temperature is measured from the change in the Young's modulus values and agrees well with values quoted in literature obtained by optical reflection (Yamada et al., 1991) and electrical conductivity (Njoroge et al., 2002).

Residual stress in the GST thin films increases sharply from almost no stress after deposition to higher values of 331.6 (1.5) MPa (GST225) and 238.6 (1.0) MPa $\left(\mathrm{GST}_{12} 4^{*}\right)$ when changing from the amorphous to crystalline phase. This rise in the residual stress is due to the formation of crystals accompanied by a reduction in volume. The increase of stress follows the same temperature behaviour as measured for the Young's modulus. The difference in the residual stress between GST225 and GST124 films can adequately be explained by the different thermal expansion behaviour of the two compositions .

We observe a slight increase in the residual stress just before crystallization 
temperature, which we believe is caused by the start of localized crystallization of the phase change material. We observed relaxation in the residual stress of the GST225 thin film when annealed above the crystallization temperature. This relaxation is not present in the GST124 films, and the cause is not yet clear to us. The residual stress is highly dependent on the annealing history, we observed higher stress values if the film is annealed longer below the crystallization temperature.

The sheet resistance measured for the two compositions of GST shows one order of magnitude difference between the amorphous and crystalline state. Unlike the Young's modulus and residual stress, there is no sharp transition temperature. The resistance rather drops monotonously over a wide temperature range. This might be caused by the fact that we measure the sheet resistance of the phase change material directly on the semiconducting silicon substrate. 



\section{Chapter 8}

\section{Summary and conclusions}

The main goal of the work compiled in this thesis is to investigate thin films for integration in micro electromechanical systems (MEMS). The miniaturization of MEMS actuators and sensors without compromising their performance requires thin films of different active materials with specific properties. The properties of materials in thin film form differ from those in bulk, because of large surface to volume ratio, unique microstructure, constraints imposed by the substrate, etc.

The work deals with easy to fabricate single crystal silicon micro cantilever structures and capacitors as test devices to explore material properties in the thin films domain. Cantilevers are deposited with the thin films under investigation and capacitors were formed by sandwiching the active material between top and bottom electrodes. Identification of the sources of error and their quantification and reduction increases the reliability and accuracy of our characterization methods.

\subsection{Summary}

\subsubsection{Cantilevers}

The Young's modulus of thin films can be determined by deposition on a micronsized silicon cantilever and measuring the resonance frequency before and after deposition. The accuracy of the method depends strongly on the initial determination of the mechanical properties and dimensions of the cantilever. We discussed the orientation of the cantilever with respect to the silicon crystal, and the inevitable undercut of the cantilever caused by process inaccuracies. By finite element modelling we show that the Young's modulus should be used instead of the analytical plate modulus approximation for the effective Young's modulus of silicon cantilevers used in this work for both the $\langle 100\rangle$ and $<110\rangle$ crystal orientation. Cantilever undercut can be corrected by variation of the cantilever length. 


\subsubsection{Anisotropic Young's modulus}

A large part of this work deals with $\mathrm{PbZr}_{0.52} \mathrm{Ti}_{0.48} \mathrm{O}_{3}$ (PZT) thin films deposited by pulsed laser deposition (PLD). These films grow epitaxially on silicon and therefore have excellent piezoelectric properties which make them outstanding candidates for application in MEMS devices.

We determined the Young's modulus of epitaxially grown PZT on microcantilevers by measuring the difference in cantilever resonance frequency before and after deposition. By carefully optimizing the accuracy of this technique, we were able to show that the Young's modulus of PZT thin films deposited on silicon is dependent on the in-plane orientation, by using cantilevers oriented along the $<110\rangle$ and $<100\rangle$ silicon directions. Deposition of thin films on cantilevers affects their flexural rigidity and increases their mass, which results in a change in the resonance frequency. An analytical relation was developed to determine the effective Young's modulus of PZT thin films from the shift in the resonance frequency of the cantilevers, measured both before and after the deposition. We took extra care to eliminate the errors in the determination of the effective Young's modulus, by accurately determining the dimensions of the cantilevers and by measuring many cantilevers of different lengths. Over-etching during the release of cantilevers from the handle wafer caused an undercut. Since this undercut can not be avoided, an effective length was determined and used in the calculations. The Young's modulus of PZT, deposited by PLD, was determined to be $113.5 \mathrm{GPa}$ with a standard error of $\pm 1.5 \mathrm{GPa}$ for the $<110>$ crystal direction of silicon. For the $<100\rangle$ silicon direction, we measured 103.5 $\mathrm{GPa}$ with a standard error of $\pm 1.9 \mathrm{GPa}$.

\subsubsection{Compositional dependence}

A strong dependence of composition on the mechanical and piezoelectric properties of $\mathrm{Pb}\left(\mathrm{Zr}_{x} \mathrm{Ti}_{1-x}\right) \mathrm{O}_{3}$ thin films fabricated by PLD on silicon substrates with a (110) preferred orientation was observed. Vibrometric measurements on capacitors showed that the effective longitudinal piezoelectric coefficient $\left(d_{33, \mathrm{f}}\right)$ of $250 \mathrm{~nm}$ thick PZT films has a maximum value of $93 \mathrm{pm} / \mathrm{V}$ for a composition of $x=0.52$. The compositional dependence of the Young's modulus shows an increase in value for the Zr-rich compositions, which is in agreement with the trend observed in their bulk ceramic counterparts. From the obtained dielectric constant and $d_{33}$, f, we show that the calculated coupling coefficients of the PLD-PZT thin films have higher values for most of the compositions than their ceramic counterparts.

We also report on the compositional dependence of the in-plane Young's modulus of $\mathrm{Pb}\left(\mathrm{Zr}_{x} \mathrm{Ti}_{1-x}\right) \mathrm{O}_{3}$ thin films with (oo1) preferred orientation. Epitaxial PZT thin films were deposited on silicon cantilevers through PLD with compositions ranging from $x=0.2$ to o.8. A higher Young's modulus of the PZT thin films was observed in the $\langle 100\rangle$ silicon direction for all the composition, with the largest variation in Young's modulus of $46 \%$ found at a composition of $x=0.2$. Consistent with bulk PZT ceramics, the minimum in the Young's modulus was found at $x=0.52$ for the $<110\rangle$ silicon direction. The value as well as the directional aniso- 
tropy in the Young's modulus of the (110) oriented films was found to be smaller than in the (001) orientation. From the higher coupling coefficient of (110) oriented $\mathrm{Pb}\left(\mathrm{Zr}_{0.52} \mathrm{Ti}_{0.48}\right) \mathrm{O}_{3}$ thin films we conclude that these are more appropriate for application in transducers.

\subsubsection{Residual stress in PZT thin films}

We investigated the residual stress in $\mathrm{Pb}\left(\mathrm{Zr}_{x} \mathrm{Ti}_{1-x}\right) \mathrm{O}_{3}$ (PZT) thin films with a (110) preferred orientation and a composition $x$ ranging from 0.2 to 0.8 . The films are grown by pulsed laser deposition on silicon cantilevers aligned along the $<110>$ and $<100>$ silicon crystal directions. Static bending of the cantilevers are used to determine the residual stress. The residual stress is tensile and shows a sharp increase from about 50 to $250 \mathrm{MPa}$ at a composition of $x=0.2$ to 0.4 . These mechanical parameters clearly depend on the cantilever orientation with respect to the silicon crystal, which we suspect to be linked to the epitaxial growth of the films. The variation in stress with composition can be explained by the difference in thermal expansion between silicon and PZT, if we assume an intrinsic stress of 200-300 MPa to be already present immediately after deposition. Strain calculated from $\mathrm{x}$-ray diffraction data leads to unreasonably high residual stress values, at least one order of magnitude higher than measured by cantilever bending.

\subsubsection{Investigation of phase-change thin films}

Next to the PZT material, we investigated phase change thin films. The Young's modulus in these films increases drastically upon annealing. This is both interesting for demonstration of our method, and from an application point of view. The Young's modulus, residual stress and sheet resistance of phase change thin films $\left(\mathrm{Ge}_{1} \mathrm{Sb}_{2} \mathrm{Te}_{4}\right.$ and $\left.\mathrm{Ge}_{2} \mathrm{Sb}_{2} \mathrm{Te}_{5}\right)$ deposited on microcantilevers were determined as a function of annealing temperature. The Young's modulus and the tensile residual stress show a sharp increase after annealing above the crystallization temperature. The sheet resistance shows a monotonous decrease with annealing temperature. The residual stress above the crystallization temperature is strongly dependent on the annealing history. The $\mathrm{Ge}_{2} \mathrm{Sb}_{2} \mathrm{Te}_{5}$ thin film shows stress relaxation above the crystallization temperature, an effect which is not observed for $\mathrm{Ge}_{1} \mathrm{Sb}_{2} \mathrm{Te}_{4}$.

\subsection{Conclusions}

\subsubsection{Determination of Young's modulus}

The Young's modulus of thin films can be reliably determined from a resonance frequency shift of microcantilevers on which the films are deposited. A high accuracy can be obtained a) by taking the difference in the resonance frequency before and after the deposition of the thin films, b) by taking into account the effective undercut length and thickness of the individual cantilevers, c) by measuring many cantilevers, and d) by applying a rigorous error analysis. 
To match this high accuracy, a precise value is needed for the effective Young's modulus of the cantilevers, taking into account the anisotropic Young's modulus of silicon and clamping of the cantilever at its base. This value of the effective Young's modulus must therefore be determined by 3 -D FE simulations.

\subsubsection{PZT piezoelectric thin films}

Epitaxially grown PZT, deposited by pulsed laser deposition, shows excellent piezoelectric and mechanical properties, which can be exploited in MEMS sensors and actuators. For instance, its higher Young's modulus results in a higher coupling coefficient in comparison to bulk PZT ceramic in clamped conditions. The results reported in this thesis facilitate the choice of the correct composition, based for instance on an optimization of figures of merit specific for the intended application.

The Young's modulus of the PZT thin films is found to be anisotropic and strongly dependent on composition. The anisotropy is lower in PZT thin films with (110) orientation compared to films with (oo1) orientation.

PZT thin films with a (110) orientation have a higher coupling factor than films with a (001) orientation. Since (110) films also have a lower anisotropy, they appear to be more suitable for MEMS applications.

Residual stress can be accurately determined from cantilever curvature. This technique is to be preferred over X-ray diffraction, which gives unlikely high values. The residual stress is found to be tensile for all compositions of PLD-PZT investigated in this thesis. It is comparable to sputter deposited films and higher than sol-gel PZT.

\subsubsection{GeTeSb phase change thin films}

We applied the Young's modulus technique to GeTeSb based phase change thin films, because the Young's modulus of the film on the cantilever can be changed by heating, without any change in its mass. Indeed we observed a strong increase in the Young's modulus and residual stress at crystallization temperature.

Calculations show that the slight reduction in the film thickness due to crystallization can be neglected.

We observed a strong dependence of the residual stress on the annealing history before the crystallization temperature, which should be taken into consideration when designing the structures using GST thin films. 


\section{Appendices}





\section{Appendix A}

\section{Cantilever process flow}

Single crystal silicon cantilevers have been fabricated. In this appendix the process flow of the cantilevers with a length direction aligned parallel to the $\langle 110\rangle$ and $<100>$ crystal directions of silicon is given.

Table A.1: Process steps

\begin{tabular}{|c|c|c|}
\hline Step & Process & Comment \\
\hline 1a & $\begin{array}{l}\text { Substrate selection }- \text { Silicon }<\mathbf{1 0 0}>\text { OSP } \\
\text { Orientation: }<100> \\
\text { Diameter: } 100 \mathrm{~mm} \\
\text { Thickness: } 525 \mu \mathrm{m} \pm 25 \mu \mathrm{m} \\
\text { Polished: Single side } \\
\text { Resistivity: } 5-10 \Omega \mathrm{cm} \text { (p-doped) }\end{array}$ & $\begin{array}{l}\text { o6 wafers } \\
\text { (dummies) }\end{array}$ \\
\hline $1 \mathrm{~b}$ & $\begin{array}{l}\text { Substrate selection }- \text { SOI }<\mathbf{1 0 0}>\text { DSP } \\
\text { Orientation: }<100> \\
\text { Diameter: } 100 \mathrm{~mm} \\
\text { Device layer thickness: } 3 \mu \mathrm{m} \pm 0.5 \mu \mathrm{m} \\
\text { Device layer resistivity: } 0.01-0.02 \Omega \mathrm{cm} \text { (p-doped) } \\
\text { Handle wafer thickness: } 380 \mu \mathrm{m} \pm 5 \mu \mathrm{m} \\
\text { Handle wafer resistivity: } 1-5 \Omega \mathrm{cm} \text { (p-doped) } \\
\text { BOX thickness: } 0.5 \mu \mathrm{m}+/-5 \%\end{array}$ & $\begin{array}{l}\text { o6 wafers } \\
\text { (process wafers) }\end{array}$ \\
\hline 2 & $\begin{array}{l}\text { Wafer thickness measurement } \\
\text { Veeco Dektak } 8\end{array}$ & SOI wafers \\
\hline 3 & $\begin{array}{l}\text { Wafer curvature measurement } \\
\text { HeidenHahn }\end{array}$ & SOI wafers \\
\hline
\end{tabular}


Table A.1 Process steps (continued)

\begin{tabular}{|c|c|c|}
\hline Step & Process & Comment \\
\hline 4 & $\begin{array}{l}\text { Standard cleaning } \\
\mathrm{HNO}_{3} \text { (99\%) Selectipur: MERCK } \\
\mathrm{HNO}_{3}(69 \%) \text { VLSI: } \mathrm{MERCK} \\
\text { - Beaker 1: fumic } \mathrm{HNO}_{3}(99 \%), 5 \mathrm{~min} \\
\text { - Beaker 2: fumic } \mathrm{HNO}_{3}(99 \%), 5 \mathrm{~min} \\
\text { - Quick Dump Rinse }>10.5 \Omega \mathrm{m} \\
\text { Two cycles of first } 3 \text { steps } \\
\text { - fill bath, } 5 \mathrm{~s} \\
\text { - spray dump, } 15 \mathrm{~s} \\
\text { - spray fill, } 90 \mathrm{~s} \\
\text { - end fill, } 200 \mathrm{~s} \\
\text { - Beaker 3: } 95^{\circ} \mathrm{C} \text { HNO } 3(69 \%), 10 \mathrm{~min} \\
\text { - Quick Dump Rinse }>10.5 \Omega \mathrm{m} \\
\text { Two cycles of first } 3 \text { steps } \\
\text { - fill bath, } 5 \mathrm{~s} \\
\text { - spray dump, } 15 \mathrm{~s} \\
\text { - spray fill, } 90 \mathrm{~s} \\
\text { - end fill, } 200 \mathrm{~s} \\
\text { - Spin drying } \\
\text { Semitool PSC101 } \\
\text { - rinse in DI: } 600 \mathrm{rpm}, 30 \mathrm{~s} \\
\text { - rinse in DI: } 600 \mathrm{rpm}, 12 \mathrm{M} \Omega \\
\text { - N } 2 \text { purge: } 600 \mathrm{rpm}, 30 \mathrm{~s} \\
\text { - drying: } 1600 \mathrm{rpm}, 150 \mathrm{~s}\end{array}$ & \\
\hline 5 & $\begin{array}{l}\text { Ellipsometer Measurement } \\
\text { Plasmos Ellipsometer }\end{array}$ & $\begin{array}{l}\mathrm{SiO}_{2} \text { thickness } \\
\text { on back side }\end{array}$ \\
\hline 6 & $\begin{array}{l}\text { Etching BHF (1:7) } \mathrm{SiO}_{2} \\
\mathrm{HF} / \mathrm{NH}_{4} \mathrm{~F}(1: 7) \text { VLSI: BASF } \\
\text { - time: } 10 \mathrm{~min} \\
\text { - Quick Dump Rinse }>10.5 \Omega \mathrm{m} \\
\text { Two cycles of first } 3 \text { steps } \\
\text { - fill bath, } 5 \mathrm{~s} \\
\text { - spray dump, } 15 \mathrm{~s} \\
\text { - spray fill, } 90 \mathrm{~s} \\
\text { - end fill, } 200 \mathrm{~s} \\
\text { - Spin drying } \\
\text { Semitool PSC101 } \\
\text { - rinse in DI: } 600 \mathrm{rpm}, 30 \mathrm{~s} \\
\text { - rinse in DI: 6oo rpm, } 12 \mathrm{M} \Omega \\
\text { - } \mathrm{N}_{2} \text { purge: } 600 \mathrm{rpm}, 30 \mathrm{~s} \\
\text { - drying: } 1600 \mathrm{rpm}, 150 \mathrm{~s}\end{array}$ & Time: $10 \mathrm{~min}$ \\
\hline
\end{tabular}


Table A.1 Process steps (continued)

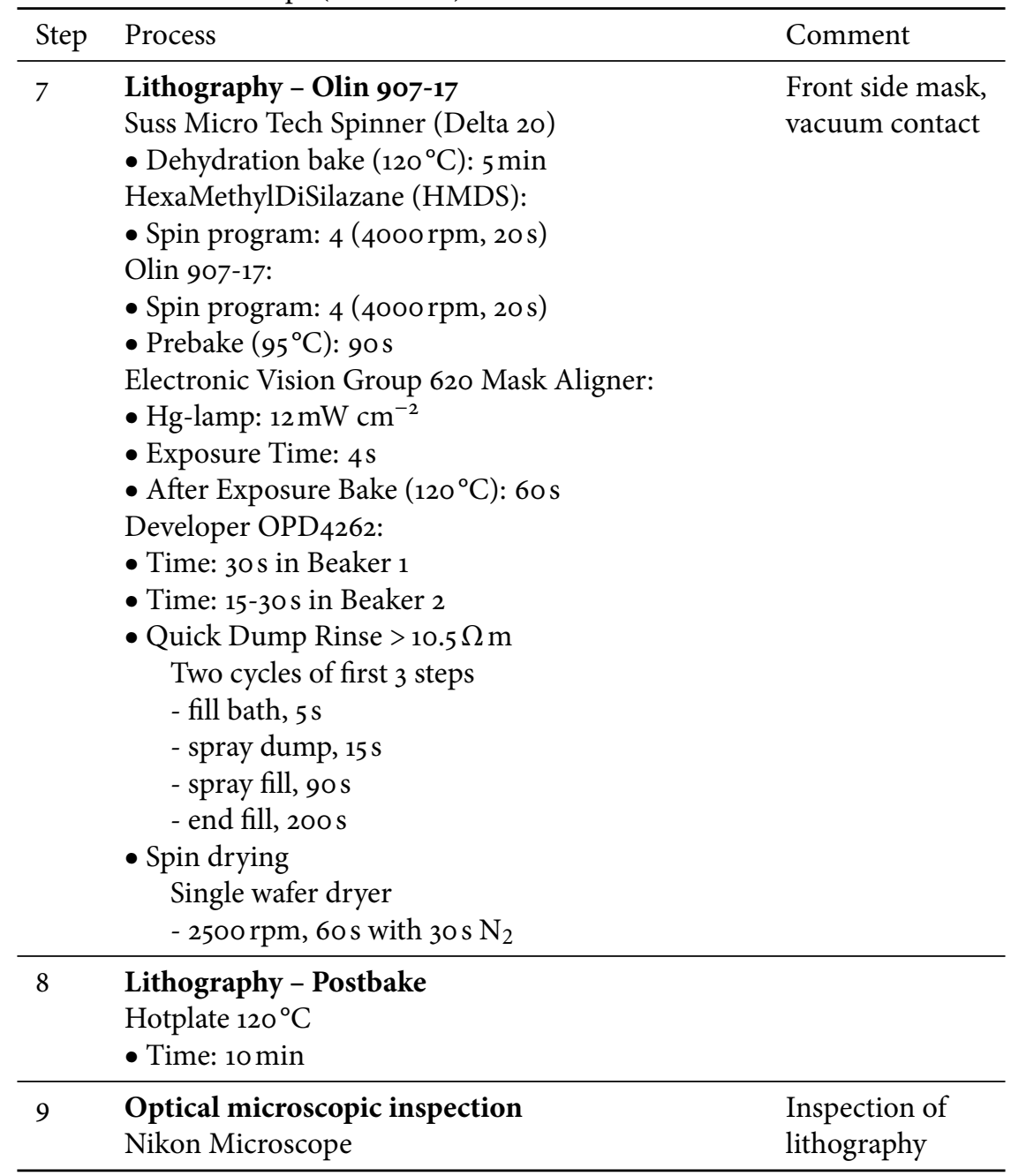


Table A.1 Process steps (continued)

\begin{tabular}{llr}
\hline Step & Process & \\
\hline 10 & Plasma etching of Si: Bosch-ADIX \\
& Adixen SE & \\
Application: Etching of device layer & \\
Note: The gas flow is optimised for the mask & & \\
\hline Parameters & Etch & Deposition \\
\hline Gas & $\mathrm{SF}_{6}$ & $\mathrm{C}_{4} \mathrm{~F}_{8}$ \\
Flow (sccm) & 300 & 150 \\
Time (s) & 7 & 2 \\
Priority & 2 & 1 \\
APC (\%) & 25 & 25 \\
ICP (Watt) & 1800 & 1800 \\
CCP (Watt [pulsed LF]) & 80 & 80 \\
on/off (msec) & $10 / 90$ & $10 / 90$ \\
He (mbar) & 10 & 10 \\
SH (mm) & 200 & 200 \\
Electrode temp. $\left({ }^{\circ} \mathrm{C}\right)$ & 10 & 10 \\
\hline & &
\end{tabular}

$11 \quad$ Optical microscopic inspection

Olympus/Leica Microscope

12 Surface profile measurement

Veeco Dektak 8

13 Stripping of Olin PR by oxygen plasma Tepla $300 \quad 10 \mathrm{~min}$

Barrel Etcher $(2.45 \mathrm{GHz})$

Ultra clean system only (no metals except $\mathrm{Al}$ )

- $\mathrm{O}_{2}$ flow: $1000 \mathrm{sccm}$

- Power: $1000 \mathrm{~W}$

- Pressure: 1 mbar 
Table A.1 Process steps (continued)

\begin{tabular}{|c|c|c|}
\hline Step & Process & Comment \\
\hline 14 & $\begin{array}{l}\text { Lithography - Polyimide Pyralin (PI-2611) } \\
\text { Suss Micro Tech Spinner (Delta } 20) \\
\text { Application: Protect cantilevers and } \\
\text { prevent He leakage } \\
\text { - Dehydration bake }\left(120^{\circ} \mathrm{C}\right): 5 \mathrm{~min} \\
\text { - Spin program: custom }(500 \mathrm{rpm}, 5 \mathrm{~s} \text { and } \\
4000 \text { rpm, } 30 \mathrm{~s}) \\
\text { - Softbake }\left(120^{\circ} \mathrm{C}\right): 60 \mathrm{~s} \\
\text { Curing polyimide: } \\
\text { - Heraeus resist bake furnace }\left(200^{\circ} \mathrm{C}\right): 30 \mathrm{~min} \\
\text { - Atmospheric environment } \\
\text { Curing polyimide in } \mathrm{N}_{2}: \\
\text { - Heraeus vacuum furnace }\left(350^{\circ} \mathrm{C}\right): 30 \mathrm{~min} \\
\text { - Nitrogen environment }(1 \mathrm{mbar})\end{array}$ & Front side \\
\hline 15 & $\begin{array}{l}\text { Surface profile measurement } \\
\text { Veeco Dektak } 8\end{array}$ & \\
\hline 16 & 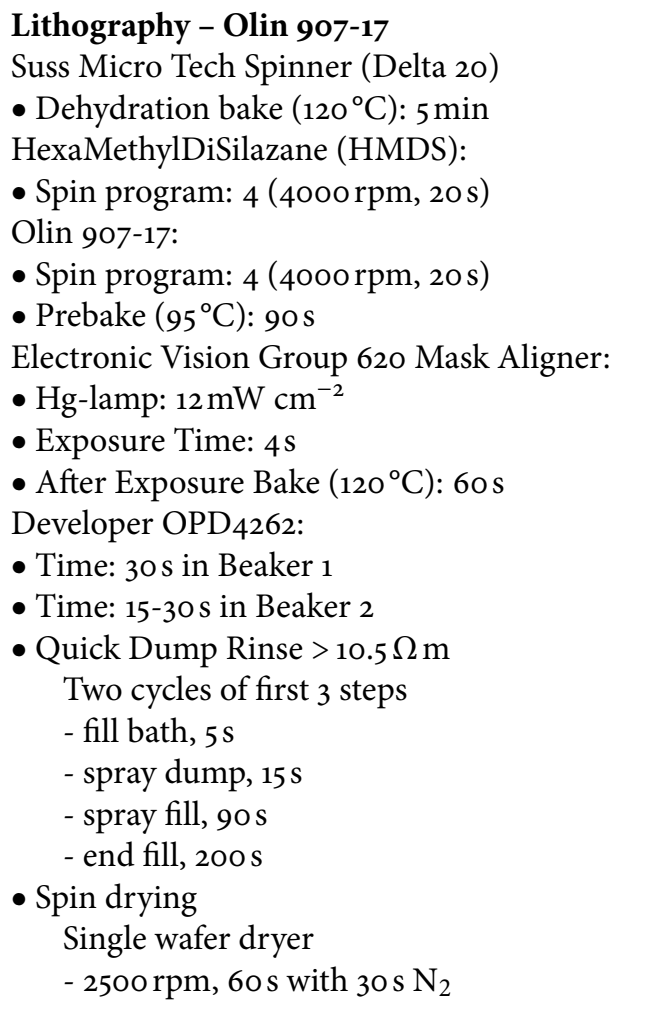 & $\begin{array}{l}\text { Back side mask, } \\
\text { vacuum contact }\end{array}$ \\
\hline
\end{tabular}


Table A.1 Process steps (continued)

\begin{tabular}{|c|c|c|c|}
\hline Step & \multicolumn{3}{|l|}{ Process } \\
\hline 17 & \multicolumn{3}{|c|}{$\begin{array}{l}\text { Lithography - Postbake } \\
\text { Hotplate } 120^{\circ} \mathrm{C} \\
\text { - Time: } 60 \mathrm{~min}\end{array}$} \\
\hline 18 & \multicolumn{3}{|c|}{$\begin{array}{l}\text { Optical microscopic inspection } \\
\text { Nikon Microscope }\end{array}$} \\
\hline 19 & \multicolumn{3}{|c|}{$\begin{array}{l}\text { Plasma etching of Si: A-pulsed-CHF } \\
\text { Adixen SE } \\
\text { Application: Etching through handle wafer } \\
\text { Note: The parameters are optimised for the }\end{array}$} \\
\hline & Parameters & Etch & Deposition \\
\hline & Gas & $\mathrm{SF}_{6}$ & $\mathrm{CHF}_{3}$ \\
\hline & Flow $(\mathrm{sccm})$ & 400 & 200 \\
\hline & Time (s) & 4 & 0.5 \\
\hline & Priority & 2 & 1 \\
\hline & $\operatorname{APC}(\%)$ & 15 & 15 \\
\hline & ICP (Watt) & 2500 & 2500 \\
\hline & CCP (Watt [pulsed LF]) & nvt & 20 \\
\hline & on/off (msec) & nvt & $25 / 175$ \\
\hline & $\mathrm{He}$ (mbar) & 10 & 10 \\
\hline & $\mathrm{SH}(\mathrm{mm})$ & 110 & 110 \\
\hline & Electrode temp. $\left({ }^{\circ} \mathrm{C}\right)$ & -110 & -110 \\
\hline
\end{tabular}

$20 \quad$ Optical microscopic inspection

Olympus/Leica Microscope

\begin{tabular}{|c|c|c|}
\hline 21 & $\begin{array}{l}\text { Stripping by oxygen plasma Tepla } 300 \\
\text { Photoresist and Pyralin removal } \\
\text { Barrel Etcher }(2.45 \mathrm{GHz}) \\
\text { Ultra clean system only (no metals except } \mathrm{Al} \text { ) } \\
\text { - } \mathrm{O}_{2} \text { flow: } 1000 \mathrm{sccm} \\
\text { - Power: } 800 \mathrm{~W} \\
\text { - Pressure: } 1 \text { mbar }\end{array}$ & $60 \mathrm{~min}$ \\
\hline 22 & $\begin{array}{l}\text { Vapour HF etching of } \mathrm{SiO}_{2} \\
\text { Idonius Vapor } \mathrm{HF} \text { Tool } \\
\text { - Temperature: } 35^{\circ} \mathrm{C} \\
\text { - Quick Dump Rinse }>10.5 \Omega \mathrm{m} \\
\text { - cascade rinsing: continuous flow } \\
\text { - Spin drying } \\
\text { Single wafer dryer } \\
\text { - 120o rpm, } 180 \mathrm{~s}\end{array}$ & Time: $7 \mathrm{~min}$ \\
\hline
\end{tabular}


Table A.1 Process steps (continued)

\begin{tabular}{lll}
\hline Step & Process & Comment \\
\hline 23 & SEM Inspection & Inspect \\
& JEOL $_{5610}$ & underetch \\
\hline
\end{tabular}





\section{Appendix B}

\section{Modified fabrication process document}

The modified cantilever fabrication process used $\mathrm{C}_{4} \mathrm{~F}_{8}$ gas in the recipe for the wafer through DRIE from the back side of the wafers. $\mathrm{C}_{4} \mathrm{~F}_{8}$ gas instead of the $\mathrm{CHF}_{3}$ gas permits the wafer through etching at a higher temperature of $-40^{\circ} \mathrm{C}$ compared to the $-110^{\circ} \mathrm{C}$ required for A-pulsed- $\mathrm{CHF}_{3}$ DRIE process. Higher temperature of $-40^{\circ} \mathrm{C}$ enables us to use the DuPont MX-5020 foil as protective coating on the front side of the cantilevers during back side etching. DuPont MX-5020 is easy to process and less time consuming as compared to the polyimide pyralin coating and curing.

Table B.1: Process steps

\begin{tabular}{lll}
\hline Step & Process & Comment \\
\hline 1a & Substrate selection - Silicon $<\mathbf{1 0 0}>$ OSP & $\begin{array}{l}\text { o8 wafers } \\
\text { (dummies) }\end{array}$ \\
& Orientation: $<100>$ & \\
& Diameter: $100 \mathrm{~mm}$ & \\
& Thickness: $525 \mu \mathrm{m} \pm 25 \mu \mathrm{m}$ & \\
& Polished: Single side & \\
& Resistivity: $5-10 \Omega \mathrm{cm}(\mathrm{p}$-doped) & o8 wafers \\
\hline $\mathrm{b}$ (process wafers) & Substrate selection - SOI $<\mathbf{1 0 0}>$ DSP & \\
& Orientation: $<100>$ & \\
& Diameter: 100 mm & \\
& Device layer thickness: $3 \mu \mathrm{m} \pm 0.5 \mu \mathrm{m}$ & \\
& Device layer resistivity: $0.01-0.02 \Omega \mathrm{cm}$ (p-doped) & \\
& Handle wafer thickness: $380 \mu \mathrm{m} \pm 5 \mu \mathrm{m}$ & \\
& Handle wafer resistivity: $1-5 \Omega \mathrm{cm}(\mathrm{p}$-doped) & \\
& BOX thickness: $0.5 \mu \mathrm{m}+/-5 \%$ &
\end{tabular}


Table B.1 Process steps (continued)

\begin{tabular}{|c|c|c|}
\hline Step & Process & Comment \\
\hline 2 & $\begin{array}{l}\text { Wafer thickness measurement } \\
\text { Veeco Dektak } 8\end{array}$ & SOI wafers \\
\hline 3 & $\begin{array}{l}\text { Wafer curvature measurement } \\
\text { HeidenHahn }\end{array}$ & SOI wafers \\
\hline 4 & $\begin{array}{l}\text { Standard cleaning } \\
\mathrm{HNO}_{3} \text { (99\%) Selectipur: MERCK } \\
\mathrm{HNO}_{3}(69 \%) \text { VLSI: } \mathrm{MERCK} \\
\text { - Beaker 1: fumic } \mathrm{HNO}_{3}(99 \%), 5 \mathrm{~min} \\
\text { - Beaker 2: fumic } \mathrm{HNO}_{3}(99 \%), 5 \mathrm{~min} \\
\text { - Quick Dump Rinse }>10.5 \Omega \mathrm{m} \\
2 \text { cycles of first } 3 \text { steps } \\
\text { - fill bath, } 5 \mathrm{~s} \\
\text { - spray dump, } 15 \mathrm{~s} \\
\text { - spray fill, } 90 \mathrm{o} \\
\text { - end fill, } 200 \mathrm{~s} \\
\text { - Beaker 3: } 95^{\circ} \mathrm{C} \mathrm{HNO},(69 \%), 10 \mathrm{~min} \\
\text { - Quick Dump Rinse }>10.5 \Omega \mathrm{m} \\
\text { Two cycles of first } 3 \mathrm{steps} \\
\text { - fill bath, } 5 \mathrm{~s} \\
\text { - spray dump, } 15 \mathrm{~s} \\
\text { - spray fill, } 90 \mathrm{~s} \\
\text { - end fill, } 200 \mathrm{~s} \\
\text { - Spin drying } \\
\text { Semitool PSC101 } \\
\text { - rinse in DI: } 600 \mathrm{rpm}, 30 \mathrm{~s} \\
\text { - rinse in DI: } 600 \mathrm{rpm}, 12 \mathrm{M} \Omega \\
\text { - N } \mathrm{N}_{2} \text { purge: } 600 \mathrm{rpm}, 30 \mathrm{~s} \\
\text { - drying: } 1600 \mathrm{rpm}, 150 \mathrm{~s}\end{array}$ & \\
\hline
\end{tabular}


Table B.1 Process steps (continued)

\begin{tabular}{|c|c|c|}
\hline Step & Process & Comment \\
\hline 5 & 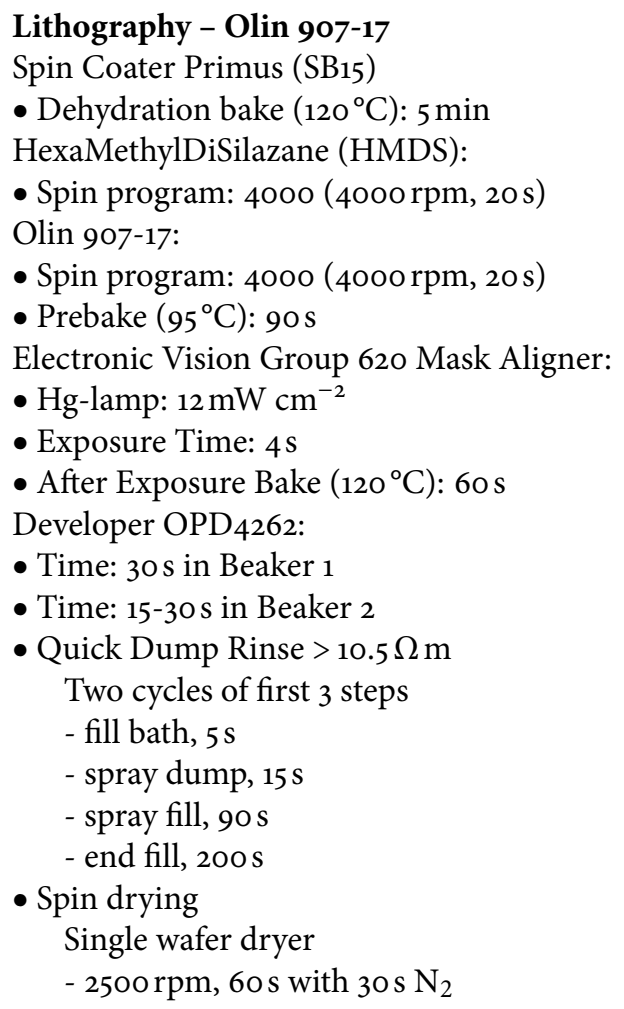 & $\begin{array}{l}\text { Front side mask, } \\
\text { vacuum contact }\end{array}$ \\
\hline 6 & $\begin{array}{l}\text { Lithography - Postbake } \\
\text { Hotplate } 120^{\circ} \mathrm{C} \\
\text { - Time: } 10 \mathrm{~min}\end{array}$ & \\
\hline 7 & $\begin{array}{l}\text { Optical microscopic inspection } \\
\text { Nikon Microscope }\end{array}$ & $\begin{array}{l}\text { Inspection of } \\
\text { lithography }\end{array}$ \\
\hline
\end{tabular}


Table B.1 Process steps (continued)

\begin{tabular}{|c|c|c|c|c|}
\hline Step & \multicolumn{3}{|l|}{ Process } & Comment \\
\hline \multirow[t]{16}{*}{8} & \multirow{4}{*}{\multicolumn{3}{|c|}{$\begin{array}{l}\text { Plasma etching of Si: Bosch-ADIX } \\
\text { Adixen SE } \\
\text { Application: Etching of device layer } \\
\text { Note: The gas flow is optimised for the mask }\end{array}$}} & \multirow{16}{*}{$\begin{array}{l}\text { Etch depth } 3 \mu \mathrm{m} \\
\text { Time: } 32 \mathrm{~s}\end{array}$} \\
\hline & & & & \\
\hline & & & & \\
\hline & & & & \\
\hline & Parameters & Etch & Deposition & \\
\hline & Gas & $\mathrm{SF}_{6}$ & $\mathrm{C}_{4} \mathrm{~F}_{8}$ & \\
\hline & Flow $(\mathrm{sccm})$ & 300 & 150 & \\
\hline & Time (s) & 7 & 2 & \\
\hline & Priority & 2 & 1 & \\
\hline & $\operatorname{APC}(\%)$ & 25 & 25 & \\
\hline & ICP (Watt) & 1800 & 1800 & \\
\hline & CCP (Watt [pulsed LF]) & 80 & 80 & \\
\hline & on/off (msec) & $10 / 90$ & $10 / 90$ & \\
\hline & $\mathrm{He}$ (mbar) & 10 & 10 & \\
\hline & $\mathrm{SH}(\mathrm{mm})$ & 200 & 200 & \\
\hline & Electrode temp. $\left({ }^{\circ} \mathrm{C}\right)$ & 10 & 10 & \\
\hline 9 & \multirow{2}{*}{\multicolumn{4}{|c|}{$\begin{array}{l}\text { Optical microscopic inspection } \\
\text { Olympus/Leica Microscope }\end{array}$}} \\
\hline & & & & \\
\hline 10 & \multirow{2}{*}{\multicolumn{4}{|c|}{$\begin{array}{l}\text { Surface profile measurement } \\
\text { Veeco Dektak } 8\end{array}$}} \\
\hline & & & & \\
\hline
\end{tabular}


Table B.1 Process steps (continued)

\begin{tabular}{|c|c|c|}
\hline Step & Process & Comment \\
\hline 11 & 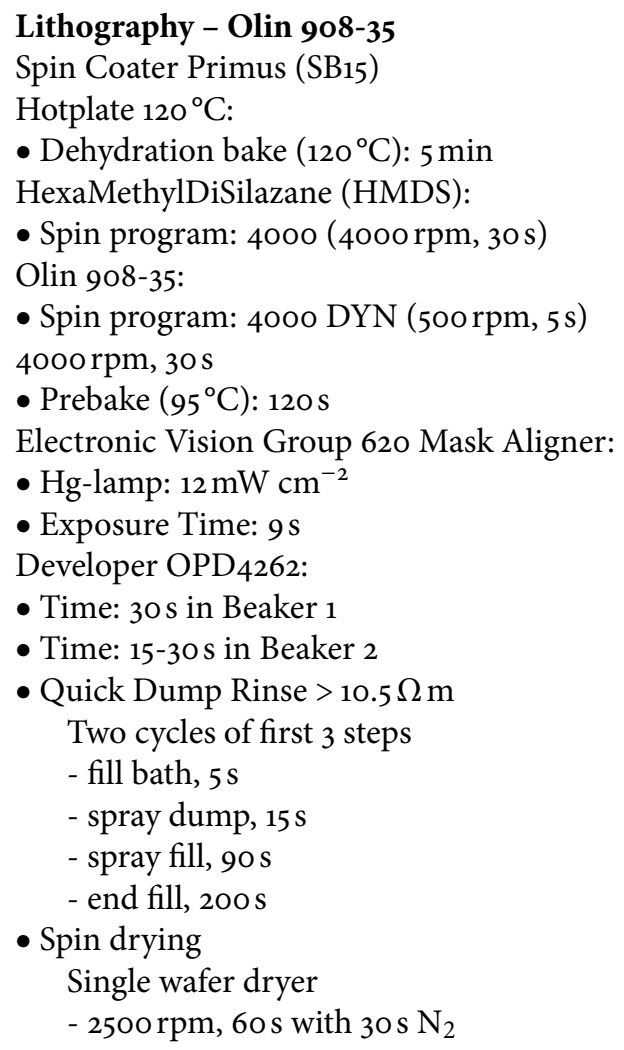 & $\begin{array}{l}\text { Back side mask } \\
\text { hard contact }\end{array}$ \\
\hline 12 & $\begin{array}{l}\text { Lithography - Postbake } \\
\text { Hotplate } 120^{\circ} \mathrm{C} \\
\text { - Time: } 120 \mathrm{~min}\end{array}$ & \\
\hline 13 & $\begin{array}{l}\text { Optical microscopic inspection } \\
\text { Nikon Microscope }\end{array}$ & $\begin{array}{l}\text { Inspection of } \\
\text { lithography }\end{array}$ \\
\hline 14 & $\begin{array}{l}\text { Front side protection } \\
\text { DuPont } \mathrm{MX}_{5020}, 20 \mu \mathrm{m} \text { thick } \\
\text { Laminator settings: } \\
\text { - Temperature: } 90^{\circ} \mathrm{C} \\
\text { - Speed: } 2\end{array}$ & \\
\hline
\end{tabular}


Table B.1 Process steps (continued)

\begin{tabular}{|c|c|c|c|c|}
\hline Step & \multicolumn{3}{|l|}{ Process } & Comment \\
\hline \multirow{16}{*}{15} & \multirow{4}{*}{\multicolumn{3}{|c|}{$\begin{array}{l}\text { Plasma etching of Si: Pulsed- } \mathbf{C}_{4} \mathbf{F}_{8} \\
\text { Adixen SE } \\
\text { Application: Etching through handle wafer } \\
\text { Note: The parameters are optimised for the mask }\end{array}$}} & \multirow{16}{*}{$\begin{array}{l}\text { Etch depth } \\
380 \mu \mathrm{m} \\
\text { Time: } 24 \mathrm{~min}\end{array}$} \\
\hline & & & & \\
\hline & & & & \\
\hline & & & & \\
\hline & Parameters & Etch & Deposition & \\
\hline & Gas & $\mathrm{SF}_{6}$ & $\mathrm{C}_{4} \mathrm{~F}_{8}$ & \\
\hline & Flow (sccm) & 400 & 35 & \\
\hline & Time (s) & 4 & 0.5 & \\
\hline & Priority & 2 & 1 & \\
\hline & APC (\%) & 15 & 15 & \\
\hline & ICP (Watt) & 2500 & 2500 & \\
\hline & CCP (Watt [pulsed LF]) & nvt & 20 & \\
\hline & on/off (msec) & nvt & $20 / 180$ & \\
\hline & He (mbar) & 10 & 10 & \\
\hline & SH (mm) & 110 & 110 & \\
\hline & Electrode temp. $\left({ }^{\circ} \mathrm{C}\right)$ & -40 & -40 & \\
\hline 16 & \multicolumn{4}{|c|}{ Optical microscopic inspection } \\
\hline & \multicolumn{4}{|c|}{ Olympus/Leica Microscope } \\
\hline 17 & \multirow{6}{*}{\multicolumn{4}{|c|}{$\begin{array}{l}\text { Stripping of DuPont MX } \mathbf{5 0 2 0} \text { - Acetone VLSI } \\
\text { Acetone VLSI: Selectipur, } 30 \mathrm{~min} \\
\text { - IPA (2- propanol-VLSI) rinsing } \\
\text { - Spin drying } \\
\text { Single wafer dryer } \\
\text { - } 1200 \text { rpm, } 180 \mathrm{~s}\end{array}$}} \\
\hline & & & & \\
\hline & & & & \\
\hline & & & & \\
\hline & & & & \\
\hline & & & & \\
\hline 18 & \multirow{7}{*}{\multicolumn{4}{|c|}{$\begin{array}{l}\text { Etching BHF (1:7) } \mathrm{SiO}_{2} \\
\mathrm{HF} / \mathrm{NH}_{4} \mathrm{~F}(1: 7) \text { VLSI: BASF } \\
\text { - Quick Dump Rinse }>10.5 \Omega \mathrm{m} \\
\text { - cascade rinsing: continuous flow } \\
\text { - Spin drying } \\
\quad \text { Single wafer dryer } \\
\text { - 120o rpm, } 180 \mathrm{~s}\end{array}$}} \\
\hline & & & & \\
\hline & & & & \\
\hline & & & & \\
\hline & & & & \\
\hline & & & & \\
\hline & & & & \\
\hline
\end{tabular}


Table B.1 Process steps (continued)

\begin{tabular}{lll}
\hline Step & Process & Comment \\
\hline 19 & Stripping by oxygen plasma Tepla 300 & 60 min \\
& Photoresist removal & \\
& Barrel Etcher $(2.45 \mathrm{GHz})$ & \\
& Ultra clean system only (no metals except $\mathrm{Al})$ & \\
& $\bullet$ O flow: $1000 \mathrm{sccm}$ & \\
& • Power: $800 \mathrm{~W}$ & \\
& • Pressure: $1 \mathrm{mbar}$ & Inspect \\
20 & SEM Inspection & underetch \\
\hline
\end{tabular}




\section{Bibliography}

Agrawal R, Espinosa H D, 2009

"Multiscale experiments: State of the art and remaining challenges"

J. Eng. Mater. Technol. 131, pp. 0412081-04120815, doi:10.1115/1.3183782

Anguita J, Briones F, 1998

" $\mathrm{HF} / \mathrm{H}_{2} \mathrm{O}$ vapor etching of $\mathrm{SiO}_{2}$ sacrificial layer for large-area surface-micromachined membranes"

Sens. Actuators A 64, pp. 247-251, doi:10.1016/S0924-4247(97)01628-2

Babaei Gavan K, van der Drift E W J M, Venstra W J, Zuiddam M R, van der Zant H S J, 2009

"Effect of undercut on the resonant behaviour of silicon nitride cantilevers"

J. Micromech. Microeng. 19, p. art. no. 035003, doi:10.1088/0960-1317/19/3/035003

Beeby S P, Tudor M J, White N M, 2006

"Energy harvesting vibration sources for microsystems applications"

Meas. Sci. Technol. 17, pp. R175-R195, doi:10.1088/0957-0233/17/12/R01

Berfield T A, Ong R J, Payne D A, Sottos N R, 2007

"Residual stress effects on piezoelectric response of sol-gel derived lead zirconate titanate thin films"

J. Appl. Phys. 101, p. 024102, doi:10.1063/1.2422778

Bhaskaran H, Li M, Garcia-Sanchez D, Zhao P, Takeuchi I, Tang H X, 2011

"Active microcantilevers based on piezoresistive ferromagnetic thin films"

Appl. Phys. Lett. 98, p. 013502, doi:10.1063/1.3533390

Blachowicz T, Beghi M G, Güntherodt G, Beschoten B, Dieker H, Wuttig M, 2007

"Crystalline phases in the $\mathrm{GeSb}_{2} \mathrm{Te}_{4}$ alloy system: Phase transitions and elastic properties"

J. Appl. Phys. 102, p. 093519, doi:10.1063/1.2809355

Brantley W A, 1973

"Calculated elastic constants for stress problems associated with semiconductor devices"

J. Appl. Phys. 44, pp. 534-535, doi:10.1063/1.1661935

Brinkman E, 2011

Applied Piezo - The hidden use of piezo technology in applications all around us, Stichting Applied Piezo, Apeldoorn, The Netherlands

URL http://www. betase.nl/en/2011/

piezo-technology-in-applications-all-around-us /

Bronson J R, Pulskamp J S, Polcawich R G, Kroninger C M, Wetzel E D, 2009

"PZT mems actuated flapping wings for insect-inspired robotics"

In: Proc. 22nd IEEE Int. Conf. on Micro ElectroMechanical Systems, MEMS 2009, pp. 1047-1050, Sorrento, Italy, doi:10.1109/MEMSYS.2009.4805566 
Brookhuis R A, Lammerink T S J, Wiegerink R J, De Boer M J, Elwenspoek M C, 2011 "Force sensor for measuring power transfer between the human body and the environment" In: Proc. 16th International Solid-State Sensors, Actuators and Microsystems Conference, TRANSDUCERS'11, pp. 2042-2045, Beijing, doi:10.1109/TRANSDUCERS.2011.5969215

Bruchhaus R, Pitzer D, Primig R, Schreiter M, Wersing W, 1998 "PZT thin films grown by multi-target sputtering: Analysis of thin film stress" Integr. Ferroelectr. 21, pp. 461-467, doi:10.1080/10584589808202086

Bruchhaus R, Pitzer D, Schreiter M, Wersing W, 1999 "Optimized PZT thin films for pyroelectric IR detector arrays" J. Electroceram. 3, pp. 151-162, doi:10.1023/A:1009995126986

Burr G W, Breitwisch M J, Franceschini M, Garetto D, Gopalakrishnan K, Jackson B, Kurdi B, Lam C, Lastras L A, Padilla A, Rajendran B, Raoux S, Shenoy R S, 2010

"Phase change memory technology"

J. Vac. Sci. Technol. B 28, pp. 223-262, doi:10.1116/1.3301579

Carria E, Mio A M, Gibilisco S, Miritello M, Grimaldi M G, Rimini E, 2011

"Tuning the crystallization temperature of amorphous $\mathrm{Ge}_{2} \mathrm{Sb}_{2} \mathrm{Te}_{5}$ by $\mathrm{O}$ and $\mathrm{Si}$ recoil implantation" Electrochem. Solid-State Lett. 14, pp. H124-H127, doi:10.1149/1.3527941

Choi H S, Ding J L, Bandyopadhyay A, Anderson M J, Bose S, 2008 "Characterization and modeling of a piezoelectric micromachined ultrasonic transducer with a very large length/width aspect ratio"

J. Micromech. Microeng. 18, p. 025037, doi:10.1088/0960-1317/18/2/025037

Cleland A N, Pophristic M, Ferguson I, 2001

"Single-crystal aluminum nitride nanomechanical resonators"

Appl. Phys. Lett. 79, pp. 2070-2072, doi:10.1063/1.1396633

Corkovic S, Whatmore R W, Zhang Q, 2008

"Development of residual stress in sol-gel derived $\mathrm{Pb}(\mathrm{Zr}, \mathrm{Ti}) \mathrm{O}_{3}$ films: An experimental study" J. Appl. Phys. 103, p. 084101, doi:10.1063/1.2890142

Cui Q, Liu C, Zha X F, 2007

"Study on a piezoelectric micropump for the controlled drug delivery system" Microfluid. Nanofluid. 3, pp. 377-39o, doi:10.1007/s10404-006-0137-0

Dawber M, Rabe K M, Scott J F, 2005

"Physics of thin-film ferroelectric oxides"

Rev. Mod. Phys. 77, pp. 1083-1130, doi:10.1103/RevModPhys.77.1083

Dekkers M, Nguyen M D, Steenwelle R, te Riele P M, Blank D H A, Rijnders G, jul 2009 "Ferroelectric properties of epitaxial $\mathrm{Pb}(\mathrm{Zr}, \mathrm{Ti}) \mathrm{O}_{3}$ thin films on silicon by control of crystal orientation" Appl. Phys. Lett. 95, p. 012902, doi:10.1063/1.3163057

Delobelle P, Guillon O, Fribourg-Blanc E, Soyer C, Cattan E, Rèmiens D, 2004 "True Young modulus of $\mathrm{Pb}(\mathrm{Zr}, \mathrm{Ti}) \mathrm{O}_{3}$ films measured by nanoindentation" Appl. Phys. Lett. 85, pp. 5185-5187, doi:10.1063/1.1827331

Delobelle P, Fribourg-Blanc E, Rèmiens D, 2006 "Mechanical properties determined by nanoindentation tests of $\left[\mathrm{Pb}(\mathrm{Zr}, \mathrm{Ti}) \mathrm{O}_{3}\right]$ and $\left[\mathrm{Pb}\left(\mathrm{Mg}_{1 / 3} \mathrm{Nb}_{2 / 3}\right)_{1-x} \mathrm{Ti}_{x} \mathrm{O}_{3}\right]$ sputtered thin films"

Thin Solid Films 515, pp. 1385-1393, doi:10.1016/j.tsf.2006.03.062 
Deshpande M, Saggere L, 2007

"PZT thin films for low voltage actuation: Fabrication and characterization of the transverse piezoelectric coefficient"

Sens. Actuators A 135, pp. 690-699, doi:10.1016/j.sna.2006.07.022

Deslattes R D, Henins A, Bowman H A, Schoonover R M, Carroll C L, Barnes I L, Machlan L A, Moore L J, Shields W R, 1974

"Determination of the avogadro constant"

Phys. Rev. Lett. 33, pp. 463-466, doi:10.1103/PhysRevLett.33.463

Desu S B, Vijay D P, Ramanathan S, Bhatt H D, Tirumala S, 1999

"Stresses in sputtered $\mathrm{RuO}_{x}$ thin films"

Thin Solid Films 350, pp. 21-29, doi:10.1016/S0040-6090(99)00265-5

Du X H, Zheng J, Belegundu U, Uchino K, 1998

"Crystal orientation dependence of piezoelectric properties of lead zirconate titanate near the morphotropic phase boundary"

Appl. Phys. Lett. 72, pp. 2421-2423, doi:10.1063/1.121373

Dubois M A, Muralt P, Taylor D V, Hiboux S, 1998

"Which PZT thin films for piezoelectric microactuator applications?"

Integr. Ferroelectr. 22, pp. 535-543, doi:10.1080/10584589808208072

Elliott S, Hegedus J, 2008

"Computer simulation of the phase-change cycle of GST-225"

In: MRS Proceedings, 1072 , 1072-G01-02, volume 1072, pp. 99-107, San Francisco, CA, doi:10.1557/PROC-1072-G01-02

Fang T H, Jian S R, Chuu D S, 2003

"Nanomechanical properties of lead zirconate titanate thin films by nanoindentation"

J. Phys.: Condens. Matter 15, pp. 5253-5259, doi:10.1088/0953-8984/15/30/307

Finot E, Passian A, Thundat T, 2008

"Measurement of mechanical properties of cantilever shaped materials"

Sensors 8, pp. 3497-3541, doi:10.3390/s8053497

Friedrich I, Weidenhof V, Njoroge W, Franz P, Wuttig M, 2000

"Structural transformations of $\mathrm{Ge}_{2} \mathrm{Sb}_{2} \mathrm{Te}_{5}$ films studied by electrical resistance measurements"

J. Appl. Phys. 87, pp. 4130-4134, doi:10.1063/1.373041

Gere J M, 2006

Mechanics of Materials. 6th,

Toronto, Canada: Thomson-Engineering

Glazov V M, Pashinkin A S, 2001

"The thermophysical properties (heat capacity and thermal expansion) of single-crystal silicon" High Temp. 39, pp. 413-419, doi:10.1023/A:1017562709942

Goh W C, Yao K, Ong C K, 2005

"Pseudo-epitaxial lead zirconate titanate thin film on silicon substrate with enhanced ferroelectric polarization"

Appl. Phys. Lett. 87, pp. 1-3, doi:10.1063/1.2010606

Gong W, Li J F, Chu X, Gui Z, Li L, 2004

"Combined effect of preferential orientation and $\mathrm{Zr} / \mathrm{Ti}$ atomic ratio on electrical properties of $\mathrm{Pb}\left(\mathrm{Zr}_{x} \mathrm{Ti}_{1-x}\right) \mathrm{O}_{3}$ thin films"

J. Appl. Phys. 96, pp. 590-595, doi:10.1063/1.1759072 
Hall J D, Apperson N E, Crozier B T, Xu C, Richards R F, Bahr D F, Richards C D, 2002 "A facility for characterizing the dynamic mechanical behavior of thin membranes for microelectromechanical systems"

Rev. Sci. Instrum. 73, pp. 2067-2072, doi:10.1063/1.1470227

Hiboux S, Muralt P, Maeder T, 1999

"Domain and lattice contributions to dielectric and piezoelectric properties of $\mathrm{Pb}\left(\mathrm{Zr}_{x}, \mathrm{Ti}_{1-x}\right) \mathrm{O}_{3}$ thin films as a function of composition"

J. Mater. Res. 14, pp. 4307-4318, doi:10.1557/JMR.1999.0584

Horwitz J S, Chang W, Kim W, Qadri S B, Pond J M, Kirchoefer S W, Chrisey D B, 2000 "Effect of stress on the microwave dielectric properties of $\mathrm{Ba}_{0.5} \mathrm{Sr}_{0.5} \mathrm{TiO}_{3}$ thin films" J. Electroceram. 4, pp. 357-363, doi:10.1023/A:1009974929096

Isarakorn D, Sambri A, Janphuang P, Briand D, Gariglio S, Triscone J M, Guy F, Reiner J W, Ahn C H, de Rooij N F, 2010

"Epitaxial piezoelectric MEMS on silicon"

J. Micromech. Microeng. 2o, p. art. no. 055008, doi:10.1088/0960-1317/20/5/055008

Isarakorn D, Briand D, Janphuang P, Sambri A, Gariglio S, Triscone J M, Guy F, Reiner J W, Ahn C H, de Rooij N F, 2011

"The realization and performance of vibration energy harvesting mems devices based on an epitaxial piezoelectric thin film"

Smart Mater. Struct. 20, p. 025015, doi:10.1088/0964-1726/20/2/025015

Jaffe B, Cook W R, Jaffe H, 1971

Piezoelectric Ceramics,

London: Academic Press

Jang M H, Park S J, Lim D H, Cho M H, Kim Y K, Yi H J, Kim H S, 2009

"Structural stability and phase-change characteristics of $\mathrm{Ge}_{2} \mathrm{Sb}_{2} \mathrm{Te}_{5} / \mathrm{SiO}_{2}$ nano-multilayered films" Electrochem. Solid State Letters 12, pp. H151-H154, doi:10.1149/1.3079479

Jansen H V, De Boer M J, Unnikrishnan S, Louwerse M C, Elwenspoek M C, 2009

"Black silicon method X: a review on high speed and selective plasma etching of silicon with profile control: an in-depth comparison between Bosch and cryostat DRIE processes as a roadmap to next generation equipment"

J. Micromech. Microeng. 19, p. 033001, doi:10.1088/0960-1317/19/3/033001

Jeon S, Thundat T, 2004

"Instant curvature measurement for microcantilever sensors"

Appl. Phys. Lett. 85, pp. 1083-1084, doi:10.1063/1.1781389

Jong C A, Fang W, Lee C M, Chin T S, 2001

"Mechanical properties of phase-change recording media: GeSbTe films"

Jpn. J. Appl. Phys. 40, pp. 3320-3325, doi:10.1143/JJAP.40.3320

Kalb J, Spaepen F, Leervad Pedersen T P, Wuttig M, $2003 a$

"Viscosity and elastic constants of thin films of amorphous te alloys used for optical data storage"

J. Appl. Phys. 94, pp. 4908-4912, doi:10.1063/1.1610775

Kalb J, Spaepen F, Wuttig M, 2003b

"Calorimetric measurements of phase transformations in thin films of amorphous Te alloys used for optical data storage"

J. Appl. Phys. 93, pp. 2389-2393, doi:10.1063/1.1540227

Kalb J A, Wuttig M, Spaepen F, 2007

"Calorimetric measurements of structural relaxation and glass transition temperatures in sputtered films of amorphous Te alloys used for phase change recording"

J. Mater. Res. 22, pp. 748-754, doi:10.1557/jmr.2007.0103 
Kaldor S, Noyan I, 2002

"Differentiating between elastically bent rectangular beams and plates"

Appl. Phys. Lett. 8o, pp. 2284-2286, doi:10.1063/1.1459762

Kalkan B, Sen S, Aitken B G, Raju S V, Clark S M, 2011

"Negative P-T slopes characterize phase change processes: Case of the $\mathrm{Ge}_{1} \mathrm{Sb}_{2} \mathrm{Te}_{4}$ phase change alloy"

Phys. Rev. B 84, p. 014202, doi:10.1103/PhysRevB.84.014202

Kim D J, Maria J P, Kingon A I, Streiffer S K, 2003

"Evaluation of intrinsic and extrinsic contributions to the piezoelectric properties of $\mathrm{Pb}\left(\mathrm{Zr}_{1-x}\right.$, $\left.\mathrm{T}_{x}\right) \mathrm{O}_{3}$ thin films as a function of composition"

J. Appl. Phys. 93, pp. 5568-5575, doi:10.1063/1.1566478

Kim J G, Yu J, 1998

"Comparative study of residual stresses measurement methods on CVD diamond films"

Scr. Mater. 39, pp. 807-814, doi:10.1016/S1359-6462(98)00182-1

Kim K, Lee S, 2006

"Integration of lead zirconium titanate thin films for high density ferroelectric random access memory"

J. Appl. Phys. 100, p. 051604, doi:10.1063/1.2337361

Kim Y K, Morioka H, Ueno R, Yokoyama S, Funakubo H, 2005

"Domain structure control of (oo1)/(100)-oriented epitaxial $\mathrm{Pb}(\mathrm{Zr}, \mathrm{Ti}) \mathrm{O}_{3}$ films grown on $(100)_{c}$ $\mathrm{SrRuO}_{3} /$ (100) $\mathrm{SrTiO}_{3}$ substrates"

Appl. Phys. Lett. 86, pp. 1-3, doi:10.1063/1.1938250

Kobayashi T, Okada H, Masuda T, Maeda R, Itoh T, 2010

"A digital output piezoelectric accelerometer using a $\mathrm{Pb}(\mathrm{Zr}, \mathrm{Ti}) \mathrm{O}_{3}$ thin film array electrically connected in series"

Smart Mater. Struct. 19, p. 105030, doi:10.1088/0964-1726/19/10/105030

Kraft O, Volkert C A, 2001

"Mechanical testing of thin films and small structures"

Adv. Eng. Mater. 3, pp. 99-110, doi:10.1002/1527-2648(200103)3:3<99::AID-ADEM99>3.0.CO;2-2

Krbal M, Kolobov A V, Haines J, Pradel A, Ribes M, Fons P, Tominaga J, Levelut C, Le Parc R, Hanfland M, 2008

"Temperature independence of pressure-induced amorphization of the phase-change memory alloy $\mathrm{Ge}_{2} \mathrm{Sb}_{2} \mathrm{Te}_{5}$ ”

Appl. Phys. Lett. 93, p. 031918, doi:10.1063/1.2956409

Krusin-Elbaum L, Cabral C, Chen K N, Copel M, Abraham D W, Reuter K B, Rossnagel S M, Bruley J, Deline V R, 2007

"Evidence for segregation of Te in $\mathrm{Ge}_{2} \mathrm{Sb}_{2} \mathrm{Te}_{5}$ films: Effect on the "phase-change" stress" Appl. Phys. Lett. 9o, p. 141902, doi:10.1063/1.2719148

Laser D J, Santiago J G, 2004

"A review of micropumps"

J. Micromech. Microeng. 14, pp. R35-R64, doi:10.1088/0960-1317/14/6/R01

Ledermann N, Seifert A, Hiboux S, Muralt P, 1999

"Effective transverse piezoelectric coefficient $\mathrm{e}_{31, f}$ of (100)/(0o1) textured PZT thin films" Integr. Ferroelectr. 24, pp. 13-18, doi:10.1080/10584589908215574

Ledermann N, Muralt P, Baborowski J, Gentil S, Mukati K, Cantoni M, Seifert A, Setter N, 2003 “ $\left\{\begin{array}{lll}1 & 0 & 0\end{array}\right.$-textured, piezoelectric $\mathrm{Pb}\left(\mathrm{Zr}_{x}, \mathrm{Ti}_{1-x}\right) \mathrm{O}_{3}$ thin films for mems: Integration, deposition and properties"

Sens. Actuators A 105, pp. 162-170, doi:10.1016/S0924-4247(03)00090-6 
Ledermann N, Muralt P, Baborowski J, Forster M, Pellaux J P, 2004

"Piezoelectric $\mathrm{Pb}\left(\mathrm{Zr}_{x}, \mathrm{Ti}_{1-x}\right) \mathrm{O}_{3}$ thin film cantilever and bridge acoustic sensors for miniaturized photoacoustic gas detectors"

J. Micromech. Microeng. 14, pp. 1650-1658, doi:10.1088/0960-1317/14/12/008

Lee C S, Nam H J, Kim Y S, Jin W H, Bu J U, 2004

"PZT cantilevers integrated with heaters and new piezoelectric sensors for SPM-based nano-data storage application"

Journal of the Korean Physical Society 45, pp. 227-230

Leervad Pedersen T P, Kalb J, Njoroge W K, Wamwangi D, Wuttig M, Spaepen F, 2001

"Mechanical stresses upon crystallization in phase change materials"

Appl. Phys. Lett. 79, pp. 3597-3599, doi:10.1063/1.1415419

Lefki K, Dormans G J M, 1994

"Measurement of piezoelectric coefficients of ferroelectric thin films"

J. Appl. Phys. 76, pp. 1764-1767, doi:10.1063/1.357693

Li M, Li J, Shi L, Yang H, Chong T, Li Y, 2008

"Crystallization-induced stress in phase change random access memory"

In: Mater. Res. Soc. Symp. Proc., volume 1137, pp. 113-118, Boston, MA, doi:10.1557/PROC-1137-

EE05-10

Lian L, Sottos N R, 2004

"Stress effects in sol-gel derived ferroelectric thin films"

J. Appl. Phys. 95, pp. 629-634, doi:10.1063/1.1632019

Liang C, Morshed S, Prorok B C, 2007

"Correction for longitudinal mode vibration in thin slender beams"

Appl. Phys. Lett. 9o, p. art. no. 221912, doi:10.1063/1.2745262

Liu D, Yoon S H, Zhou B, Prorok B C, Kim D J, 2009

"Investigation of the crystalline orientations and substrates dependence on mechanical properties of PZT thin films by nanoindentation"

In: MRS Proceedings, 1129 , 1129-V11-05, volume 1129, pp. 47-52, Boston, MA, doi:10.1557/PROC1129-V11-05

Loh N C, Schmidt M A, Manalis S R, 2002

"Sub-10 $\mathrm{cm}^{3}$ interferometric accelerometer with nano-g resolution"

J. Microelectromech. Syst. 11, pp. 182-187, doi:10.1109/JMEMS.2002.1007396

Mamazza R, Mark N Y, Polcawich R G, Piekarski B H, Muralt P, Reynolds G J, 2006

"Comparison of ferroelectric and piezoelectric properties of sol-gel grown and sputter deposited $\mathrm{Pb}(\mathrm{Zr}, \mathrm{Ti}) \mathrm{O}_{3}$ thin films"

In: Proc. 15th IEEE Int. Symp. on Applications of ferroelectrics, ISAF 2006, pp. 314-317, IEEE, doi:10.1109/ISAF.2006.4387895

Marmier A, Kohary K, Wright C D, 2011

"Determination of the anisotropic elastic properties of $\mathrm{Ge}_{1} \mathrm{Sb}_{2} \mathrm{Te}_{4}$ "

Appl. Phys. Lett. 98, p. 231911, doi:10.1063/1.3598934

Matin M A, Akai D, Kawazu N, Hanebuchi M, Sawada K, Ishida M, 2010

"FE modeling of stress and deflection of PZT actuated micro-mirror: Effect of crystal anisotropy"

Comput. Mater. Sci. 48, pp. 349-359, doi:10.1016/j.commatsci.2010.01.020

Matsunaga T, Yamada N, 2004

"Structural investigation of $\mathrm{GeSb}_{2} \mathrm{Te}_{4}$ : A high-speed phase-change material"

Phys. Rev. B 69, pp. 1041111-1041118, doi:10.1103/PhysRevB.69.104111 
McFarland A, Poggi M, Bottomley L, Colton J, 2005

"Characterization of microcantilevers solely by frequency response acquisition"

J. Micromech. Microeng. 15, pp. 785-791, doi:10.1088/0960-1317/15/4/016

Muralt P, 2000

"PZT thin films for microsensors and actuators: Where do we stand?"

IEEE Trans. Ultrason. Ferr. Freq. Control 47, pp. 903-915, doi:10.1109/58.852073

Murata M, Kondoh T, Yagi T, Funatsu N, Tanaka K, Tsukuni H, Ohno K, Usami H, Nayve R, Inoue N, Seto S, Morita N, 2009

"High-resolution piezo inkjet printhead fabricated by three dimensional electrical connection method using through glass via"

In: 22nd IEEE International Conference on Micro Electro Mechanical Systems, MEMS 2009, pp. 507-510, Sorrento, doi:10.1109/MEMSYS.2009.4805430

Nam H J, Kim Y S, Lee C S, Jin W H, Jang S S, Cho I J, Bu J U, Choi W B, Choi S W, 2007 "Silicon nitride cantilever array integrated with silicon heaters and piezoelectric detectors for probe-based data storage"

Sens. Actuators A 134, pp. 329-333, doi:10.1016/j.sna.2006.05.030

Nazeer H, Nguyen M D, Rijnders G, Woldering L A, Sardan Sukas O, Abelmann L, Elwenspoek M C, "Compositional dependence of the Young's modulus and piezoelectric coefficient of (110) oriented pulsed laser deposited PZT thin films"

To be submitted

Chapter 4 is based on this paper

Nazeer H, Nguyen M D, Woldering L A, Abelmann L, Rijnders G, Elwenspoek M C, 2011 a "Determination of the Young's modulus of pulsed laser deposited epitaxial PZT thin films" J. Micromech. Microeng. 21, p. 0740o8, doi:10.1088/0960-1317/21/7/074008 Chapter 3 is based on this paper

Nazeer H, Woldering L A, Abelmann L, Nguyen M D, Rijnders G, Elwenspoek M C, $2011 b$ "Influence of silicon orientation and cantilever undercut on the determination of the Young's modulus of thin films" Microelectron. Eng. 88, pp. 2345-2348, doi:10.1016/j.mee.2011.01.028

Chapter 2 is based on this paper

Nguyen M D, Nazeer H, Karakaya K, Pham S V, Steenwelle R, Dekkers M, Abelmann L, Blank D H A, Rijnders G, 2010

"Characterization of epitaxial $\mathrm{Pb}(\mathrm{Zr}, \mathrm{Ti}) \mathrm{O}_{3}$ thin films deposited by pulsed laser deposition on silicon cantilevers"

J. Micromech. Microeng. 2o, p. o85022, doi:10.1088/0960-1317/20/8/085022

Nix W D, 1989

"Mechanical properties of thin films"

Metall. Trans. A 20, pp. 2217-2245, doi:10.1007/BF02666659

Njoroge W K, Wöltgens H W, Wuttig M, 2002

"Density changes upon crystallization of $\mathrm{Ge}_{2} \mathrm{Sb}_{2.04} \mathrm{Te}_{4.74}$ films"

J. Vac. Sci. Technol. A 20, pp. 230-233, doi:10.1116/1.1430249

Noheda B, Gonzalo J, De Frutos J, González A, Moure C, 1997

"Thermal expansion anomalies at the antiferroelectric-ferroelectric $\left(\mathrm{F}_{R L}\right)$, ferroelectric $\left(\mathrm{F}_{R L}\right)$ ferroelectric $\left(\mathrm{F}_{R H}\right)$ and ferroelectric $\left(\mathrm{F}_{R H}\right)$-paraelectric transitions in $\mathrm{Pb}\left(\mathrm{Zr}_{1-x}, \mathrm{Ti}_{x}\right) \mathrm{O}_{3}(\mathrm{o}), \mathrm{x}$, 0.35 "

J. Mater. Sci. Lett. 16, pp. 101-103, doi:10.1023/A:1018573422768 
Ogawa T, Senda A, Kasanami T, 1991

"Controlling the crystal orientations of lead titanate thin films"

Jpn. J. Appl. Phys., Part 1 30, pp. 2145-2148, doi:10.1143/JJAP.30.2145

Okada Y, Tokumaru Y, 1984

"Precise determination of lattice parameter and thermal expansion coefficient of silicon between 300 and $1500 \mathrm{k}$ "

J. Appl. Phys. 56, pp. 314-320, doi:10.1063/1.333965

Oliver W C, Pharr G M, 1992

"An improved technique for determining hardness and elastic modulus using load and displacement sensing indentation experiments"

J. Mater. Res. 7, pp. 1564-1580, doi:10.1557/JMR.1992.1564

Oliver W C, Pharr G M, 2004

"Measurement of hardness and elastic modulus by instrumented indentation: Advances in understanding and refinements to methodology"

J. Mater. Res. 19, pp. 3-20, doi:10.1557/jmr.2004.19.1.3

Park I M, Jung J K, Ryu S O, Choi K J, Yu B G, Park Y B, Han S M, Joo Y C, 2008

"Thermomechanical properties and mechanical stresses of $\mathrm{Ge}_{2} \mathrm{Sb}_{2} \mathrm{Te}_{5}$ films in phase-change random access memory"

Thin Solid Films 517, pp. 848-852, doi:10.1016/j.tsf.2008.08.194

Park J H, Yoon S H, Shen D, Choe S Y, Yoon Y S, Park M, Kim D J, 2009

"Effects of preferred orientation on the piezoelectric properties of $\mathrm{Pt} / \mathrm{Pb}\left(\mathrm{Zr}_{0.3} \mathrm{Ti}_{0.7}\right) \mathrm{O}_{3} / \mathrm{Pt}$ thin films grown by sol-gel process"

J. Mater. Sci.: Mater. Electron. 2o, pp. 366-373, doi:10.1007/s10854-008-9735-9

Piekarski B, DeVoe D, Dubey M, Kaul R, Conrad J, 2001

"Surface micromachined piezoelectric resonant beam filters"

Sens. Actuators A 91, pp. 313-320, doi:10.1016/S0924-4247(01)00601-X

Piekarski B, Dubey M, Zakar E, Polcawich R, DeVoe D, Wickenden D, 2002

"Sol-gel PZT for mems applications"

Integr. Ferroelectr. 42, pp. 25-37, doi:10.1080/10584580210868

Poelma R H, Sadeghian H, Noijen S P M, Zaal J J M, Zhang G Q, 2011

"A numerical experimental approach for characterizing the elastic properties of thin films: Application of nanocantilevers"

J. Micromech. Microeng. 21, p. 065003, doi:10.1088/0960-1317/21/6/065003

Poon B, Rittel D, Ravichandran G, 2008

"An analysis of nanoindentation in linearly elastic solids"

Int. J. Solids Struct. 45, pp. 6018-6033, doi:10.1016/j.ijsolstr.2008.07.021

Ræder H, Tyholdt F, Booij W, Calame F, Østbø N P, Bredesen R, Prume K, Rijnders G, Muralt P, 2007 "Taking piezoelectric microsystems from the laboratory to production"

J. Electroceram. 19, pp. 357-362, doi:10.1007/s10832-007-9036-3

Rasmussen P A, 2003

Cantilever-based sensors for surface stress measurements

Ph.D. thesis, Technical university of Denmark

Reaney I M, Taylor D V, Brooks K G, 1998

"Ferroelectric PZT thin films by sol-gel deposition"

J. Sol-Gel Sci. Technol. 13, pp. 813-820, doi:10.1023/A:1008690316261 
Rúa A, Fernández F E, Cabrera R, Sepúlveda N, 2009

"Young's modulus of pulsed-laser deposited $\mathrm{V}_{6} \mathrm{O}_{13}$ thin films"

J. Appl. Phys. 105, p. art. no. 113504, doi:10.1063/1.3137191

Schneider D, Tucker M D, 1996

"Non-destructive characterization and evaluation of thin films by laser-induced ultrasonic surface waves"

Thin Solid Films 290-291, pp. 305-311, doi:10.1016/S0040-6090(96)09029-3

Schweitz J A, 1991

"A new and simple micromechanical approach to the stress-strain characterization of thin coatings"

J. Micromech. Microeng. 1, pp. 10-15, doi:10.1088/0960-1317/1/1/003

Setter N, Damjanovic D, Eng L, Fox G, Gevorgian S, Hong S, Kingon A, Kohlstedt H, Park N Y, Stephenson G B, Stolitchnov I, Taganstev A K, Taylor D V, Yamada T, Streiffer S, 2006

"Ferroelectric thin films: Review of materials, properties, and applications"

J. Appl. Phys. 100, p. 051606, doi:0.1063/1.2336999

Shen D, Park J H, Ajitsaria J, Choe S Y, Wikle H C, Kim D J, 2008

"The design, fabrication and evaluation of a MEMS PZT cantilever with an integrated Si proof mass for vibration energy harvesting"

J. Micromech. Microeng. 18, p. 055017, doi:10.1088/0960-1317/18/5/055017

Shepard Jr J F, Trolier-McKinstry S, Hendrickson M A, Zeto R, 1996

"Properties of PZT thin films as a function of in-plane biaxial stress"

In: Proc. 1oth IEEE Int. Symp. on Applications of ferroelectrics, ISAF 1996, volume 1, pp. 161-165, IEEE, doi:10.1109/ISAF.1996.602728

Shepard Jr J F, Moses P J, Trolier-McKinstry S, 1998

"The wafer flexure technique for the determination of the transverse piezoelectric coefficient $\left(\mathrm{d}_{31}\right)$ of PZT thin films"

Sens. Actuators A 71, pp. 133-138, doi:10.1016/S0924-4247(98)00161-7

Shirane G, Suzuki K, 1952

"Crystal structure of $\mathrm{Pb}(\mathrm{Zr}-\mathrm{Ti}) \mathrm{O}_{3}$ "

J. Phys. Soc. Jpn. 7, p. 333, doi:DOI:10.1143/JPSJ.7.333

Shirane G, Suzuki K, Takeda A, 1952

"Phase transitions in solid solutions of $\mathrm{PbZrO}_{3}$ and $\mathrm{PbTiO}_{3}$ (II) x-ray study"

J. Phys. Soc. Jpn. 7, pp. 12-18, doi:10.1143/JPSJ.7.12

Stoney G, 1909

"The tension of metallic films deposited by electrolysis"

Proc. R. Soc. Lond. A 82, pp. 172-175, doi:10.1098/rspa.1909.0021

Tadigadapa S, Mateti K, 2009

"Piezoelectric MEMS sensors: State-of-the-art and perspectives"

Meas. Sci. Technol. 20, p. o92001, doi:10.1088/0957-0233/20/9/092001

Tagantsev A K, Landivar M, Colla E, Setter N, 1995

"Identification of passive layer in ferroelectric thin films from their switching parameters"

J. Appl. Phys. 78, pp. 2623-2630, doi:10.1063/1.360122

Taylor D V, Damjanovic D, 2000

"Piezoelectric properties of rhombohedral $\mathrm{Pb}(\mathrm{Zr}, \mathrm{Ti}) \mathrm{O}_{3}$ thin films with (100), (111), and "random" crystallographic orientation"

Appl. Phys. Lett. 76, pp. 1615-1617, doi:10.1063/1.126113 
Taylor J R, 1997

An introduction to error analysis: the study of uncertainties in physical measurements,

Univ Science Books, Sausalito, CA

Tomforde J, Bensch W, Kienle L, Duppel V, Merkelbach P, Wuttig M, 2011

"Thin films of Ge-Sb-Te-based phase change materials: Microstructure and in situ transformation" Chem. Mater. 23, pp. 3871-3878, doi:10.1002/chin.201145008

Trolier-Mckinstry S, Muralt P, 2004

"Thin film piezoelectrics for MEMS"

J. Electroceram. 12, pp. 7-17, doi:10.1023/B:JECR.0000033998.72845.51

Tsuchiya T, Shikida M, Sato K, 2002

"Tensile testing system for sub-micrometer thick films"

Sens. Actuators A 97-98, pp. 492-496, doi:10.1016/S0924-4247(01)00862-7

Tsuchiya T, Hirata M, Chiba N, Udo R, Yoshitomi Y, Ando T, Sato K, Takashima K, Higo Y, Saotome Y, Ogawa H, Ozaki K, 2005

"Cross comparison of thin-film tensile-testing methods examined using single-crystal silicon, polysilicon, nickel, and titanium films"

J. Microelectromech. Syst. 14, pp. 1178-1186, doi:10.1109/JMEMS.2005.851820

Van Kampen R, Wolffenbuttel R, 1998

"Modeling the mechanical behavior of bulk-micromachined silicon accelerometers"

Sens. Actuators A 64, pp. 137-150, doi:10.1016/S0924-4247(98)80007-1

Volterra E, Zachmanoglou E C, 1965

Dynamics of vibrations,

CE Merrill Books, Columbus, $\mathrm{OH}$

Walmsley B A, Liu Y, Hu X Z, Bush M B, Winchester K J, Martyniuk M, Dell J M, Faraone L, 2005 "Effects of deposition temperature on the mechanical and physical properties of silicon nitride thin films"

J. Appl. Phys. 98, pp. 1-6, doi:10.1063/1.2006972

Wang Q M, Cross L E, 1998

"Performance analysis of piezoelectric cantilever bending actuators"

Ferroelectrics 215, pp. 187-213, doi:10.1080/00150199808229562

Wang Q M, Ding Y, Chen Q, Zhao M, Cheng J, 2005

"Crystalline orientation dependence of nanomechanical properties of $\mathrm{Pb}\left(\mathrm{Zr}_{0.52} \mathrm{Ti}_{0.48}\right) \mathrm{O}_{3}$ thin films"

Appl. Phys. Lett. 86, p. 162903, doi:10.1063/1.1901805

Weaire D, Ashby M F, Logan J, Weins M J, 1971

"On the use of pair potentials to calculate the properties of amorphous metals"

Acta Metallurgica 19, pp. 779-788, doi:10.1016/0001-6160(71)90134-9

Weidenhof V, Friedrich I, Ziegler S, Wuttig M, 1999

"Atomic force microscopy study of laser induced phase transitions in $\mathrm{Ge}_{2} \mathrm{Sb}_{2} \mathrm{Te}_{5}$ "

J. Appl. Phys. 86, pp. 5879-5887, doi:10.1063/1.371606

Weihs T P, Hong S, Bravman J C, Nix W D, 1988

"Mechanical deflection of cantilever microbeams: A new technique for testing the mechanical properties of thin films"

J. Mater. Res. 3, pp. 931-942, doi:10.1557/JMR.1988.0931

Wikipedia,

URL http: //en.wikipedia.org/wiki/Nanoindentation

(accessed 7 Feb. 2012) 
Wright C D, Armand M, Aziz M M, 2006

"Terabit-per-square-inch data storage using phase-change media and scanning electrical nanoprobes"

IEEE Trans. Nanotechnol. 5, pp. 50-61, doi:10.1109/TNANO.2005.861400

Wuttig M, Yamada N, 2007

"Phase-change materials for rewriteable data storage"

Nat. Mater. 6, pp. 824-832, doi:10.1038/nmat2009

Xu B, Cross L E, Bernstein J J, 2000

"Ferroelectric and antiferroelectric films for microelectromechanical systems applications"

Thin Solid Films 377-378, pp. 712-718, doi:10.1016/S0040-6090(00)01322-5

Xu F, Chu F, Trolier-McKinstry S, 1999

"Longitudinal piezoelectric coefficient measurement for bulk ceramics and thin films using pneumatic pressure rig"

J. Appl. Phys. 86, pp. 588-594, doi:10.1063/1.370771

Yagnamurthy S, Chasiotis I, Lambros J, Polcawich R, Pulskamp J, Dubey M, 2008 "Mechanical properties of PZT films and their composites for RF-MEMS"

In: 11th International Congress and Exhibition on Experimental and Applied Mechanics 2008, volume 3, pp. 1253-1259, Orlando, FL

Yamada N, Ohno E, Nishiuchi K, Akahira N, Takao M, 1991

"Rapid-phase transitions of $\mathrm{GeTe}_{\mathrm{S}} \mathrm{Sb}_{2} \mathrm{Te}_{3}$ pseudobinary amorphous thin films for an optical disk memory"

J. Appl. Phys. 69, pp. 2849-2856, doi:10.1063/1.348620

Yao K, Tay F E H, 2003

"Measurement of longitudinal piezoelectric coefficient of thin films by a laser-scanning vibrometer"

IEEE Trans. Ultrason. Ferr. Freq. Control 5o, pp. 113-116, doi:10.1109/TUFFC.2003.1182115

Yao K, Yu S, Tay F E H, 2003

"Residual stress analysis in ferroelectric $\mathrm{Pb}\left(\mathrm{Zr}_{0.52} \mathrm{Ti}_{0.48}\right) \mathrm{O}_{3}$ thin films fabricated by a sol-gel process"

Appl. Phys. Lett. 82, pp. 4540-4542, doi:10.1063/1.1587272

Zhuang Z Q, Haun M J, Jang S J, Cross L E, 1989

"Composition and temperature dependence of the dielectric, piezoelectric and elastic properties of pure pzt ceramics"

IEEE Trans. Ultrason. Ferr. Freq. Control 36, pp. 413-416, doi:10.1109/58.31777 



\section{Samenvatting}

Het belangrijkste doel van het werk dat beschreven is in dit proefschrift is het onderzoeken van dunne films ten behoeve van hun integratie in microelectromechanische systemen (MEMS). Voor het miniaturiseren van MEMS actuatoren en sensoren, met behoud van efficiëntie, zijn dunne films nodig met verschillende actieve materialen die specifieke eigenschappen hebben. De eigenschappen van dunne lagen verschillen met die van dezelfde materialen in bulk. Dit is een gevolg van de grote verhouding tussen oppervlak en volume, de unieke microstructuur, de interactie met het substraat, enzovoorts.

In monokristallijn silicium zijn met een eenvoudige methode cantilevers en capaciteiten gemaakt die als teststructuur dienen om hun materiaaleigenschappen te verkennen in het dunne film domein. De te onderzoeken dunne films zijn vervolgens op de gemaakte cantilevers gedeponeerd. De capaciteiten zijn verkregen door het actieve materiaal tussen een top en een bodem elektrode aan te brengen. Door mogelijke foutbronnen te identificeren en deze daarna te kwantificeren en te reduceren is de betrouwbaarheid en de nauwkeurigheid van onze karakterisatiemethode vergroot.

\section{Cantilevers}

De Young's modulus van dunne films kan bepaald worden door deze te deponeren op een silicium microcantilever en de resonantiefrequentie van de cantilever voor en na deze depositie te meten. De nauwkeurigheid van deze methode hangt sterk af van de initiële bepaling van de mechanische eigenschappen en de dimensies van de silicium cantilevers. Dit werk beschrijft de oriëntatie van de cantilever ten opzichte van het monokristallijn silicium en beschrijft de onderets van de gemaakte cantilevers. Deze onderets is het gevolg van procesonnauwkeurigheden en is onvermijdbaar. Met behulp van eindige elementen modellering laten we zien dat als waarde voor de effectieve Young's modulus niet de analytische plate modulus benadering gebruikt moet worden, maar de ongecorrigeerde Young's modulus. Dit geldt voor zowel de $\langle 100\rangle$ en de $<110\rangle$ kristalrichting van het silicium. De onderets van de cantilevers kan gecorrigeerd worden door de effectieve cantilever lengte te variëren. 


\section{Anisotropie in de Young's modulus}

Een groot deel van dit werk beschrijft $\mathrm{PbZr}_{0.52} \mathrm{Ti}_{0.48} \mathrm{O}_{3}$ (PZT) dunne films die gemaakt zijn door middel van pulsed laser deposition (PLD). PLD is een depositieproces waarbij gebruik wordt gemaakt van een gepulseerde laserbundel. De resulterende films groeien epitaxiaal op het siliciumsubstraat en hebben daarom uitstekende piëzoelektrische eigenschappen. Deze goede eigenschappen zorgen ervoor dat de films uitstekende kandidaten zijn om gebruikt te worden in MEMS toepassingen.

We hebben de Young's modulus van epitaxiaal gegroeid PZT op microcantilevers bepaald door het verschil te meten in de resonantiefrequentie van de cantilevers voor en na depositie van de dunne lagen. Door de nauwkeurigheid van deze methode zorgvuldig te optimaliseren hebben we laten zien dat de Young's modulus van deze dunne PZT films afhangt van de oriëntatie in het vlak. Dit resultaat is bereikt door gebruik te maken van de $\langle 110\rangle$ en $\langle 100\rangle$ kristalrichtingen in het silicium. De depositie van dunne films op cantilevers beïnvloedt hun buigstijfheid en vergroot de massa. Dit resulteert in een verschuiving van de resonantiefrequentie. In dit werk is een analytische vergelijking ontwikkeld om de effectieve Young's modulus te bepalen aan de hand van het verschil in resonantiefrequentie, gemeten voor en na depositie van de dunne lagen. Door de dimensies van de cantilevers zeer nauwkeurig te bepalen en door cantilevers te gebruiken met verschillende lengten zijn foutbronnen in het bepalen van de Young's modulus geëlimineerd. Tijdens het vrij-etsen van de cantilevers van de dragerwafers ontstaat een onderets. Omdat deze onderets onvermijdelijk is, hebben we een effectieve cantilever lengte bepaald en deze gebruikt in de berekeningen. De gemeten Young's modulus van PLD gedeponeerd PZT is $113.5 \mathrm{GPa}$ (met een standaardfout van $\pm 1.5 \mathrm{GPa}$ ) in de $<110\rangle$ silicium kristalrichting en $103.5 \mathrm{GPa}$ (met een standaardfout van $\pm 1.9 \mathrm{GPa}$ ) in de $<100>$ silicium kristalrichting.

\section{Afhankelijkheid van PZT compositie}

De mechanische- en piëzoelektrische eigenschappen van $\mathrm{PLD} \mathrm{Pb}\left(\mathrm{Zr}_{x} \mathrm{Ti}_{1-x}\right) \mathrm{O}_{3}$ dunne films met een (110) voorkeursrichting zijn sterk afhankelijk van hun compositie. Vibrometrische bepalingen op gestructureerde capaciteiten hebben laten zien dat de longitudinale piëzoelektrische coëfficent $\left(d_{33, \mathrm{f}}\right)$ gemeten met PZT films met een dikte van $250 \mathrm{~nm}$ een maximum heeft van $93 \mathrm{pm} / \mathrm{V}$ voor de compositie met $x=0.52$. De gemeten Young's modulus neemt toe bij Zr-rijke composities. Dit resultaat is in overeenstemming met de trends die geobserveerd zijn bij bulk keramisch PZT. Met behulp van de gemeten diëlektrische constante en de $d_{33 \text {,f }}$ hebben we laten zien dat de vervolgens berekende koppel-coëfficienten van de PLD-PZT dunne films met verschillende composities hoger zijn in vergelijking met hun keramische tegenhangers.

We hebben de compositieafhankelijkheid van de in-plane Young's modulus van $\mathrm{Pb}\left(\mathrm{Zr}_{x} \mathrm{Ti}_{1-x}\right) \mathrm{O}_{3}$ dunne films met een (oo1) voorkeursrichting bepaald. Hiervoor 
zijn epitaxiale dunne PLD-PZT films met composities variërend van $x=0.2$ tot 0.8 gedeponeerd op silicium cantilevers. Bij alle composities is in de $<100>$ silicium kristalrichting een hogere Young's modulus gevonden. Tevens is een maximale anisotropie van $46 \%$ aanwezig bij de compositie met $x=0.2$. Evenals bij bulk keramiek PZT, is een minimum Young's modulus gevonden bij $x=0.52$ in de $<110>$ silicium richting. De waarde en de anisotropie van de Young's modulus van (110) geörienteerde dunne films was kleiner in vergelijking met de (oo1) richting. Dankzij de hogere koppelingscoëfficient van (110) geörienteerde $\mathrm{Pb}\left(\mathrm{Zr}_{0.52} \mathrm{Ti}_{0.48}\right) \mathrm{O}_{3}$ dunne films concluderen we dat deze meer geschikt zijn voor toepassingen in transducers.

\section{Restspanning in PZT dunne films}

We hebben de restspanning gemeten in $\mathrm{Pb}\left(\mathrm{Zr}_{x} \mathrm{Ti}_{1-x}\right) \mathrm{O}_{3}$ (PZT) dunne films met een (110) voorkeursoriëntatie en met composities variërend van $x=0.2$ tot 0.8 . De films zijn gedeponeerd met behulp van PLD op cantilevers die uitgelijnd zijn langs de $\langle 110\rangle$ en $\langle 100\rangle$ kristalrichtingen in silicium. Om de restspanning te bepalen is de statische buiging van de cantilevers gebruikt. De restspanning is tensiel en vertoont een sterke toename van ongeveer 50 tot $250 \mathrm{MPa}$ bij de composities $x=0.2$ tot o.4. Deze mechanische parameters zijn duidelijk afhankelijk van de oriëntatie van de cantilevers ten opzichte van het silicium kristal. We denken dat dit gerelateerd is aan de epitaxiale groei van de films. Als we aannemen dat een intrinsieke stress van 200-300 MPa aanwezig is in het materiaal na depositie, dan is de variatie in de gemeten stress als functie van compositie $x$ te verklaren door het verschil in de thermische expansie van silicum en van PZT. De spanning die we berekenen aan de hand van de gemeten $\mathrm{x}$-ray diffractie data leidt tot onredelijk hoge waarden voor de restspanning. Deze waarden zijn minstens één orde hoger dan die welke zijn bepaald met behulp van de statische buiging van de cantilevers.

\section{Metingen aan faseverandering materialen}

Naast het PZT materiaal hebben we gemeten aan zogenaamde "faseverandering" materialen. Tijdens het annealen van deze films veranderde hun Young's modulus drastisch. Dit resultaat is interessant als demonstratie van onze meetmethode en vanwege mogelijke toepassingen. De Young's modulus, de restspanning en de laagweerstand van op silicium microcantilever gedeponeerde "faseveranderings"dunne films $\left(\mathrm{Ge}_{1} \mathrm{Sb}_{2} \mathrm{Te}_{4}\right.$ and $\left.\mathrm{Ge}_{2} \mathrm{Sb}_{2} \mathrm{Te}_{5}\right)$ zijn bepaald als functie van de annealtemperatuur. De Young's modulus en de restspanning vertonen een sterke toename boven de kristallisatietemperatuur. De laagweerstand vertoont een monotone afname als functie van annealtemperatuur. De restspanning boven de kristallisatietemperatuur hangt sterk af van de eerdere annealstappen. Verder vertoont de $\mathrm{Ge}_{2} \mathrm{Sb}_{2} \mathrm{Te}_{5}$ dunne film stress relaxatie boven de kristallisatietemperatuur. Dit effect is niet geobserveerd voor $\mathrm{Ge}_{1} \mathrm{Sb}_{2} \mathrm{Te}_{4}$. 



\section{Acknowledgements}

The work described in this thesis was conducted within the Transducers Science and Technology group (TST) of the $\mathrm{MESA}^{+}$institute for nanotechnology. During my affiliation, I witnessed a big landmark in the history of $\mathrm{MESA}^{+}$, the evolution from the old cleanroom facility to the state of the art nanotechnology centre. Mean time the TST group also shifted from the Hogekamp building to the new technologically advanced Carré building. During my stay here, I came across many talented persons, to whom I am really grateful and very thankful for all their support, guidance and help. I am taking this opportunity to thank a few in particular.

I would first like to warmly thank the members of my committee, for the honour they gave me to judge this work. Prof. dr. Guus Rijnders, Prof. dr. Rob Wolters, Prof. Ian Reaney, Dr. Harish Bhaskaran and Dr. Merlijn van Spengen showed their interest in this work by agreeing to participate in the committee and have spent their valuable time.

Let me think, how can I explain Leon Abelmann: is he a better supervisor, a researcher, a manager, or a better critic? I found him as a best leader who can help you in difficult times, as well as groom you for doing good research independently. He loves to see his students shinning in the research field, leaving footprints for the new students that are joining the research. Whether it is about interpreting the results or writing an impressive article or giving a presentation or planning the $\mathrm{PhD}$, I have always found him very helpful. Thanks for being my supervisor during these years of $\mathrm{PhD}$ and for the many comments and advices that you have given me during the preparation of this project and the publications derived from that. Thanks Leon for introducing me to the world of LATEX, which made my life easier during the difficult thesis writing phase.

Miko, you showed trust in me by accepting me as a PhD candidate in TST. My very first interaction with TST was through Miko, a polite, generous and outstanding man of science and reasoning. I always find it difficult to explain that a person can enjoy life without beer, even though the alcohol evaporates from your glühwein. The very first reference from you in our first meeting eventually became the best source and basis of my orientation in this research. Whenever needed, you guided me, either by asking critical questions about my results or by suggesting improvements in my papers. Thank you for being my supervisor and making TST the best group in the University of Twente. I wish to extend this thanks to Gijs, 
whose questions and comments always ignite a new spark to do more and analyse the work from totally different perspective.

Joost van Honscoten, with whom I interacted a lot during the start of my research work will always be remembered in our hearts. I am really thankful to Joost for all the support he provided in short interval of time.

The two persons that gave me the winning combination in my research are Léon Woldering and Özlem. Thanks to Léon W. for taking the error analysis so seriously that eventually it became the strong part of this work. Lots and loads of discussions with a freedom of disturbing him at any time. I still remember the tiring fabrication work and minute details of analysing the scanning electron micrographs, for which he guided me so well. I am thankful to you Léon W. for all the guidance you provided during the course of this work. Özlem always showed up with so many alternatives whenever I needed her, she kept my morale high and helped me not to deviate from the research planning.

I wholeheartedly thank Meint who showed me the wonderful world of the cleanroom, who is very strict about perfection in the preparation of process documents, but also shares the happiness with you after the first successful product out of the cleanroom. A dedicated person who developed such a nice fabrication process database in the MESA+ information system that will keep helping the $\mathrm{PhD}$ students in large. How can I forget my last fabrication run in the cleanroom for which Meint took the special effort to use the cleanroom facility after office hours and we worked with ADIXEN in the cleanroom until 22:0o hours. Thanks to Erwin too, my work did not allow me to interact a lot with Erwin, that I really missed, but during our fabrication related meetings, he was always there to guide me about the expected results of the various fabrication steps that only an experienced fabrication guy can tell you. Thank you Kees for long discussions about my project. The feeling of your presence around the cleanroom was wonderful and gave extra confidence. Discussions with Niels during the development of the analytical model were very nice and I am grateful to him for his time and guidance provided in my project.

The ever happy Pino (except when he sends the really angry mails to the group that generally reads like "who took the equipment from the lab, I need it back in the lab ASAP, picture attached"). Thanks for your readiness to answer my same old question without raising an eyebrow, every time I asked in front of the Vibrometer.

Martin, Johnny and Henk: thanks for your efforts to make me understand various lab equipment and your trust in me to handle these independently. Martin, believe me, picking up a single cantilever with a tweezer from a chip is not a joke, but you made me learn that too. Johnny and Henk: without your suggestions it wouldn't be possible for me to take such nice micrographs.

This acknowledgement can not be completed without mentioning the TST group (a.k.a MicMec), my second home, a wonderful bunch of multidisciplinary persons. Many group outings, smikkel parties, the most recent adventure of wild kart racing that finished with only one broken arm (I was expecting more). Thank 
you all MicMec for providing me such a nice environment. My office mate Ahmad, willing to be disturbed by so many queries regarding studies and administrative matters, I do acknowledge your patience. The last four years in TST would not have been so easy without Karen, Susan and Satie, who took care of all the administrative issues from day one and are still taking care of the last day in MicMec by arranging the $\mathrm{PhD}$ promotion activities.

A special thanks to my nice project mate, Minh, from the IMS group. He was always around for long discussions after office hours and many measurements together in the weekends. Ruud and Matthijn thanks for making me understand the PZT material so well.

Weekends in the summer can not be more joyous than the ones I enjoyed with my Pakistani friends. From arranging the activities of the PSA to the whole day long BBQ are unforgettable memories. I must take this opportunity to appreciate all my PSA friends.

My doctoral dream can not be possible without the support and help provided by my family members, special thanks to Uncle Zaheer and Aunt Farhat who took all my responsibilities back home which I was supposed to fulfill. They provided me the peace at mind so that I can concentrate on my research work. I would like to say thanks to my mother-in-law for her best wishes and prayers throughout these years.

I do not have appropriate words to thank my mother and late father for making me what I am right now. The days and nights they have spent on my up-bringing, sacrificing their own happiness and time for developing my habits and thoughts. They taught me the first word and till date my mother likes to listen to me talking about MEMS and PZT and keeps a vigilant eye on my progress, even though she does not understand these technical things. They are and will always be the source of energy for me in all endeavours of my life. I am thankful to my sister and brotherin-law for their tremendous moral support and love. I would like to thank my beloved wife, for her support, love, care and help. To my kids, during this thesis we missed many precious moments of life which we could have spent with each other.

I would like to acknowledge the Higher education commission (HEC) of Pakistan for the generous scholarships offered for Ph.D. studies.

- Hammad, apr 2012 Enschede. 



\section{Publications}

\section{Journal articles}

Nazeer H, Nguyen M D, Woldering L A, Abelmann L, Rijnders G, Elwenspoek M C, 2011 "Determination of the Young's modulus of pulsed laser deposited epitaxial PZT thin films" J. Micromech. Microeng. 21, p. 0740o8, doi:10.1088/0960-1317/21/7/074008

Nazeer H, Woldering L A, Abelmann L, Nguyen M D, Rijnders G, Elwenspoek M C, 2011 "Influence of silicon orientation and cantilever undercut on the determination of the Young's modulus of thin films" Microelectron. Eng. 88, pp. 2345-2348, doi:10.1016/j.mee.2011.01.028

Nguyen M D, Nazeer H, Karakaya K, Pham S V, Steenwelle R, Dekkers M, Abelmann L, Blank D H A, Rijnders G, 2010

"Characterization of epitaxial $\mathrm{Pb}(\mathrm{Zr}, \mathrm{Ti}) \mathrm{O}_{3}$ thin films deposited by pulsed laser deposition on silicon cantilevers"

J. Micromech. Microeng. 20, p. 085022, doi:10.1088/0960-1317/20/8/085022

Nazeer H, Nguyen M D, Rijnders G, Woldering L A, Sardan Sukas O, Abelmann L, Elwenspoek M C, "Compositional dependence of the Young's modulus and piezoelectric coefficient of (110) oriented pulsed laser deposited PZT thin films"

To be submitted

Nazeer H, Nguyen M D, Rijnders G, Woldering L A, Sardan Sukas O, Abelmann L, Elwenspoek M C, "Young's modulus of pulsed laser deposited $\mathrm{Pb}\left(\mathrm{Zr}_{x} \mathrm{Ti}_{1-x}\right) \mathrm{O}_{3}$ thin films with (oo1) and (110) orientation"

To be submitted

Nazeer H, Nguyen M D, Rijnders G, Woldering L A, Sardan Sukas O, Abelmann L, Elwenspoek M C, "Residual stress in pulsed laser deposited PZT thin films; effect of orientation and composition" To be submitted

Nazeer H, Bhaskaran H, Wright D, Pauza A, Abelmann L, Elwenspoek M C, "Young's modulus and residual stress of GeSbTe phase-change thin films"

To be submitted

\section{Conference contributions}

Nazeer H, Nguyen M D, Woldering L A, Rijnders G, Elwenspoek M C, Abelmann L, 19-22 June 2011 "Composition dependence of mechanical and piezoelectric properties of pulsed laser deposited $\mathrm{Pb}(\mathrm{Zr}, \mathrm{Ti}) \mathrm{O}_{3}$ thin films"

In: Proc. Micromechanics and Microsystems Europe, pp. 238-241, Tønsberg, Norway 
Nazeer H, Nguyen M D, Rijnders G, Woldering L A, Abelmann L, Elwenspoek M C, 24-27 Jul. 2011 "Pulsed laser deposited $\mathrm{Pb}(\mathrm{Zr}, \mathrm{Ti}) \mathrm{O}_{3}$ thin films with excellent piezoelectric and mechanical properties"

In: 2oth IEEE Int. Symp. on Applications of ferroelectrics, ISAF 2011, Vancouver, Canada

Nazeer H, Woldering L A, Abelmann L, Elwenspoek M C, 26-29 Sept. 2010

"Determination of Young's modulus of PZT-influence of cantilever orientation."

In: Proc. Micromechanics and Microsystems Europe, pp. 257-26o, Enschede, The Netherlands

Nazeer H, Woldering L A, Abelmann L, Nguyen M D, Rijnders G, Elwenspoek M C, 19-22 Sep. 2010 "Influence of silicon orientation and cantilever undercut on the determination of Young's modulus of pulsed laser deposited PZT"

In: Micro \& Nano Engineering, Genoa, Italy

Nazeer H, Abelmann L, Tas N R, van Honschoten J W, Siekman M H, Elwenspoek M C, 21-23 Sep. 2009

"Determination of Young's modulus of PZT and $\mathrm{Co}_{80} \mathrm{Ni}_{20}$ thin films by means of micromachined cantilevers"

In: Proc. Micromechanics and Microsystems Europe, pp. 278-281, Toulouse, France

Nguyen M D, Dekkers M, van Zalk M, Broekmaat J, Janssens A, Nazeer H, Blank D, Rijnders G, 26 Jun.-1 Jul. 2011

"Large-area pulsed laser deposition and assembly processes for piezoelectric MEMS devices based on all-oxide $\mathrm{LaNiO}_{3} / \mathrm{Pb}(\mathrm{Zr}, \mathrm{Ti}) \mathrm{O}_{3} / \mathrm{LaNiO}_{3}$ thin-films"

In: Materials for advanced technologies, Suntec, Singapore 


\section{About the author}

Hammad Nazeer was born in Karachi, Pakistan on 30 September 1975 . He attended the primary education in C.O.D. public school, Karachi, Pakistan. In 1997, he obtained his Bachelors (B.E.) from the N.E.D. University of Engineering and Technology, Karachi, Pakistan and secured the first position. In 2000, he finished his Masters (M.Sc.) in electrical engineering from the N.E.D. University of Engineering and Technology, Karachi, Pakistan and was awarded with the gold medal from The President of Pakistan. After completing his Masters, he engaged himself in various assignments related to design and engineering of electrical equipment and systems. In 2007, he joined the Transducers Science and Technology group at the University of Twente, Enschede, The Netherlands, led by Miko Elwenspoek on the assignment presented in this thesis. He was supervised by Leon Abelmann. The group is part of the $\mathrm{MESA}^{+}$Institute for Nanotechnology of the University of Twente. His work was funded by the SmartMix Program 'SmartPie' of the Netherlands Ministry of Economic Affairs and the Netherlands Ministry of Education, Culture and Science.

Electronic mail address: h.nazeer@alumnus . utwente.nl 



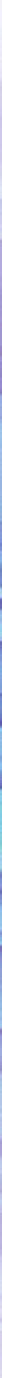

doi:10.3990/1.9789036533454

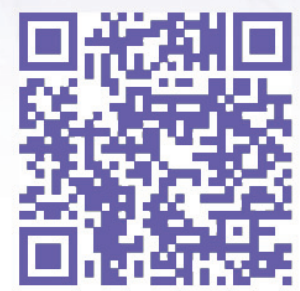

